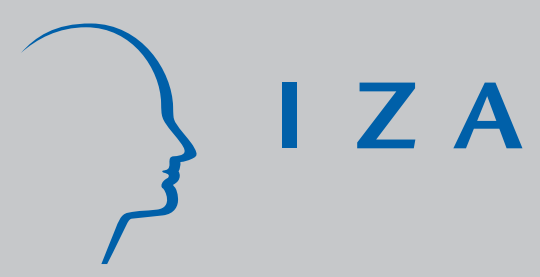

IZA DP No. 2980

The Effects of In-Work Benefit Reform in Britain on Couples: Theory and Evidence

Marco Francesconi

Helmut Rainer

Wilbert van der Klaauw

August 2007 


\title{
The Effects of In-Work Benefit Reform in Britain on Couples: Theory and Evidence
}

\author{
Marco Francesconi \\ University of Essex and IZA
}

Helmut Rainer

University of St Andrews

\author{
Wilbert van der Klaauw \\ Federal Reserve Bank of New York
}
Discussion Paper No. 2980
August 2007

IZA

P.O. Box 7240

53072 Bonn

Germany

Phone: +49-228-3894-0

Fax: +49-228-3894-180

E-mail: iza@iza.org

\begin{abstract}
Any opinions expressed here are those of the author(s) and not those of the institute. Research disseminated by IZA may include views on policy, but the institute itself takes no institutional policy positions.

The Institute for the Study of Labor (IZA) in Bonn is a local and virtual international research center and a place of communication between science, politics and business. IZA is an independent nonprofit company supported by Deutsche Post World Net. The center is associated with the University of Bonn and offers a stimulating research environment through its research networks, research support, and visitors and doctoral programs. IZA engages in (i) original and internationally competitive research in all fields of labor economics, (ii) development of policy concepts, and (iii) dissemination of research results and concepts to the interested public.
\end{abstract}

IZA Discussion Papers often represent preliminary work and are circulated to encourage discussion. Citation of such a paper should account for its provisional character. A revised version may be available directly from the author. 


\section{ABSTRACT \\ The Effects of In-Work Benefit Reform in Britain on Couples: Theory and Evidence*}

This paper examines the effects of the Working Families' Tax Credit (WFTC) on couples in Britain. We develop a simple model of household decisions which explicitly accounts for the role played by the tax and benefit system. Its main implications are then tested using panel data from the British Household Panel Survey collected between 1991 and 2002. Overall, the financial incentives of the reform had negligible effects on a wide range of married mothers' decisions, such as eligible (working at least 16 hours per week) and full-time employment (working at least 30 hours per week), employment transitions, childcare use, and divorce rates. Women's responses, however, were highly heterogeneous, depending on their partners' labour supply and earnings. Mothers married to low-income men showed larger responses in employment, especially if they had younger children. They were more likely to remain in the labour force and had higher rates at which they entered it. While more likely to receive the tax credit, they also experienced a greater risk of divorce. We find virtually no effect for women with higher-income husbands. Likewise, there are no statistically significant responses among married men.

JEL Classification: $\quad \mathrm{C} 23, \mathrm{H} 31, \mathrm{I38}, \mathrm{J} 12, \mathrm{~J} 13, \mathrm{~J} 22$

Keywords: tax credit, household labour supply, intrahousehold bargaining, divorce

Corresponding author:

Marco Francesconi

Department of Economics

University of Essex

Colchester CO4 3SQ

United Kingdom

E-mail: mfranc@essex.ac.uk

\footnotetext{
* We are grateful to the British Academy for financial support. We benefited from comments from Richard Blundell, Mike Brewer, Jeff Grogger, Hillary Hoynes, Heather Joshi and seminar participants at the 2006 ESPE meetings (Verona), 2006 IFAU/IZA Conference on Labour Market Policy Evaluation (Uppsala), and University of St Andrews. The views and opinions offered in this article do not necessarily reflect those of the Federal Reserve Bank of New York or the Federal Reserve System as a whole.
} 


\section{Introduction}

In October 1999, the Working Families' Tax Credit (WFTC) replaced Family Credit (FC) with the explicit objective to enhance the work incentives of parents in low-income households. As illustrated in the Introduction of this Symposium, WFTC was more generous than FC in four salient ways: it had higher credits, particularly for children in the age group 0-10, families could earn more before the benefit began to be withdrawn, the taper rate at which earnings above the threshold are taxed was lowered, and it offered a large childcare tax credit (Brewer et al., 2007).

Since its introduction, much research has been undertaken to assess whether WFTC was successful or not. ${ }^{1}$ Most of the existing studies, however, focus on labour market outcomes and are primarily concerned with single mothers. Much less is known about the credit's impact on married women and men. ${ }^{2}$ Moreover, as pointed out by Blundell and Walker (2001), there is a need to broaden the debate from work incentives to wider questions that are raised by in-work transfer programmes. These include intra-household distributional effects, analysis of a wider set of socioeconomic outcomes, inter-temporal incentive effects, and the relationship between child outcomes and parental resources. Our paper contributes to this debate by taking on the first two issues, that is, by looking at married couples and how the WFTC reform has affected their intra-household allocations, and by assessing a wide array of outcomes other than employment and earnings.

If the introduction of WFTC led married women and men to change their labour supply, these changes could have had an effect on a number of other family domains, such as the time spent with children, the likelihood of having additional children and the chance of breaking the partnership down. Examination of individuals' response in such domains is important both because it gives us a more complete picture of the consequences of the 1999 in-work benefit reform and because it allows us to check for the occurrence of unintended effects, which may be crucial for the longer-term success of the reform itself.

We address the issues above by developing a simple household bargaining model that allows us to analyse several individual- and household-level outcomes and how these have changed as a result of the WFTC reform. In particular, the model focuses explicitly on three be-

1 The first formal econometric analysis of the effect of the WFTC on labour market behaviour was reported in Blundell et al. (2000). For surveys of subsequent analyses, see Blundell (2001), Blundell and Hoynes (2004) and Gregg and Harkness (2003).

2 Throughout the paper, the terms "marriage", "couples", "married couples" or "marital unions" are used in a broad sense to include all types of live-in partnerships, such as cohabitations, stepfamilies and blended families. 
havioural responses for women in couples: work incentives (and possible ramifications for the allocation of marital bargaining power), paid childcare utilisation, and divorce decisions. One particularly important implication of the model is that the reform is likely to have generated highly heterogeneous responses, depending on partners' labour supply and earnings. Our empirical analysis therefore was conducted with those results in mind.

This analysis uses longitudinal data drawn from the first twelve waves of the British Household Panel Survey (BHPS) covering the period 1991-2002. Notwithstanding the potential problems of small sample size and differential attrition that apply to most longitudinal household studies, data from the BHPS are likely to provide us with a better description of the impacts of in-work benefit reform than analyses based on data from repeated cross sections for at least two reasons. First, the BHPS data contain information on changes in each of the outcomes of interest, and thus allow us to focus on a large set of transitions. Following individuals and their families over time is essential here, because it informs us on their precise socioeconomic circumstances both before and after the reform. Second, the BHPS will provide us with nationally representative samples of the population of Britain as it changes over the 1990 s and into the twenty-first century.

Our theoretical analysis shows that the work incentives of women whose partners work fewer than 16 hours per week or do not work at all are positively affected by the reform. Conversely, for women whose partners work more than 16 hours per week we predict (depending on the partner's earnings) either ambiguous or negative employment responses. The model also predicts the reform to have ambiguous effects on childcare use, but implies an unambiguous increase in in-work credit receipt among married women after the reform. Finally, there might be situations in which couples face a "marriage penalty", in the sense that their utility gains from the in-work benefit reform are greater if they separate than if they remain married. In such situations, the probability of divorce is expected to rise as a result of WFTC.

The empirical results tie in well with the theoretical predictions. In particular, while we find no statistically significant labour supply effects for women married to partners working 16 or more hours per week, we find that the reform led to an increase in eligible employment of 3 percentage points for women whose partner worked less than 16 hours, due to a statistically significant increase in the entry rate into eligible employment and a reduction in the exit rate out of eligible employment. This labour supply response estimate represents an average across married women and hides considerable variation with household composition, where mothers of a single pre-school child were found to have increased their eligible employment 
rate by 5 percentage points, while mothers of multiple older children increased theirs only by 2 percentage points. Instead, the reform had no measurable effect on the labour supply of married men.

The reform also led to a 3 percentage point increase in the rate at which married women became eligible and chose to receive the tax credit. At the same time, while it did not affect the use of paid childcare for married women whose partners worked less than 16 hours (and therefore were not eligible for the childcare credit), it led to a 2 percentage point increase (a relative increase of 30 percent) in paid childcare usage by women married to men in eligible employment. Finally, we find evidence that the introduction of the WFTC led to a reduction in the gains from marriage for women in low-income households, with a 2 percentage point increase in the rate at which their marriages dissolved (which represents an almost 80 percent increase in the divorce rate for these women).

In the next section we lay down the theoretical framework within which we interpret our empirical results. After outlining the basic setup, we discuss the main implications for work incentives, divorce and marital bargaining power. (For ease of exposition, all proofs and mathematical derivations are relegated to Appendices.) Section 3 presents the data used in the empirical analysis and discusses the econometric method and its related identification issues. Section 4 presents a wide range of empirical findings and links them back to the theoretical analysis. Section 5 concludes.

\section{Setup}

Our theoretical framework rests on a few simplifying assumptions. First, we formulate a model of a two-person household in which the husband's labour supply is treated as exogenously predetermined. Each household, therefore, is assumed to choose Pareto optimal allocations of consumption and mother's time, taking as given the husband's labour supply and earnings. ${ }^{3}$ Second, we ignore all taxes and transfers except those entailed by WFTC. Third, the model ignores unpaid informal childcare which may be available to some mothers. Fourth, the outside option that matters for household bargaining is the 'single state' after divorce rather than a non-cooperative equilibrium within the household.

\footnotetext{
3 This is not a strong assumption if men's labour supply is insensitive to taxes as suggested by a large body of empirical evidence (e.g., Heckman, 1993; Eissa and Hoynes, 2004).
} 


\section{A. Baseline Model}

There is a continuum of households. Every household comprises a husband $h$ and a wife $w$, with a fixed number of children. Families' prior formation, fertility, and education choices are taken as exogenous. Each married woman has the potential to earn an hourly market wage $w$, which is distributed on the interval $[\underline{w}, \bar{w}]$ according to the cumulative distribution function $G(w)$. The variation in earning opportunities could be due to differences in human capital, which does not appear explicitly, since it is assumed to be exogenous. Men inelastically supply $l_{h}$ units of labour and earn a fixed hourly wage given by $w_{h}$. The earnings of married men, denoted by $m \equiv w_{h} l_{h}$, are thus predetermined. As we shall see below, the husband's exogenous labour supply will nonetheless affect the wife's labour supply decision through total family income and eligibility for in-work support.

Each spouse has preferences over own consumption and childcare quality. ${ }^{4}$ Formally, let all women be endowed with $t$ units of time (per week). Let $l_{w}$ denote a woman's labour supply (with $0 \leqslant l_{w} \leqslant t$ ), and $x_{i}(i=h, w)$ be member $i$ 's consumption of a private good whose price is set to unity. Preferences of household's member $i$ are represented by the utility functions

$$
U_{i}=\alpha_{i} \ln \left(x_{i}\right)+\beta_{i} \underbrace{\ln \left[\gamma\left(t-l_{w}\right)+\delta l_{w}\right]}_{\text {childcare quality }}-\psi_{i} l_{i}-\omega_{i} P \quad \text { where } \quad i=w, h
$$

where $P$ is an indicator that equals one if a household meets the eligibility criteria for WFTC and chooses to participate in the programme. If instead a household does not meet the eligibility criteria for the WFTC, or chooses not to participate, then the indicator variable $P$ takes on the value zero. Men and women may have different preferences over own consumption $\left(\alpha_{h}, \alpha_{w}\right)$, childcare quality $\left(\beta_{h}, \beta_{w}\right)$, disutility of work $\left(\psi_{h}, \psi_{w}\right)$, and potential transaction costs or stigma attached to programme participation $\left(\omega_{h}, \omega_{w}\right)$. Childcare quality is produced according to a technology that is linear in both the amount of time the mother spends with the child $\left(t-l_{w}\right)$ and the number of hours the child is looked after by someone else while the mother works $\left(l_{w}\right)$. This rules out the possibility that a child is left on his or her own. A family has to pay for childcare at an hourly price $p_{c}$ during the time the mother works, while unpaid childcare services provided by friends or relatives are normalized to zero. In (1), we assume that the two inputs to childcare quality are imperfect substitutes,

\footnotetext{
${ }^{4}$ In another study of this Symposium, Grogger and Karoly (2007) present a bargaining model of marriage and divorce in which parents have egoistic preferences, which do not depend on child well-being. This different setup will have a number of ramifications, especially for the analysis of divorce.
} 
with the quality or marginal productivity in childcare quality of maternal care being $\gamma$ and the quality of non-maternal care being $\delta$.

The model embeds a simple in-work benefit system, which captures the main features of the FC/WFTC programmes. Couples choose the levels of private consumption and female labour supply to maximise (1) subject to the following budget constraint:

$$
x_{h}+x_{w}+p_{c} l_{w}=w l_{w}+m+B\left(m, l_{w}, w, p_{c}\right) P
$$

where $m$ represents the husband's exogenous income, and $B$ denotes the transfers, taxes and subsidies contained in FC/WFTC. ${ }^{5}$ The level of in-work support is a function of the household's number and age of children, hours of work, and earned income. More precisely, a household with dependent children needs to have at least one adult member working at least $\underline{l}=16$ hours per week to be eligible for "in-work" benefits. Each household is eligible to a maximum amount $T_{\max }$ which increases with the number of children in the household. $T_{\text {max }}$ is payable if total family income is lower than a threshold $M_{\min }$. Income in excess of this threshold reduces entitlement to the tax credit by the "taper rate" $\pi$ for every pound of excess income. In addition, the childcare credit element of WFTC subsidizes a proportion $\phi \in(0,1)$ of the total childcare expenditure $p_{c} l_{w} \cdot{ }^{6}$ The childcare credit is available only if both partners work $\underline{l}$ hours or more per week. With $M \equiv w l_{w}+m$ denoting total family income, the basic schedule for the tax credit can be expressed as

$$
B= \begin{cases}0 & \text { if } l_{h}<\underline{l} \text { and } l_{w}<\underline{l} \\ T_{\max }-\pi\left(M-M_{\min }\right) & \text { if } l_{h} \geq \underline{l} \text { or } l_{w} \geq \underline{l}, \text { and } M<M_{\max } \\ T_{\max }-\pi\left(M-M_{\min }\right)+\phi p_{c} l_{w} & \text { if } l_{h} \geq \underline{l} \text { and } l_{w} \geq \underline{l}, \text { and } M<M_{\max } \\ 0 & \text { if } M \geq M_{\max },\end{cases}
$$

where $M_{\max }=\frac{1}{\pi}\left[T_{\max }+\pi M_{\min }\right]$. For simplicity, this schedule ignores the cap on the childcare credit component and, with zero non-labour income, the asset test for FC/WFTC eligibility. The assumption we make to solve for the equilibrium household resource allocation is that it is Pareto efficient. One way of doing this is to maximize one member's utility subject to a given level of the other. As shown by Chiappori, Fortin and Lacroix (2002) and Iyigun and Walsh (2007), an equivalent approach is one where each couple solves the

5 For convenience, non-labour income is set to zero.

6 Under FC instead part of the childcare cost could be deducted from earnings in computing benefits. Because this benefit was considerably less generous than the childcare tax credit under WFTC and given that very few women took advantage of the deduction (Blundell and Hoynes, 2004), we ignore it in our analysis. 
following problem:

$$
\max _{\left\{x_{h}, x_{w}, l_{w}, P\right\}} \Omega \equiv \theta U_{w}+(1-\theta) U_{h}
$$

subject to (2) and (3). The term $\theta$ is a weighting factor defined over the unit interval, which now is assumed to be constant. Thus, the baseline model corresponds to a unitary framework with weakly separable household preferences. Below we will show that any reform of the policy parameters parameters $\pi, T_{\max }, M_{\min }$ and $\phi$ may also affect $\theta$ through its influence on the bargaining position of married men and women.

\section{B. Work Incentives}

We examine the WFTC's effect on married women's labour supply. We first turn to households in which the husband works less than $\underline{l}$ hours per week (Household Class A). We then consider households in which the husband works at least $\underline{l}$ hours (Household Class B). In what follows we define $\Delta=\gamma-\delta$ and assume that $\psi_{i}=\omega_{i}=0$ for $i=h, w$. Our results regarding the impact of the WFTC reform do not depend on these latter normalizations.

\section{Household Class A}

In this class of households, male partners are assumed to work less than $\underline{l}$ hours per week. This implies that (a) the male partner's labour supply is below the hours cut-off for WFTC eligibility $\left(l_{h}<\underline{l}\right)$, and (b) the household is not eligible to the childcare credit element of WFTC $(\phi=0)$. The household's eligibility status therefore hinges on the wife's labour supply: the household may be ineligible to receive the tax credit either because the woman's labour supply is below the cut-off $\underline{l}$ or because total family income exceeds $M_{\max }$.

The following result holds WFTC parameters, preferences and the level of husband earnings constant, and provides a categorization of the population based on female wage differences.

Result 1 There exists a set of in-work benefit parameters, preference parameters, and husband earnings values such that the population of married women can be divided into four groups, according to the wage rate that each married woman can earn.

a. Type-1 women have a wage in the interval $\left[\underline{w}, w^{*}\right)$. They either do not work or work fewer than $\underline{l}$ hours $\left(0 \leqslant l_{w}^{1}<\underline{l}\right)$ and hence are ineligible for WFTC.

b. Type-2 women have a wage in the interval $\left[w^{*}, w^{* *}\right)$. They work exactly $\underline{l}$ hours $\left(l_{w}^{2}=\underline{l}\right)$ and receive WFTC. 

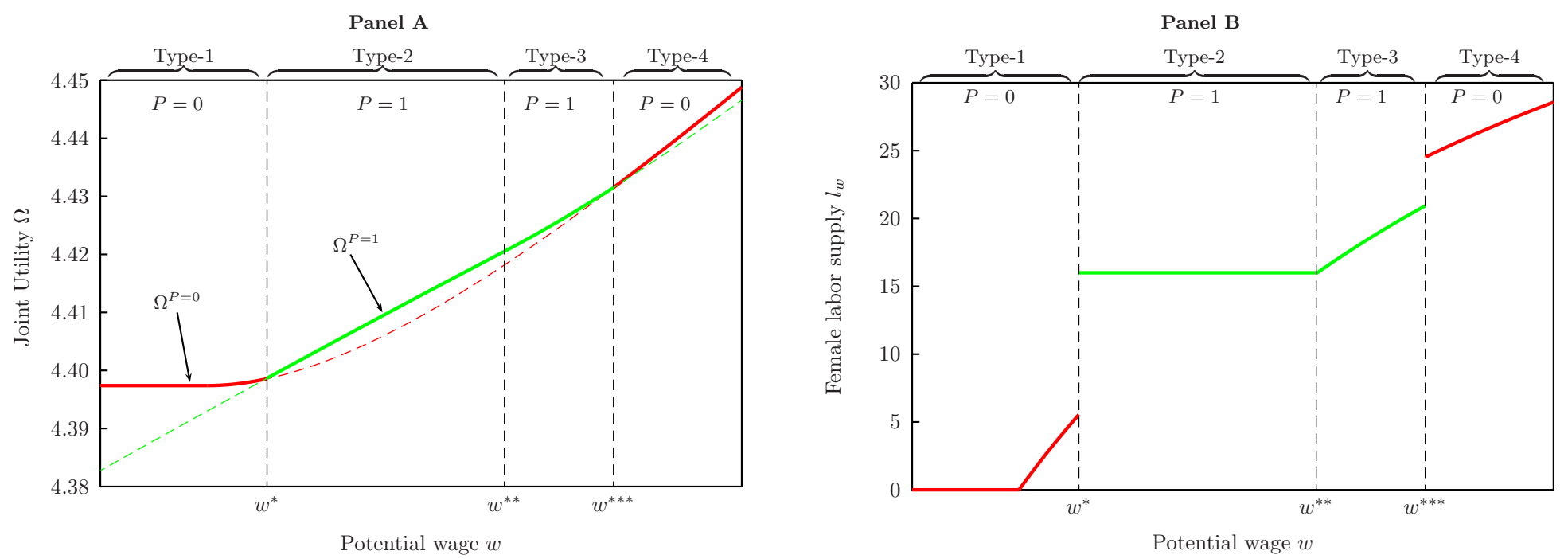

Fig. 1. This figure is based on the following parameter values: $\theta=0.5, \alpha_{w}=\alpha_{h}=0.5, \beta_{w}=\beta_{h}=0.5, \gamma=2, \delta=1, t=60$, $m=110, p_{c}=1.2$. The policy parameters are: $\underline{l}=16, T_{\max }=6.5, M_{\min }=10, \pi=0.04$, and $\phi=0$. The implied cut-off wages are $\left(w^{*}, w^{* *}, w^{* * *}\right)=(2.21,2.58,2.75)$.

c. Type-3 women have a wage in the interval $\left[w^{* *}, w^{* * *}\right)$. They work strictly more than $\underline{l}$ hours and receive WFTC.

d. Type- 4 women have a wage in the interval $\left[w^{* * *}, \bar{w}\right]$. They work more than $\underline{l}$ hours and either have earnings too high to be eligible for WFTC or choose not to participate.

The cutoff wages $w^{*}, w^{* *}$ and $w^{* * *}$ are functions of the policy parameters $\pi, T_{\max }$ and $M_{\min }$.

Note that even without stigma effects $\left(\omega_{w}=0\right)$, a subset of type-4 women who at their chosen hours of work are eligible for a positive credit prefer not to participate in the programme. ${ }^{7}$ To derive the cutoff wages, it is convenient to consider a household choosing the optimal resource allocation under either $P=0\left(l_{w}\right.$ unrestricted $)$ or $P=1\left(l_{w}\right.$ greater or equal to $\underline{l}$ ), determine the corresponding indirect utility levels, and pick the solution that delivers the highest utility. Panel A of Figure 1 illustrates the argument by plotting the indirect utility functions $\Omega^{P=0}$ and $\Omega^{P=1}$ against potential wages. The cutoff wages $w^{*}, w^{* *}$ and $w^{* * *}$ are characterized in Appendix 1. Panel B of Figure 1 instead illustrates the allocation of worked hours across women's types. The figure shows that bunching in hours occurs at the eligibility cutoff $\underline{l}$, with a gap in the distribution of hours below that cutoff. The reason for this is simple. There are women who, in the absence of WFTC, would optimally choose to work strictly less than $\underline{l}$ hours. But in the presence of WFTC, they increase their labour supply to $\underline{l}$ in order to obtain eligibility for benefits. There is also a gap in worked

7 The participation decision differs from the household's eligibility status at the chosen hours of work, so $P \neq$ $1\left\{B\left(m, l_{w}, w, p_{c}\right)>0\right\}$. 
hours at $w^{* * *}$, the cutoff wage separating women who do and women who do not choose to participate in the programme, among those with labour supply and income levels that meet the eligibility criteria for receiving a positive amount of benefit. The discontinuity is due to the taper rate $\pi$ applied to the income of participants, which leads to a higher net marginal wage rate for those choosing not to participate. Put differently, there is a tradeoff between receiving the tax credit but earning a lower net wage and not participating in the programme while earning a higher net wage.

It is worthwhile emphasizing that not all arbitrarily chosen parameter values and husband earnings levels can deliver Result 1. There are parameter settings and earnings values that lead to different groupings of the population. For example, when husband's earnings are sufficiently low then for some set of preference parameter values women would always work $\underline{l}$ hours or more in order to be eligible for in-work support (thus, type-1 women would not exist). Conversely, when husband's earnings are too high, the household may be ineligible for the credit (and types 2 and 3 may not exist). As the comparative statics results regarding WFTC's behavioral impacts are qualitatively the same for these alternative population categorizations, we focus here only on situations in which Result 1 holds. ${ }^{8}$ This result shows how different women (with different wage rates ceteris paribus) determine their labour supply for initial values of the credit base amount $T_{\max }$, the threshold $M_{\min }$, and the taper rate $\pi$. We use Result 1 to characterise the choices of women who faced WFTC as opposed to the choices of those who faced the previous FC programme. WFTC increased the generosity of in-work support relative to FC class-A households in three ways: by increasing both $T_{\max }$ and $M_{\text {min }}$ and by reducing $\pi$. Although the actual changes were discrete, our discussion is based on comparative statics that look at marginal changes in each of these three policy parameters. The formal analysis is in Appendix 1. Here we provide a summary of the main findings for each type.

Type-1 women. For women who chose to work fewer than $\underline{l}$ hours under FC, the WFTC reform is expected to have a non-negative effect on the probability of working $\underline{l}$ hours or more per week. This is because the financial benefits associated with working at least $\underline{l}$ hours are greater after the introduction of WFTC. As a result, the indirect utility that can be achieved if the woman works at least $\underline{l}$ hours goes up, i.e., the graph labelled $\Omega^{P=1}$

\footnotetext{
8 As discussed in Appendix 1, for some parameter values the optimal labour supply would initially equal $\underline{l}$ up to some wage level, followed by a discontinuous drop (instead of increase as in Panel B of Figure 1) in hours worked (types 1 and 2 are switched). However, the qualitative impacts of WFTC on the mother's labour supply and WFTC participation are comparable to those discussed in Result 1.
} 
in Figure 1 shifts upwards. This lowers the cutoff wage $w^{*}$, which, in turn, increases the population-weighted measure of married women working at least $\underline{l}$ hours. At the same time, the increased generosity of the program increases its participation rate.

Type-2 women. The labour supply of women who worked exactly $\underline{l}$ hours while receiving in-work support prior to the reform is expected to stay constant or increase. These women do not find it beneficial to reduce their labour supply below $\underline{l}$; in fact, the higher net wage under WFTC (due to the drop in the taper rate) may lead some type-2 women to increase their hours of work (i.e. $w^{* *}$ may fall). The FC/WFTC participation rate for this group is unaffected.

Type-3 women. Women who worked more than $\underline{l}$ hours while receiving in-work support prior to the reform would not reduce their labour supply below the eligibility cut-off $\underline{l}$. However, whether they are induced to increase their labour supply above their pre-reform level or reduce it towards $\underline{l}$ is less clear. On the one hand, the increases in $T_{\max }$ and $M_{\min }$ raise the benefit amount at their chosen hours of work, generating an income effect that decreases work incentives. On the other hand, the reduction in $\pi$ produces both a substitution effect and an income effect. The substitution effect follows from the fact that a decrease in $\pi$ increases the marginal wage rate. This, in turn, increases the opportunity cost of non-market activities, and therefore increases hours of work. The income effect, by contrast, decreases hours of work. While $w^{* * *}$ increases as a consequence of the reform, its effect on $w^{* *}$ and on optimal labour supply at any given wage between the two cutoffs for type-3 women is ambiguous, producing an overall ambiguous effect on hours or work. As in the case of type-2 women, the increased generosity of the programme means that its participation rate for this group remains unchanged.

Type-4 women. The work incentives of women who worked at least $\underline{l}$ hours but chose not, or were ineligible, to receive FC decrease as a consequence of WFTC. This is driven by the fact that some women who were ineligible for FC at their chosen hours of work now become eligible for WFTC. For other type-4 women, the increased financial advantage from participating in the WFTC programme would induce them to reduce their hours worked in order to gain eligibility. The reform leads to an increase in the cut-off wage $w^{* * *}$, which in turn leads to an increase in the tax credit recipience rate among this latter group of women. The overall effect is therefore an unambiguous reduction in hours of work, and an increase in the program participation rate.

In sum, for class-A households, the WFTC reform is predicted to increase the proportion 

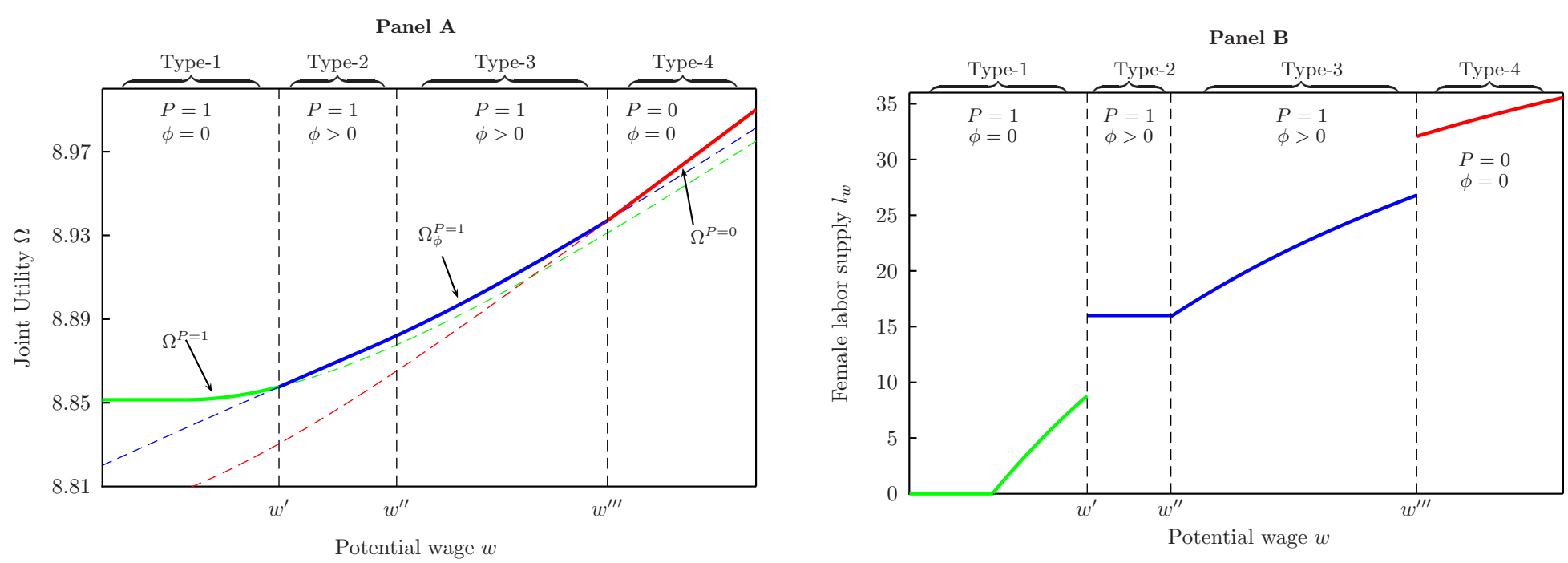

Fig. 2. This figure is based on the following parameter values: $\theta=0.5, \alpha_{w}=\alpha_{h}=0.5, \beta_{w}=\beta_{h}=0.5, \gamma=2, \delta=1, t=60$, $m=110, p_{c}=1.2$. The policy parameters are: $l_{\min }=16, T_{\max }=8, M_{\min }=90, \pi=0.08, \phi=0.03$. The implied cut-off wages are $\left(w^{\prime}, w^{\prime \prime}, w^{\prime \prime \prime}\right)=(2.54,2.70,3.17)$.

of married women working at least $\underline{l}$ hours and to increase the proportion of households participating in the programme. The overall impact on worked hours, however, is ambiguous. This comprises an increase in hours of work at a lower end of the wage distribution, a negative effect at higher wage rates, and an ambiguous effect for those with wages in between. (The proofs of all the predictions stemming from Result 1 are in Appendix 1.)

\section{Household Class B}

We now consider the work incentives for the group of women whose partners work more than 16 hours per week and therefore satisfy the hours requirement for eligibility to in-work benefit support. In this case, the childcare credit element of WFTC subsidizes a proportion $\phi \in(0,1)$ of the incurred childcare costs, provided both partners work more than 16 hours per week. If the husband's earnings $m$ exceed $M_{\max }$ defined in equation (4), the household would be ineligible for WFTC, irrespective of the wife's hours of work choice. We therefore focus on households where the husband's earnings are sufficiently low to make the household eligible for WFTC receipt at zero hours of work by the wife.

As before, the population of women can be divided into different groups, according to the wage rate that each woman potentially earns.

Result 2 There exists a set of in-work benefit parameters, preference parameters, and husband earnings values such that the population of married women can be divided into four groups, according to the wage rate that each married woman can potentially earn. 
a. Type-1 women have a wage in the interval $\left[\underline{w}, w^{\prime}\right)$. They either do not work or work fewer than $\underline{l}$ hours, and receive WFTC, but cannot receive its childcare subsidy.

b. Type-2 and Type-3 women have wages in the intervals $\left[w^{\prime}, w^{\prime \prime}\right)$ and $\left[w^{\prime \prime}, w^{\prime \prime \prime}\right)$, respectively. They respectively work $\underline{l}$ hours and more than $\underline{l}$ hours, and receive both WFTC and its childcare subsidy.

c. Type-4 women have a wage in the interval $\left[w^{\prime \prime \prime}, \bar{w}\right]$. They either have earnings too high to be eligible for WFTC or choose not to participate in the programme.

Each of $w^{\prime}, w^{\prime \prime}$ and $w^{\prime \prime \prime}$ is a function of the policy parameters $\pi, \phi, T_{\max }$, and $M_{\min }$.

Figure 2 illustrates this case. The cutoff wages $w^{\prime}, w^{\prime \prime}$ and $w^{\prime \prime \prime}$ are characterized in Appendix 1. To evaluate the impact of the WFTC reform, we again consider the marginal effects of an increase in $T_{\max }, M_{\min }, \phi$ as well as that of a reduction in $\pi$. It should be kept in mind that eligibility to WFTC does not require the wife to work at least $\underline{l}$ hours, while eligibility to the childcare component of the tax credit can be achieved only if she works at least $\underline{l}$ hours. The analysis (which is detailed in Appendix 1) yields the following results by woman's type.

Type-1 women. The effect of WFTC on the labour supply of women who worked less than $\underline{l}$ hours prior to the reform is ambiguous. On the one hand, the effect of the childcare credit element of WFTC is to enhance the probability of working at least 16 hours per week (i.e., the cutoff wage $w^{\prime}$ decreases in response to an increase in $\left.\phi\right)$. On the other hand, the increases in $T_{\max }$ and $M_{\min }$ imply an income increase which generates a negative income effect, causing $w^{\prime}$ to increase and optimal labour supply at hours below $w^{\prime}$ to fall. The reduction in $\pi$ instead leads to an increase in the net wage and thus generates a negative income effect and positive substitution effect. These changes combined therefore have an ambiguous effect on labour supply. More generally, the overall effect of WFTC on the probability of working at least 16 hours, average worked hours, and childcare usage for type-1 women is ambiguous. Their FC/WFTC participation rate, however, is expected to be unaltered.

Type-2 and type-3 women. The effect of WFTC on women who already worked at least $\underline{l}$ hours and participated in the programme prior to the reform is also ambiguous. The increases in $T_{\max }$ and $M_{\min }$ create an incentive to reduce working hours towards the eligibility cut-off $\underline{l}$ (or even below it, as it is predicted to cause $w^{\prime}$ to increase). The increase in $\phi$, on the other hand, has an unambiguous positive effect on hours of work of type-2 and type-3 women. Finally, the reduction in $\pi$ has an ambiguous labour supply effect for type-2 and type-3 women. Again, the reform should leave the programme participation rate unchanged for both types of women. 
Type-4 women. The work incentives for women who either had earnings too high to be eligible for in-work support or chose not to participate in the FC programme tend to decrease. The intuition for this result is similar to that provided for type- 4 women in class-A households, with the effect of an increase in $\phi$ being qualitatively similar to that of a decrease in $\pi$. Thus, for this type of women, the reform is predicted to reduce their labour supply (through an increase in the cutoff wage $w^{\prime \prime \prime}$ ) and to have an unambiguous positive effect on their in-work benefit receipt.

In sum, for women in class-B households in which male earnings are sufficiently low, the reform is predicted to generate ambiguous labour supply responses at the low end of the female wage distribution and negative responses at the top end of the same distribution. While not explicitly discussed here, the situation for women married to men working at least 16 hours and with high earnings is comparable to that of type- 4 women in class-B households. In such households, therefore, WFTC is predicted to reduce or leave unaffected female labour supply and to increase programme participation. The overall labour supply response for married women whose partners work at least 16 hours per week will thus depend on the distribution of husbands' earnings, the distribution of married women's wage rates, and the relative magnitudes of their labour supply responses, which in turn depend on the size of the changes in the programme parameters. The total labour supply effect is an empirical issue that will be analysed below.

\section{Indirect Effects}

The insights developed so far are based on the assumption that the weights assigned to the preferences of women and men in the household allocation decision are unaffected by the reform. That is, the reform is assumed not to affect the bargaining power of women measured by $\theta$ in (P1). But if the introduction of WFTC affects the feasible utilities of divorced women (positively or negatively), and if the outside option to marriage is divorce, then the reform might affect couples indirectly by changing the intra-household bargaining process so as to reflect the preferences of partnered women either more or less strongly. ${ }^{9}$ As shown in section 2C below, the introduction of WFTC may have either increased or decreased the marital bargaining power of women measured by $\theta$ for different subsets of households. In such cases, in addition to the direct effects discussed earlier, we have the following indirect effects on married womens labour supply:

9 Ever since the seminal work by Manser and Brown (1980) and McElroy and Horney (1981), divorce has been a much used threat point in family bargaining models. For recent divorce-threat bargaining models see Clark (1999), Fella et al. (2004), Rasul (2006), Iyigun and Walsh (2007), Rainer (2007) among many other studies. 
Result $3 A$ change in $\theta$ induced by WFTC is predicted to affect married women's work incentives as follows:

a. If the wife places a higher value on an additional hour of her labour supply than her husband does - in the sense that $\alpha_{w} / \beta_{w}>\alpha_{h} / \beta_{h}$ - then her labour supply is an increasing function of $\theta$.

$b$. If the wife places a lower value on an additional hour of her labour supply than her husband does - in the sense that $\alpha_{w} / \beta_{w}<\alpha_{h} / \beta_{h}$ - then her labour supply is a decreasing function of $\theta$.

c. If the wife places the same value on an additional hour of her labour supply than her husband does - in the sense that $\alpha_{w} / \beta_{w}=\alpha_{h} / \beta_{h}$ - then her hours of work are independent of $\theta .{ }^{10}$

This result has a few important implications. ${ }^{11}$ Suppose that the reform has led to an increase in the marital bargaining power of women measured by $\theta .{ }^{12}$ Then, if the wife places a lower value on an additional hour of her labour supply than her husband does (as in Result 3.a), then the bargaining power effect operates in such a way to (i) mitigate the positive labour supply response at the low end of the wage distribution (class-A households, type-1 women), and (ii) magnify the negative labour supply response at the top (class-A and class-B households, type-4 women). If, on the other hand, the wife places a higher value on an additional hour of her labour supply than her husband does (as in Result 3.b), the bargaining power effect leads to (i) a reinforcement of the positive labour supply response at the low end of the female wage distribution (class-A households, type-1 women), and (ii) an offset of the negative labour supply response at the top of the wage distribution (class-A and class-B households, type-4 women).

As a special case of the previous analysis, consider households where the male partner is in work and his income $m$ exceeds the post reform value of $M_{\max }$, called $M_{\max }^{*}$. In this case the male partner's income is so high that the household will remain ineligible for in-work support

\footnotetext{
${ }^{10}$ The intuition is as follows. If men and women have the same preferences over consumption and childcare quality, then there is no allocational conflict as to how the wife should allocate her time between the labour market and maternal childcare. This, in turn, implies that the equilibrium time allocation of the wife - and hence the cutoff wages - are independent of the bargaining weight $\theta$ in that case.

${ }^{11}$ We ought to stress that the ratio $\alpha_{i} / \beta_{i}$ is referred to as the valuation of an additional hour of the wife's labour supply. Strictly speaking, the utility parameters $\alpha_{i}$ and $\beta_{i}$ relate to preferences over consumption and childcare quality, respectively. But since both consumption and childcare quality are determined by the hours of work chosen by the wife (with consumption monotonically increasing and childcare quality monotonically decreasing in her labour market hours), this interpretation of the $\alpha_{i} / \beta_{i}$ ratio is appropriate.

${ }^{12}$ Opposite points hold if the reform has led to a decrease in the marital bargaining power of women.
} 
even after the reform. However, while not affecting the joint budget set for such couples, the reform may still affect intra-household allocations through a change in the bargaining weight $\theta$ for these women in marriage. The latter could occur if WFTC affected the utility of these women as divorced single mothers. Interestingly, we will show in the next subsection that the bargaining power of married women in such households may either improve or decline as a consequence of the reform.

\section{Divorce and Marital Bargaining Power}

The reform may have had an impact on divorce, because it affected the situation of single parents relative to that of married couples with children (Francesconi and van der Klaauw, 2007; Gregg and Harkness, 2003), which could lead to a 'marriage tax penalty' (Anderberg et al., 2006). We explore this possibility with a simple variant of the framework used so far. The utility functions in marriage are those of the baseline model. For marriage to be preferred over divorce, the intra-household allocation has to be incentive-compatible, i.e., it must be such that the utility levels of married men and women are at least as high as their reservation utilities outside marriage. For simplicity, but without loss of generality, we assume that the wife receives her reservation utility while married.

Divorce is endogenous and occurs whenever one of the spouses can be made better off by breaking the relationship and the other spouse is not willing or unable to compensate her for this potential gain (Weiss and Willis, 1985; Clark, 1999). We assume that either partner can costlessly initiate a divorce, even without the consent of the other. Remarriage is assumed not to be an option. We also assume that, after divorce, child custody is assigned to the mother and the mother is the only parent spending time and resources on childcare, even though both parents continue to receive utility from childcare quality. Let $a$ be a child support transfer from the father to the mother, such that $0 \leqslant a \leqslant m$. To adhere to the British situation, we take the child support transfer made by the noncustodial father, $a \in[0, m]$, to be chosen voluntarily. ${ }^{13}$ Finally, let $\sigma$ be a shock common to the spouses's divorce payoffs, which can be thought of as a measure of the mismatch of the marriage that disappears on divorce. Each partner's divorce utility is

$$
D_{i}=\alpha_{i} \ln \left(x_{i}\right)+\beta_{i} \ln \left[\gamma\left(t-l_{w}\right)+\delta l_{w}\right]+\eta_{i} \ln (\sigma) \quad \text { where } \quad i=h, w
$$

For computational simplicity we shall assume in our subsequent analysis that $\alpha_{i}=\beta_{i}=\eta_{i}$.

\footnotetext{
${ }^{13}$ In Britain, the vast majority of child support payments are made informally. In fact, even though the Child Support Agency can set and order transfers, these are not enforced adequately (Blackwell and Dawe, 2003; Ermisch and Pronzato, 2006).
} 
We now determine the choice of childcare quality by the custodial mother and the transfer from the noncustodial father to the custodial mother. Our theory builds upon the work of Del Boca and Flinn (1995) and Flinn (2000), who examined the child-support transfer decisions of divorced parents. It is useful to think of the decision-making in the divorce state as proceeding sequentially: given a transfer of the father, the mother decides on consumption and childcare quality. The father uses his knowledge of the mother's decision rule in deciding on the size of the transfer to make. Define $\mathbf{d}=T_{\max }+\pi M_{\min }$ and $\mathbf{w}=w(1-\pi)-p_{c}(1-\phi)$. Conditional on the father's transfer, the mother's divorce utility is maximized subject to $x_{w}=l_{w} \mathbf{w}+\mathbf{d}+a$ if she meets the eligibility criteria for in-work support, and $x_{w}=l_{w}(w-$ $\left.p_{c}\right)+a$ otherwise. ${ }^{14}$ As shown in Appendix 2, under certain parameter restrictions, the population of divorced women can be divided into the following four groups:

(1) Divorced women who receive a transfer larger than or equal to $a^{*}$ don't work and hence are ineligible for WFTC.

(2) Divorced women who receive a transfer in the interval $\left[a^{* *}, a^{*}\right)$ work exactly $\underline{l}$ hours and receive WFTC.

(3) Divorced women who receive a transfer in the interval $\left[a^{* * *}, a^{* *}\right)$ work strictly more than $\underline{l}$ hours and receive WFTC.

(4) Divorced women who receive a transfer smaller than $a^{* * *}$ work strictly more than $\underline{l}$ hours and either have earnings too high to be eligible for WFTC or choose not to participate.

The implied labour supply schedule is ${ }^{15}$

$$
\begin{cases}l_{w}^{00}=0 & \text { if } a \geqslant a^{*} \\ l_{w}^{01}=\underline{l} & \text { if } a^{* *} \leqslant a<a^{*} \\ l_{w}^{11}=[\mathbf{w} \gamma t-\Delta(a+\mathbf{d})] /(2 \mathbf{w} \Delta) & \text { if } a^{* * *} \leqslant a<a^{* *} \\ l_{w}^{10}=[\omega \gamma t-\Delta a] /(2 \omega \Delta) & \text { if } a<a^{* * *}\end{cases}
$$

There is a discontinuous downward-jump in the labor supply schedule at both $a^{* * *}$ and $a^{*}$, while the labor supply function is continuous at $a^{* *}$.

Given the mother's labor supply schedule, the father's problem is to choose the level of the

\footnotetext{
${ }^{14}$ Under the assumption that mothers receive child custody, divorced fathers are ineligible to WFTC because they do not live with dependent children. Both budget constraints are specified assuming full child maintenance disregard so that any child support transfer received does not affect the amount of tax credit received by divorced mothers.

${ }^{15} \mathrm{~A}$ detailed derivation and definitions of the transfer cutoff values $a^{*}, a^{* *}$ and $a^{* * *}$ in terms of underlying parameters are provided in Appendix 2.
} 
transfer to make to her. The father spends his net income $m-a$ on private consumption $x_{h}$ while still benefiting from the wife's contributions to childcare quality. His problem is to choose $a \in[0, m]$ so as to maximize

$$
D_{h}(a)= \begin{cases}\alpha_{h} \ln [\sigma(m-a) \gamma t] \equiv D_{h}^{00}(a) & \text { if } a \geqslant a^{*} \\ \alpha_{h} \ln [\sigma(m-a)(\gamma t-\Delta \underline{l})] \equiv D_{h}^{01}(a) & \text { if } a^{* *} \leqslant a<a^{*} \\ \alpha_{h} \ln [\sigma(m-a)[\gamma \mathbf{w} t+\Delta(\mathbf{d}+a)] /(2 \mathbf{w})] \equiv D_{h}^{11}(a) & \text { if } a^{* * *} \leqslant a<a^{* *} \\ \alpha_{h} \ln [\sigma(m-a)(\gamma \omega t+\Delta a) /(2 \omega)] \equiv D_{h}^{10}(a) & \text { if } a<a^{* * *}\end{cases}
$$

The utility function in (5) is only piecewise differentiable and has two points of upward discontinuity, at $a^{* * *}$ and $a^{*}$. Furthermore, it is a strictly decreasing function of $a$ over $\left[a^{* *}, a^{*}\right)$ and $\left[a^{*}, m\right)$, and a strictly concave function of $a$ over $\left[0, a^{* * *}\right)$ and $\left[a^{* * *}, a^{* *}\right)$. Let $\hat{a}$ and $\tilde{a}$ denote the (unique) maximizers of $D_{h}^{11}(a)$ and $D_{h}^{10}(a)$, respectively. In general, the set of transfers that could be observed in equilibrium is given by $\left\{0, \hat{a}, \tilde{a}, a^{*}, a^{* *}, a^{* * *}\right\}$ (as shown in Appendix 2).

In order to highlight the various aspects of household allocation and divorce decisions, as well as illustrate the heterogeneity in, and overall ambiguity of, WFTC's impact on divorce rates, we next consider two special cases. In both examples we focus on households in which it would be optimal for the woman as divorced single mother to work and to receive a positive tax credit, including its childcare component. More specifically, we consider the case where $m$ and $w$ are such that the optimal child support transfer in divorce $a^{e}$ has the property $a^{* * *} \leqslant a^{e}<a^{* *}$. As discussed earlier, the wife's optimal labour supply will then equal $[\mathbf{w} \gamma t-\Delta(a+\mathbf{d})] /(2 \mathbf{w} \Delta)$, which exceeds $\underline{l}$, while her divorce utility equals

$$
D_{w}(a)=\alpha_{w} \ln \left[\sigma[\gamma t \mathbf{w}+\Delta(\mathbf{d}+a)]^{2} /(4 \Delta \mathbf{w})\right] .
$$

Under certain restrictions on the parameters $m$ and $w$ (see Figure 3), the father's problem is then reduced to choosing $a \in[0, m]$ so as to maximize

$$
D_{h}(a)=\alpha_{h} \ln [\sigma(m-a)[\gamma \mathbf{w} t+\Delta(\mathbf{d}+a)] /(2 \mathbf{w})]
$$

His decision rule in this case can be stated explicitly as follows: Define the income threshold $\hat{m}=(\gamma t \mathbf{w}+\Delta \mathbf{d}) / \Delta$. Then

$$
a^{e}(\mathbf{d}, \mathbf{w})=\left\{\begin{array}{ll}
0 & \text { if } m \leqslant \hat{m} \\
{[\Delta m-(\gamma t \mathbf{w}+\Delta \mathbf{d})] /(2 \Delta) \equiv \hat{a}} & \text { if } m>\hat{m}
\end{array},\right.
$$




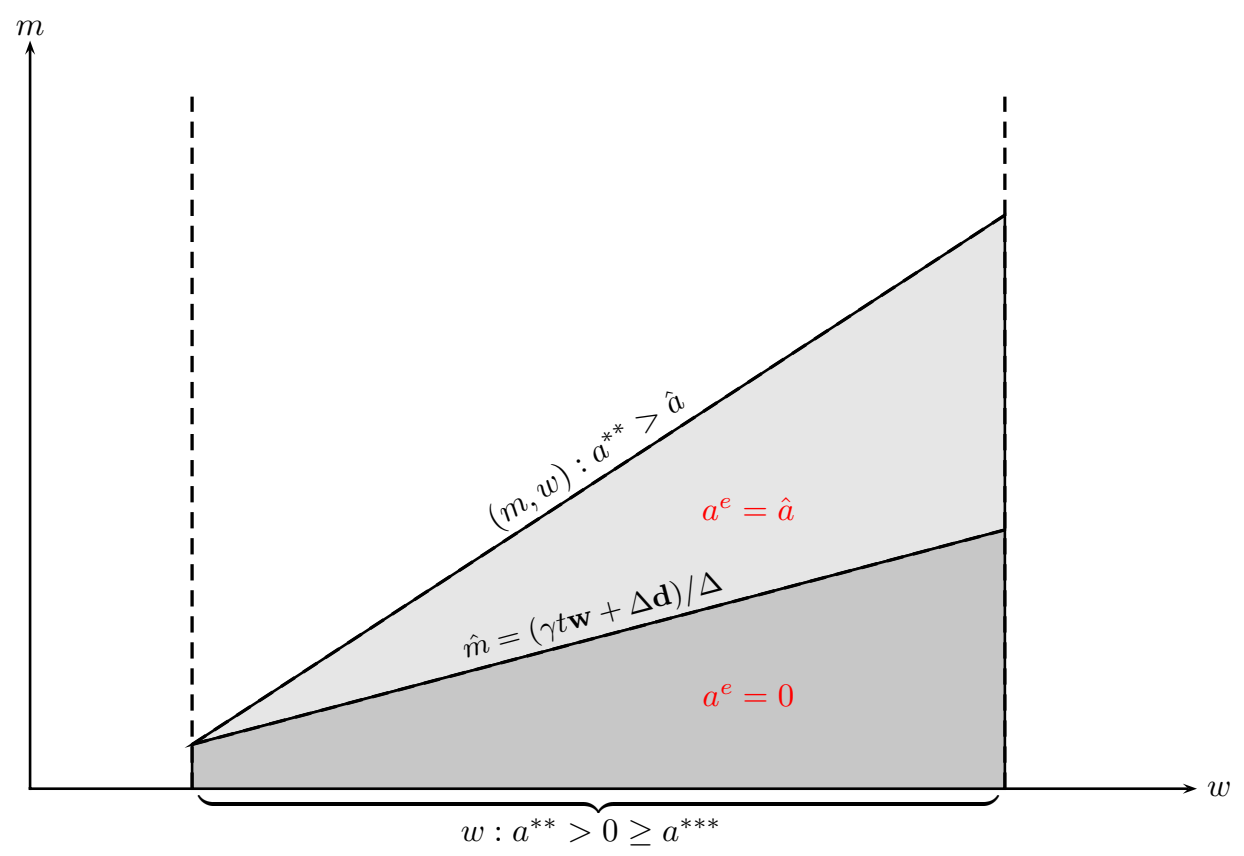

Fig. 3. For parameters values and values of $m$ and $w$ for which $a^{* * *}<0 \leqslant \hat{a}<a^{* *}$, the father's decision rule is simply given by $a^{e}(\mathbf{d}, \mathbf{w})=\arg \max \alpha_{h} \ln [\sigma(m-a)[\gamma \mathbf{w} t+\Delta(\mathbf{d}+a)] /(2 \mathbf{w})]$. His optimal transfer is $a^{e}=\max \{0, \hat{a}\}$.

where in each case the mother optimally chooses to work more than $\underline{l}$ hours while receiving WFTC benefits.

It is easy to see that the introduction of the WFTC reform can differentially affect the child support transfer for low- and high-income fathers. For example, low-income fathers $(m \leqslant \hat{m})$ would optimally choose not to pay any child support $\left(a^{e}=0\right)$, and their decisions once divorced would be unaffected by the reform. On the other hand, higher-income fathers $(m>\hat{m})$ who typically would choose to make positive transfers $\left(a^{e}=\hat{a}\right)$, would reduce their payments in response to the reform. ${ }^{16}$ The equilibrium values of the mother's and father's respective utility-maximization problems are

$$
\begin{gathered}
D_{w}^{e}=\alpha_{w} \ln \left[\sigma\left[\gamma t \mathbf{w}+\Delta\left(\mathbf{d}+a^{e}\right)\right]^{2} /(4 \Delta \mathbf{w})\right] \\
\text { and } \\
D_{h}^{e}=\alpha_{h} \ln \left[\sigma\left(m-a^{e}\right)\left[\gamma \mathbf{w} t+\Delta\left(\mathbf{d}+a^{e}\right)\right] /(2 \mathbf{w})\right],
\end{gathered}
$$

where $a^{e}=0$ or $a^{e}=\hat{a}$ depending on whether $m \leqslant \hat{m}$ or $m>\hat{m}$. With these preliminaries, we can now proceed in our analysis by examining two specific cases. The two cases represent subsets of each of the two shaded areas in Figure 3.

\footnotetext{
${ }^{16}$ This follows from the fact that $\hat{a}$ is decreasing in $\mathbf{w}$ (and thus decreasing in $\phi$ and increasing in $\pi$ ) and decreasing in $\mathbf{d}$ (and thus decreasing in $T_{\max }$ and $\left.M_{\min }\right)$.
} 
High-Income Father $(m>\hat{m})$ - Couple Ineligible as Family - Mother Eligible as Single Parent - Positive Child Support Payment from Father to Mother ( $a^{e}=\hat{a}>0$ ). Consider a couple where the male partner is in eligible employment and his income $m$ exceeds the post-reform value of $M_{\max }$, that is, the male partner's income is so high that the household will remain ineligible for in-work support even after the reform. Assuming that $w>p_{c}+\frac{\Delta m}{\gamma t}$, the optimal labour supply of the wife equals $\left[\gamma t\left(w-p_{c}\right)-m \Delta\right] /\left[2\left(w-p_{c}\right) \Delta\right]$. The female and male utilities are respectively

$$
U_{w}(\theta)=\alpha_{w} \ln [\kappa \Upsilon /(1+\kappa)] \quad \text { and } \quad U_{h}(\theta)=\alpha_{h} \ln [\Upsilon /(1+\kappa)]
$$

where $\Upsilon \equiv\left[\gamma t\left(w-p_{c}\right)+m \Delta\right]^{2} /\left[4 \Delta\left(w-p_{c}\right)\right]$ and $\kappa \equiv \alpha_{w} \theta /\left[\alpha_{h}(1-\theta)\right]$. The implied utility frontier relating $U_{h}$ and $U_{w}$ during marriage is given by:

$$
\exp \left(\frac{U_{h}}{\alpha_{h}}\right)=\Upsilon-\exp \left(\frac{U_{w}}{\alpha_{w}}\right)
$$

(proof provided in Appendix 3).

In the scenario analyzed here, the mother on her own would qualify for the tax credit as a single parent by working more than 16 hours, while also receiving a child support transfer from the father. In this case the utility frontier relating the father's utility, $D_{h}$, and the mother's utility, $D_{w}$ when the couple separates is

$$
\exp \left(\frac{D_{h}}{\alpha_{h}}\right)=\Phi \cdot \sqrt{\sigma \exp \left(\frac{D_{w}}{\alpha_{w}}\right)}-2 \exp \left(\frac{D_{w}}{\alpha_{w}}\right),
$$

where $\Phi=\gamma t \mathbf{w}+\Delta(m+\mathbf{d}) / \sqrt{\Delta \mathbf{w}}$. Note that the frontier traces out utility combinations in divorce for alternative child support transfer amounts. The utility pair $\left(D_{w}^{e}, D_{h}^{e}\right)$ in $(9)$ and (10) (with $a^{e}=\hat{a}>0$ ) corresponds to the subgame-perfect equilibrium which represents one particular point on this frontier and defines the minimal utilities that husband and wife would accept within marriage (Clark, 1999). If $\left(D_{h}^{e}, D_{w}^{e}\right)$ lies outside the set of feasible levels of utility that can be achieved in marriage, then there exists no marital allocation that makes both partners better off compared to divorce. Putting this together, we obtain the following results regarding the impact of changes in policy parameters underlying WFTC on the likelihood of divorce (see Appendix 3 for proof and details):

Result 4 Consider the case where the father's earnings $m$ exceed the post-reform value of $M_{\text {max }}$, and where preference parameters, $m$ and the mother's wage rate $w$ are such that in divorce the mother works more than 16 hours while receiving a positive tax credit as well as a positive child support transfer from the father $\left(a^{e}=\hat{a}>0\right)$. 
(a) Denote by $U_{w}^{c r i t}(\sigma)$ the utility level of the mother at which $P_{d}$ and $P_{m}$ intersect, and let $\hat{\sigma}$ be defined as the value of $\sigma$ such that $U_{w}^{c r i t}(\sigma)=D_{w}^{e}(\sigma)^{17}$. Divorce occurs if $\sigma>\hat{\sigma}$, and marriage survives if $\sigma<\hat{\sigma}$.

(b) An increase in the childcare subsidy $\phi$ and a reduction in the taper rate $\pi$, both represented by an increase in $\mathbf{w}$, raise $\hat{\sigma}$ and therefore reduce the likelihood of divorce. An increase in the tax credit $T_{\max }$ and an increase in the threshold $M_{\min }$, both represented by an increase in $\mathbf{d}$, reduce $\hat{\sigma}$ and therefore increase the likelihood of divorce. ${ }^{18}$

This result indicates that the introduction of WFTC does not necessarily lead to a reduction in the gains from marriage and an increase in the incidence of divorce, even if a couple is only entitled to benefits if they separate. Indeed, if the effect of $\mathbf{w}$ on $\hat{\sigma}$ is larger than the effect of $\mathbf{d}$ on $\hat{\sigma}$, then the reform consequences can easily go the other way and work to increase the gains from marriage over divorce. It is an important, but often overlooked, theoretical result that a more generous wage subsidy or tax credit for single mothers does not necessarily reduce the gains from marriage, nor does it necessarily lead to an increase in welfare of women when married or even when divorced.

Figure 4.A illustrates the latter possibility using a numerical example. Consider first the prereform outcome. If the divorce option is exercised, then the divorce outcome is represented by the point $D^{\text {pre }}$ on the frontier $P_{d}(\mathbf{d}, \mathbf{w})$. The point $D^{\text {pre }}$ lies within the set of feasible levels of utility that can be achieved through continued marriage, the boundary of which is given by the frontier $P_{m}$. Under the assumption that the wife receives her reservation utility, continued marriage leads to the utility pair labeled $M^{\text {pre }}$ on the frontier $P_{m}$. In the pre-reform outcome, the gains from marriage over divorce are given by the vertical distance between $M^{\text {pre }}$ and $D^{\text {pre }}$. Thus marriage offers a Pareto improvement over divorce for both spouses.

Consider next the post-reform outcome, with $\sigma$ fixed at its pre-reform value. Three different mechanisms are at work. First, holding $\mathbf{w}$ and $a^{*}(\cdot)$ constant, an increase in $\mathbf{d}$ shifts (i) the utility possibility frontier in divorce from $P_{d}(\mathbf{d}, \mathbf{w})$ to $P_{d}\left(\mathbf{d}^{\prime}, \mathbf{w}\right)$, and (ii) the divorce outcome from $D^{\text {pre }}$ to $D^{\prime}$. Both effects lead to an increase in the incidence of divorce. A couple who

\footnotetext{
${ }^{17}$ More specifically, in this case $\hat{\sigma}=4 \mathbf{w} \Delta \Upsilon\left[\gamma \mathbf{w} t+\Delta\left(2 m+\mathbf{d}-a^{e}\right)\right]^{-1}\left[\gamma t \mathbf{w}+\Delta\left(\mathbf{d}+a^{e}\right)\right]^{-1}$, where $a^{e}=\hat{a}$.

${ }^{18}$ To see this, substitute $a^{e}=\hat{a}$ into $\hat{\sigma}$ (in footnote 17$)$ to obtain $\hat{\sigma}=(16 \Delta \mathbf{w} \Upsilon) /\left[3(\gamma t \mathbf{w}+\Delta(\mathbf{d}+m))^{2}\right]$. Then observe that

$$
\frac{\partial \hat{\sigma}}{\partial \mathbf{d}}=-\frac{32 \Delta^{2} \mathbf{w} \Upsilon}{3(\gamma t \mathbf{w}+\Delta(\mathbf{d}+m))^{3}}<0 \quad \text { and } \quad \frac{\partial \hat{\sigma}}{\partial \mathbf{w}}=\frac{16 \Delta \Upsilon[\Delta(m+\mathbf{d})-\gamma t \mathbf{w}]}{3(\gamma t \mathbf{w}+\Delta(\mathbf{d}+m))^{3}}>0 \quad \forall m>\hat{m}
$$
}


A. High-Income Father

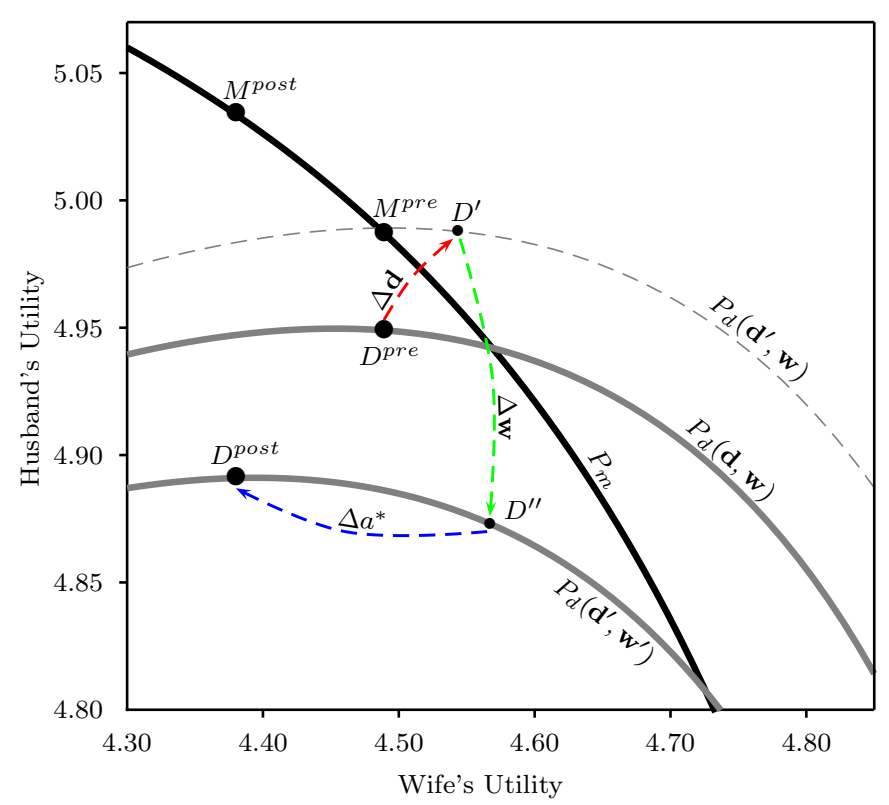

B. Low-Income Father

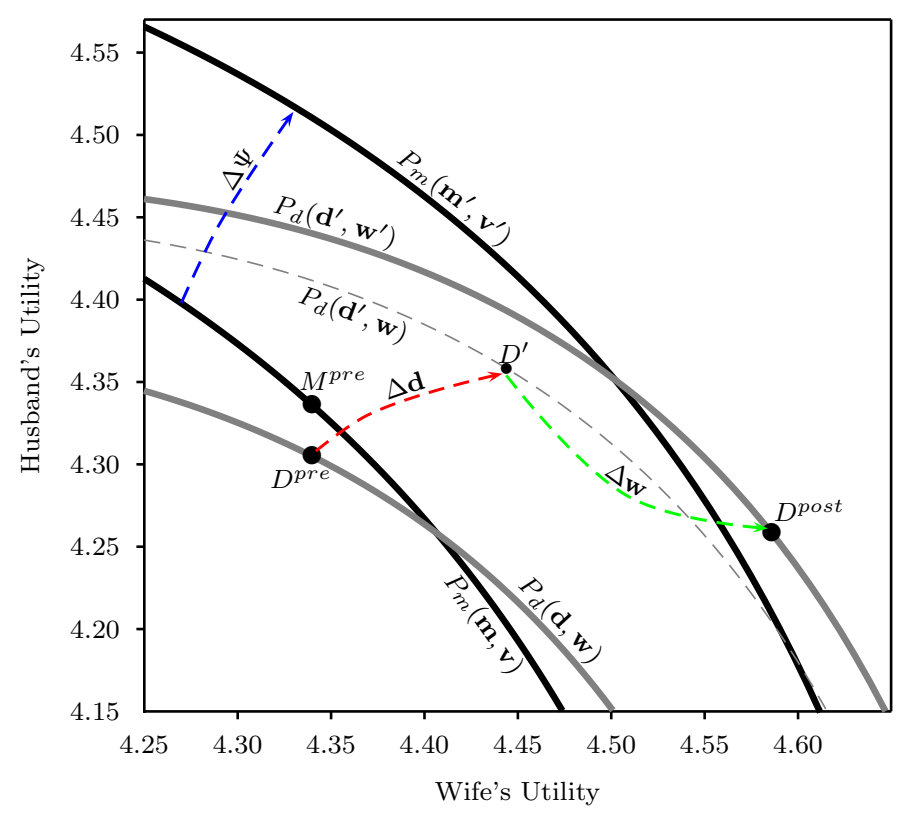

Fig. 4. The figure is based on the following parameter values: $\alpha_{h}=\alpha_{w}=0.5, \beta_{h}=\beta_{w}=0.5, \gamma=2, \delta=1, t=60, \sigma=.97$, $w=2.8$. The income of the father is $m=300$ in Panel A and $m=80$ in Panel B. The pre-reform policy parameters are $\pi=0.2, \phi=0.1, T_{\max }=20, M_{\min }=60$. In Panel A, the implied utility pairs in marriage and divorce are $M^{\text {pre }}=(5.04,4.69)$ and $D^{\text {pre }}=(4.99,4.69)$. The optimal voluntary child support transfer by the father in divorce is $a^{*}=64.4$. In Panel B, the implied utility pairs in marriage and divorce are $M^{\text {pre }}=(4.34,4.34)$ and $D^{\text {pre }}=(4.44,4.34)$. The optimal voluntary child support transfer by the father in divorce is $a^{*}=0$. The post-reform policy parameters are $\pi=0.1, \phi=0.55, T_{\max }=35$, $M_{\text {min }}=80$. In Panel A, the implied utility pairs in marriage and divorce are $M^{\text {post }}=(5.08,4.58)$ and $D^{\text {post }}=(4.94,4.58)$. The optimal voluntary child support transfer by the father in divorce is $a^{*}=10.8$. In Panel B, the implied utility pair in divorce is $D^{\text {post }}=(4.26,4.59)$. The optimal voluntary child support transfer by the father in divorce is $a^{*}=0$.

is at $D^{\text {pre }}$ before the reform would prefer marriage over divorce. But with the shift from $P_{d}(\mathbf{d}, \mathbf{w})$ to $P_{d}\left(\mathbf{d}^{\prime}, \mathbf{w}\right)$, the same couple would be at $D^{\prime}$ after the increase in $\mathbf{d}$, and divorce would Pareto dominate (and be preferred to) marriage. Note that the outward movement of the utility frontier in divorce reflects a positive income effect on divorced mothers, which through a decline in the mother's labor supply leads to higher child quality, which at the fixed transfer amount $a^{*}$ increases the divorced father's utility.

Second, holding $\mathbf{d}$ and $a^{*}(\cdot)$ constant, an increase in $\mathbf{w}$ shifts (i) the utility possibility frontier in divorce inwards, from $P_{d}\left(\mathbf{d}^{\prime}, \mathbf{w}\right)$ to $P_{d}\left(\mathbf{d}^{\prime}, \mathbf{w}^{\prime}\right)$, and (ii) the divorce outcome from $D^{\prime}$ to $D^{\prime \prime}$. A couple who is at $D^{\prime}$ prefers divorce over marriage, but the increase in $\mathbf{w}$ places $D^{\prime \prime}$ inside the frontier $P_{m}$, with the consequence that at the pre-reform value of $\sigma$ marriage is preferred over divorce. As measured by the vertical distance between $D^{\prime}$ and $P_{m}$, keeping the child support transfer amount fixed, the gains from marriage have increased due to the changes in $\mathbf{d}$ and $\mathbf{w}$. Note that this effect is accompanied by an increase in the welfare of the mother, both when divorced and when married, and a decline in utility of the father 
in both marital states. Within marriage, this shift along the utility possibility frontier $P_{m}$ towards the right is represented by an increase in bargaining power of the wife (an increase in $\theta$ ). The inwards shift of the utility frontier in divorce is due to the public goods nature of child quality. On the one hand, an increase in w leads to expansion of the mother's budget set expands and an improvement in her divorce utility. On the other hand, an increase in w also induces the mother to work more, which leads to a reduction in childcare quality and a utility loss of the father. The utility loss experienced by the high-income father making a positive child support transfer offsets the utility gain of the mother, resulting in an inward shift of the utility frontier.

Third, increments to both $\mathbf{d}$ and $\mathbf{w}$ optimally induce the father (as the noncustodial parent) to reduce the child support transfer $a^{e}(\mathbf{d}, \mathbf{w})=\hat{a}$. Thus in this particular situation the effect of the reform is to crowd out child support transfers by the father to the mother. Note that this response by the father reflects a substitution from child quality to consumption. The latter is caused by a decline in the marginal benefit from a small increase in child support, which in turn was the result of a decline in the effectiveness of transfers in reducing the mother's labor supply. It is important to note that this result does not depend on the simplifying assumption imposed at the beginning of the section that $\alpha_{i}=\beta_{i}=\eta_{i}$. Without this assumption, the optimal transfer in this case would equal $a^{e}=\left[\beta_{h} \Delta m-\alpha_{h}(\gamma t \mathbf{w}-\right.$ $\left.\Delta \mathbf{d})] /\left[\alpha_{h}+\beta_{h}\right) \Delta\right]$. It is easy to see that $a^{e}$ is increasing in $\mathbf{w}$ and $\mathbf{d}$, which implies that in the case described the reform will lead to a decline in child support payments.

The reduction in the child support transfer decreases the mother's outside option, while it improves that of the father. Diagrammatically, the optimal reduction in $a^{e}(\mathbf{d}, \mathbf{w})$ induced by increases in $\mathbf{d}$ and $\mathbf{w}$ shifts the divorce utility pair from $D^{\prime \prime}$ to $D^{\text {post }}$. At $D^{\text {post }}$, the gains from marriage over divorce (evaluated at the pre-reform shock component $\sigma$ ) is measured by the vertical distance between $D^{\text {post }}$ and $M^{\text {post }}$ on $P_{m}$. It is interesting to note that the gains from marriage are in fact larger in the post-reform than in the pre-reform regime. This implies that in this case WFTC leads to a decrease, rather than an increase, in the incidence of the divorce. Perhaps even more surprising, in this numerical example the mother's utility in divorce as well as in marriage have both declined relative to pre-reform values, while it has reduced the value of the outside option for the father, but increased his utility in marriage. These changes reflect a shift in bargaining power from the wife to the husband.

It is possible to analyze the effect of the reform on the distribution of marital bargaining power in this high-income-husband scenario more generally. Under the assumption that the 
wife receives her reservation utility while married, the endogenous bargaining weight $\theta^{e}$ solves $U_{w}(\theta)-D_{w}^{e}=0$. Since $U_{w}(\theta)$ is strictly increasing in $\theta$, the wife's bargaining power, measured by $\theta^{e}$, can be studied by examining her utility in the divorce state: an increase in $D_{w}^{e}$ increases $\theta^{e}$; conversely, a decrease in $D_{w}^{e}$ reduces $\theta^{e}$. The wife's utility in the divorce state is $D_{w}^{e}=\alpha_{w} \ln [\sigma[\gamma t \mathbf{w}+\Delta(\mathbf{d}+m)] /(16 \Delta \mathbf{w})] .{ }^{19}$ Observe that

$$
\frac{\partial D_{w}^{e}}{\partial \mathbf{d}}=\frac{2 \alpha_{w} \Delta}{[\gamma t \mathbf{w}+\Delta(m+\mathbf{d})]}>0 \quad \text { and } \quad \frac{\partial D_{w}^{e}}{\partial \mathbf{w}}=-\frac{\alpha_{w}[\Delta(m+\mathbf{d})-\gamma t \mathbf{w}]}{\mathbf{w}[\gamma t \mathbf{w}+\Delta(m+\mathbf{d})]}<0 \quad \forall m>\hat{m}
$$

On the one hand, an increase in the childcare subsidy $\phi$ and a decrease in the taper rate $\pi$, both measured by an increase in w, reduces $D_{w}^{e}$ and therefore decreases the wife's bargaining power $\theta^{e}$. On the other hand, an increase in the tax credit $T_{\max }$ and an increase in the threshold $M_{\text {min }}$, both measured by an increase in $\mathbf{d}$, raises $D_{w}^{e}$ and therefore increases the wife's bargaining power $\theta^{*}$. The total effect of WFTC on the distribution of marital bargaining power is therefore ambiguous. In other words, for women married to high income husbands, it is theoretically unclear whether the reform will change the intra-household bargaining process so as to reflect their preferences more strongly. The numerical example illustrated in Figure 4.A shows that it is in fact possible for the opposite to occur.

Before discussing the second special case, it is important to clarify that the purpose of these cases and numerical examples is to exemplify the heterogeneity in, and multifaceted nature of responses to the reform. They make clear that overall, without any restrictions on preference parameters or values of $m$ and $w$, the theoretical model produces an ambiguous impact of the reform on divorce. In fact, the two special cases show that even with additional parameter restrictions, it generally is not feasible to generate an unambiguous impact on the likelihood of divorce. They also help understand predictions that may at first sight appear counterintuitive to some.

Low-Income Father $(m \leqslant \hat{m})$ - Couple Eligible as Family - Mother Eligible as Single Parent - No Child Support Payment From Father to Mother ( $a^{e}=0$ ). Consider now a case in which the father works fewer than 16 hours and has a low income. As we have shown in Result 1 , such a family is eligible and chooses to receive WFTC (but not its childcare subsidy) if the mother's wage lies in the interval $\left[w^{*}, w^{* * *}\right)$. As an example, suppose $w \in\left[w^{* *}, w^{* * *}\right)$. Then the optimal female labour supply is $[\gamma t \mathbf{v}-\mathbf{m} \Delta] /[2 \mathbf{v} \Delta]$, where $\mathbf{v}=w(1-\pi)-p_{c}$ and $\mathbf{m}=(1-\pi) m+T_{\max }+\pi M_{\min }$. The corresponding utilities are respectively

$$
U_{w}(\theta)=\alpha_{w} \ln [\kappa \Psi(\mathbf{m}, \mathbf{v}) /(1+\kappa)] \quad \text { and } \quad U_{h}(\theta)=\alpha_{h} \ln [\Psi(\mathbf{m}, \mathbf{v}) /(1+\kappa)] .
$$

\footnotetext{
${ }^{19}$ To obtain this, substitute $a^{e}=\hat{a}$, defined in (8), into (9).
} 
where $\Psi(\mathbf{m}, \mathbf{v}) \equiv[\gamma t \mathbf{v}+\mathbf{m} \Delta]^{2} /(4 \Delta \mathbf{v})$ is a measure of the feasible utility levels if the couple remains married. The utility frontier relating husband's and wife's utilities during marriage is

$$
\exp \left(\frac{U_{h}}{\alpha_{h}}\right)=\Psi(\mathbf{m}, \mathbf{v})-\exp \left(\frac{U_{w}}{\alpha_{w}}\right)
$$

(a proof is provided in Appendix 3).

Assuming that the preference parameters, father's earnings $m$ and the mother's wage rate $w$ are such that the father's optimal transfer in divorce is zero $(m \leqslant \hat{m})$, while the divorced mother optimally chooses to work more than 16 hours while receiving a positive WFTC credit, the utility possibility frontier when the couple separates is given by $\left(P_{d}\right)$ above. In this case we obtain the following

Result 5 Consider the case where the father works fewer than 16 hours with earnings $m$ sufficiently low such that he optimally pays no child support when divorced $\left(a^{e}=0\right)$. Further, let the values of the preference parameters, $m$ and the mother's wage rate $w$ be such that in divorce the mother receives a positive tax credit.

(a) Denote by $V_{w}^{\text {crit }}(\sigma)$ the utility level of the mother at which $P_{d}$ and $P_{m}^{\prime}$ intersect, and let $\tilde{\sigma}$ be defined as the value of $\sigma$ such that $V_{w}^{\text {crit }}(\sigma)=D_{w}^{e}(\sigma)^{20}$. Divorce occurs if $\sigma>\tilde{\sigma}$, and marriage survives if $\sigma<\tilde{\sigma}$.

(b) An increase in the tax credit $T_{\max }$ and the threshold $M_{\min }$, and a reduction in the taper rate $\pi$, tend to decrease the likelihood of divorce through positive effects on the feasible levels of utility gained during marriage, as measured by $\Psi(\mathbf{m}, \mathbf{v})$.

(c) Keeping the utility frontier when married fixed (with $\Psi(\mathbf{m}, \mathbf{v})$ fixed), the reform affects utility in the divorce state, as follows: An increase in the childcare subsidy $\phi$ and a reduction in the taper rate $\pi$, both represented by an increase in $\mathbf{w}$, reduce $\tilde{\sigma}$ and therefore $\underline{\text { increase }}$ the likelihood of divorce. An increase in the tax credit $T_{\max }$ and an increase in the threshold $M_{\text {min }}$, both represented by an increase in $\mathbf{d}$, reduce $\tilde{\sigma}$ and therefore increase the likelihood of divorce. $^{21}$

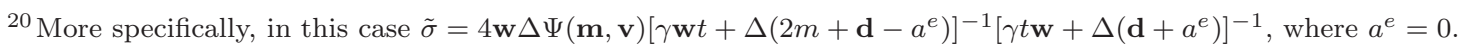

${ }^{21}$ To see this, substitute $a^{e}=0$ into $\tilde{\sigma}$ (in footnote 20$)$ to get $\tilde{\sigma}=4 \Delta \mathbf{w} \Psi /[(\gamma t \mathbf{w}+\Delta(2 m+\mathbf{d}))(\gamma t \mathbf{w}+\Delta \mathbf{d})]$. Then observe that

$$
\frac{\partial \tilde{\sigma}}{\partial \mathbf{d}}=-\frac{8 \Delta^{2} \mathbf{w} \Psi}{[\gamma t \mathbf{w}+\Delta(2 m+\mathbf{d})]^{2}(\gamma t \mathbf{w}+\Delta \mathbf{d})^{2}}<0 \quad \text { and } \quad \frac{\partial \tilde{\sigma}}{\partial \mathbf{w}}=-\frac{4 \Delta^{2} \Psi[\hat{m}(\gamma t \mathbf{w}-\Delta \mathbf{d})-2 m \mathbf{d} \Delta]}{[\gamma t \mathbf{w}+\Delta(2 m+\mathbf{d})]^{2}(\gamma t \mathbf{w}+\Delta \mathbf{d})^{2}}<0 \quad \forall m<\xi \hat{m}
$$

where $\xi=\frac{\mathbf{w}}{\mathbf{d}} \cdot \frac{\gamma t \mathbf{w}-\Delta d}{2 \mathbf{w} \Delta}$. Note that in stating the sign for $\partial \tilde{\sigma} / \partial \mathbf{w}$, we focus on cases in which $\xi \geqslant 1$ (recall that $m \leqslant \hat{m}$ by assumption). The condition $\xi \geqslant 1$ requires that the mother's earned income (her net wage $\mathbf{w}$ times her labor supply $\frac{\gamma t \mathbf{w}-\Delta d}{2 \mathbf{w} \Delta}$ ) exceeds the amount of tax credit received (as measured by $\mathbf{d}$ ). 
This result indicates that the effect of the reform in the divorce state in isolation will generally have a positive effect on the incidence of divorce, but combined with a positive effect on utility when married, the overall effect on the likelihood of divorce is ambiguous.

Figure 4.B illustrates the case considered here with a numerical example, where we again keep $\sigma$ fixed at its pre-reform value. First, holding $\mathbf{w}$ and $\Psi(\cdot)$ constant, an increase in $\mathbf{d}$ shifts (i) the utility possibility frontier in divorce from $P_{d}(\mathbf{d}, \mathbf{w})$ to $P_{d}\left(\mathbf{d}^{\prime}, \mathbf{w}\right)$ and the divorce outcome from $D^{\text {pre }}$ to $D^{\prime}$. A couple who is at $D^{\text {pre }}$ prior to the reform prefers marriage over divorce, receiving the utility pair $M^{\text {pre }}$ on $P_{m}(\mathbf{m}, \mathbf{v})$. But with the shift to $D^{\prime}$ on $P_{d}\left(\mathbf{d}^{\prime}, \mathbf{w}\right)$, the parties will have higher utilities in the divorce state than within marriage, and so choose to divorce.

Second, holding $\mathbf{d}^{\prime}$ and $\Psi(\cdot)$ constant, an increase in $\mathbf{w}$ shifts (i) the utility possibility frontier in divorce further outwards, from $P_{d}\left(\mathbf{d}^{\prime}, \mathbf{w}\right)$ to $P_{d}\left(\mathbf{d}^{\prime}, \mathbf{w}^{\prime}\right)$, and (ii) the divorce outcome from $D^{\prime}$ to $D^{\text {post }}$. Differently from the high-income husbands case, these effects tend to increase the incidence of divorce. Note that the outwards shift in the utility frontier due to the increase in $\mathbf{w}$ indicates that, at the chosen parameter values and low value of $m$, the utility gain experienced by the divorced mother outweighs the utility loss by the father that is associated with the reduction in child quality. In Figure 4.A instead, the increase in w produced a utility loss to a high-income father making a positive child support transfer that outweighted the utility gain by the mother.

Finally, the reform-induced increase in $\Psi(\mathbf{m}, \mathbf{v})$ shifts the utility frontier for marriage outwards, from $P_{m}(\mathbf{m}, \mathbf{v})$ to $P_{m}\left(\mathbf{m}^{\prime}, \mathbf{v}^{\prime}\right)$. The latter shift is the result of an expansion in the budget set. However, despite the positive effects on the feasible utility levels within marriage, the reform has placed $D^{\text {post }}$ outside $P_{m}\left(\mathbf{m}^{\prime}, \mathbf{v}^{\prime}\right)$. As a result, in the absence of large positive shocks $\sigma$, there would be no marital allocation on $P_{m}\left(\mathbf{m}^{\prime}, \mathbf{v}^{\prime}\right)$ that would make both parties better off compared to $D^{\text {post}}$, and so at least one party will want to break marriage. Thus it is quite possible that WFTC has led to an increase in the incidence of divorce, even if it has left couples with higher joint resources within marriage.

It is interesting to note that in the case shown in Figure 4.B only the wife gains by the move from marriage in the pre-reform regime, $M^{\text {pre }}$, to divorce in the post-reform regime, $D^{\text {post }}$. In other words, WFTC may have created incentives to divorce by making the wife better off apart than together. But even in marriage, an important side effect of WFTC may now be to improve the bargaining position of married women. To see this, note that the wife's 
utility in the divorce state is now $D_{w}^{e}=\sigma[\gamma t \mathbf{w}+\Delta \mathbf{d}] /(4 \Delta \mathbf{w}) .{ }^{22}$ Then observe that

$$
\frac{\partial D_{w}^{e}}{\partial \mathbf{d}}=\frac{2 \alpha_{w} \Delta}{[\gamma t \mathbf{w}+\Delta \mathbf{d}]}>0 \quad \text { and } \quad \frac{\partial D_{w}^{e}}{\partial \mathbf{w}}=\frac{\alpha_{w}[\gamma t \mathbf{w}-\Delta \mathbf{d}]}{\mathbf{w}[\gamma t \mathbf{w}+\Delta \mathbf{d}]}>0 .
$$

Differently from the high-income husbands case, both an increase in $\mathbf{w}$ and an increase in d raise $D_{w}^{e}$ and therefore lead to an improvement of the wife's bargaining situation in this case. Hence for women married to low income husbands, with preferences and wage rates that correspond to the case analyzed here, an important side effect of the WFTC reform is to change the household bargaining process so as to reflect the preferences of married women more strongly.

In summary, in this section we have analyzed the different aspects and tradeoffs underlying WFTC's overall impact on divorce decisions. As illustrated by two different examples, the reform is likely to have differential impacts on households who differ in terms of preferences, mothers' wage rates and fathers' earnings. In section 4 we empirically assess WFTC's overall impact on divorce as well as its impact for several subgroups of married couples.

\section{Data and Methods}

\section{A. Sample Selection and Descriptive Statistics}

The data we use are from the first twelve waves of the British Household Panel Survey (BHPS) collected over the period 1991-2002. Since Fall 1991 the BHPS has annually interviewed a representative sample of about 5,500 households covering more than 10,000 individuals. All adults and children in the first wave are designated as original sample members. On-going representativeness of the non-immigrant population has been maintained by using a 'following rule' typical of household panel surveys. At the second and subsequent waves, all original sample members are followed (even if they moved house or if their households split up), and there are interviews, at approximately one-year intervals, with all adult members of all households containing either an original sample member, or an individual born to an original sample member whether or not they were members of the original sample. The sample therefore remains broadly representative of the population of Britain as it changes over time. ${ }^{23}$

\footnotetext{
${ }^{22}$ This follows immediately after substituting $a^{e}(\mathbf{d}, \mathbf{w})=0$ into (9).

${ }^{23}$ Of the individuals interviewed in 1991, 88 percent were re-interviewed in wave 2 (1992). The wave-on-wave response rates from the third wave onwards have been consistently above 95 percent. Detailed information on the BHPS can also be obtained at http://www.iser.essex.ac.uk/ulsc/bhps/doc. The households from the European Community Household Panel subsample
} 
Our estimation sample includes married and cohabiting couples in which the woman is at least 16 years old and was born after 1946 (thus aged at most 55 in 2002). ${ }^{24}$ We exclude those couples where one partner was long-term ill or disabled, or in school full time in a given year. To focus on the segment of the population for whom the reform is more likely to be of potential relevance, we also excluded couples where the man worked more than 16 hours and earned in the top quartile of the earnings distribution. These earnings far exceeded the income eligibility thresholds for WFTC benefit receipt. The resulting sample includes 3,235 couples, of which 1,430 have dependent children during the sample period and the remaining 1,805 do not have children during the observation period. In line with the Inland Revenue's definition, a child must be aged 16 or less (or be under the age of 19 and in full-time education) to count as a dependent child for whom parents are responsible. Therefore, households with non-dependent children are included in the group of childless couples. Most of our analysis will focus on the mothers. Some 42 percent of the women have been observed over the whole sample period, and almost 75 percent of them are observed for at least eight years. The resulting sample size, after pooling all twelve years for women in households with and without dependent children, is 22,146 person-year observations $(10,162$ on mothers and 11,984 on childless women).

Table 1 presents summary statistics of the labour market outcomes and characteristics of couples by gender and presence of children. The first column presents the statistics for all couples without children, while the second column presents the statistics for all couples with children. There are some noticeable differences in characteristics between the two groups. Male and female partners with children are on average somewhat younger, less educated, and more likely to be in social housing. There also appear to be systematic differences in the employment behaviour between the two groups. Compared to married childless women, married mothers are less likely to work 16 or more hours per week (57 percent versus 84 percent), as well as 30 or more hours per week (30 versus 67 percent). ${ }^{25}$ These differences go in the opposite direction in the case of male partners, with a somewhat stronger involvement in the labour market (in terms of either labour market participation, or working 16 or more hours, or full-time employment) among fathers than among married men without children.

The differences between the two groups of women are mirrored in their labour market tran-

(followed since the seventh wave in 1997), those from the Scotland and Wales booster subsamples (added to the BHPS in the ninth wave) and those from the Northern Ireland booster subsample (which started in wave 11) are excluded from our analysis.

${ }^{24}$ Married couples are not distinguished from cohabiting unions in the analysis below, because we could not detect any relevant difference in terms of outcome responses between these two types of partnerships.

${ }^{25}$ Throughout the paper, worked hours are defined by usual weekly hours of work plus usual weekly hours of overtime work. 
sitions: women with children have a lower probability of staying in the labour market, both in eligible employment and full-time work. However, among those not in eligible employment in the previous year, they are more likely to enter eligible employment in a given year. For mothers we also examine further fertility decisions, and entry rates into motherhood for childless women.

Finally we consider a few outcomes that are measured at the household (rather than individual) level. Couples with children are more likely to be in receipt of Income Support and are also more likely to break down their (marital or cohabiting) unions. The other householdlevel outcomes listed in Table 1 are relevant only for couples with children (i.e., FC/WFTC receipt, and usage of and expenditures on childcare services).

Figures 5-8 plot the time trends for the main labour market outcomes between 1991 and 2002 for women in the two groups as a whole or distinguished by their partners' employment and earnings position in line with the model presented in Section 2. Figure 9 plots the trends for men. In each figure, panels (a) and (b) focus on eligible employment and full-time employment, respectively. Figure 5 shows slightly increasing participation in both outcomes among women with children and, correspondingly, decreasing trends for women without children. Among mothers whose partner does not work or works fewer than 16 hours per week, we observe greater increases in conjunction with the 1999 reform (Figure 6). To a lesser extent, this can be detected among mothers whose partners work 16 or more hours per week but have earnings in the bottom third of the sample's male earnings distribution (or bottom quarter in the total sample, Figure 7). The labour market outcomes of women (whether with or without children) married to men with earnings above the bottom third show relatively stable profiles, with the possible exception of a slight long-term increase in full-time employment for married mothers (Figure 8, panel (b)). For men, Figure 9 reveals a modest increase in both outcomes among fathers and a correspondingly more marked decline among childless married men.

These trends suggest that the labour market behaviour of couples overall was not systematically related to the introduction of the WFTC reform, in the sense that we cannot detect a clear-cut change in behaviour among couples who were directly affected by the reform (couples with children) after 1998. Perhaps, the only group of couples who showed labour market movements that were possibly related to the in-work benefit reform are those in which the male partner did not work or worked fewer than 16 hours per week. This evidence is broadly in line with the main predictions of the model presented in Section 2. In the next section we 
examine whether the same evidence also emerges from our multivariate regression analysis.

\section{B. Econometric Method}

We do not estimate our structural model directly, so we do not retrieve the deep parameters which are behind our theoretical results. Rather, we use those results to guide our way of looking at the data and interpreting estimates from our reduced form empirical analysis. This will be based on standard regression models that can be linked to the setup of the previous section and can also be related to the evaluation literature (Blank, 2002; Hotz and Scholz, 2003) and especially to earlier studies on British couples (Blundell and Hoynes, 2004; Blundell et al. 2004).

Let $d_{i}$ denote a dummy variable that is equal to 1 if woman $i$ is a married mother (treatment group) and 0 if she is married without children (control group), and let $s$ be the time period in which the reform occurs (i.e., $s=1999$ ). Then, the outcome variable $y_{i t}$ is given by

$$
\begin{aligned}
y_{i t}= & a_{0}+a_{1} d_{i t}+\left(a_{21}+a_{22} d_{i t}\right) t+\left[a_{31}+a_{32}(t-s)\right] I(t \geq s) \\
& +b d_{i t} I(t \geq s)+\mathbf{X}_{i t}^{\prime} \Gamma+\varphi_{i}+u_{i t},
\end{aligned}
$$

where the term $I(w)$ is a function indicating that the event $w$ occurs, $\mathbf{X}_{i t}^{\prime}$ is a vector of individual characteristics, $\varphi_{i}$ represents individual fixed effects, and $u_{i t}$ is an i.i.d. error term. Equation (13) allows for different intercepts (when $a_{1} \neq 0$ ) and different linear trends (when $a_{22} \neq 0$ ) for married without and with children. The parameters $a_{31}$ and $a_{32}$ measure possible shifts in the intercept and slope of the process generating $y$ at the time of the reform. In our case, they capture the effects of all the other (non-WFTC) policy changes that occurred at $s$ (e.g., the introduction of the minimum wage). With this specification we extend the method developed in Francesconi and van der Klaauw (2007) to married women. As in that study, our key identification assumption is that, other than the introduction of WFTC, there are no contemporaneous shocks that affect the relative outcomes of the treatment and control groups. ${ }^{26}$

As a means of controlling for potential differences in group-specific compositional changes

${ }^{26}$ As just mentioned here and discussed in Brewer et al. (2007), the WFTC reform, however, was accompanied, preceded and followed by the introduction of new programmes (such as the National Minimum Wage and various New Deal schemes) and by changes in key parameters of other existing schemes (such as Income Support). Most of these changes affected married couples equally whether they had children or not (e.g., the minimum wage). But some changes (such as the increase in the child benefit under Income Support for lone mothers working less than 16 hours a week) affected couples with children in the same way as WFTC did. This could lead to a downward bias in our effect estimates. 
over time, $\mathbf{X}_{i t}^{\prime}$ includes a set of individual characteristics (such as age, education, region of residence, number and ages of children). Because married childless women tend to be more concentrated at the bottom and top ends of the age distribution, we account for different age effects by including a quartic polynomial in age. By using panel data, we also account for compositional changes in unobserved characteristics with the inclusion of individual-specific fixed effects, subsumed in $\varphi_{i}$. Unlike studies based on cross-sectional data, this permits us to address the possibility that time changes in married-mother status (i.e., inclusion in our sample) as well as changes in time-varying individual characteristics are endogenous to the policy reform as long as the fixed effect captures the source of this endogeneity.

Since we use panel data which follow people over time, we can examine whether the introduction of WFTC led to changes in the rate at which married women entered and left the labour force. That is, we can directly assess the impact of WFTC on year-to-year employment transitions. This is important in relation to some of our theoretical predictions. It also helps us understand whether any given WFTC effect is associated with a change in the rate at which married women entered the labour force and/or with a change in the rate at which people left it. We implement this analysis by estimating separate outcome equations (13) for each value of $y_{i, t-1}$.

\section{Empirical Evidence}

\section{A. Basic Estimates for the Labour Market Outcomes of Married Women}

Table 2 presents the estimates for our key labour market outcomes, that is, eligible employment and full-time employment for the whole sample of married women. These estimates are obtained from models that do not condition on partner's labour supply and earnings. For simplicity of interpretation, we only report least squares estimates based on linear probability models with fixed effects. Marginal effects estimates from Chamberlain fixed-effects logit models were very similar, and thus not reported. The first column of the table shows constant treatment effect estimates with group-specific pre-programme linear trends (as in (13)). ${ }^{27}$ The estimates imply that married mothers overall increased their full-time employment rates by about 1.7 percentage points, and their likelihood of working 16 or more hours per week by 0.7 percentage points. Neither of these two estimates is statistically significant. These results are close to those reported in Blundell et al. (2000) and Blundell and Hoynes

${ }^{27}$ We also experimented with group-specific pre-programme quadratic trends and found estimates almost identical to those reported in Table 2. These estimates therefore are not shown. 
(2004) and are broadly consistent with the general predictions of our analysis in Section 2, where we emphasized that the introduction of WFTC might have led to ambiguous overall employment effects for married women.

\section{B. Heterogeneity in Responses}

The theory we developed in Section 2 suggests that the labour supply responses of women in couples is highly heterogeneous depending on the employment status and earnings of their partners. We therefore re-estimated the previous models after stratifying the sample of women by partner's labour supply and earnings. In particular, we distinguish three groups: women whose partners do not work or work fewer than 16 hours per week; women whose partners work 16 or more hours per week and have earnings in the bottom third of the male earnings sample distribution; and women whose partners work 16 or more hours per week and have earnings in the top two-third of the male earnings distribution. With the first group we try to identify women in class-A households without attempting to discriminate between different types of women. The other two groups intend to isolate class-B households, and the distinction between low-earning and high-earning husbands is meant to separate type- 4 women from the other three types. This categorisation captures the heterogeneity implied by the model only imperfectly, but it has the advantage of being fairly parsimonious. In some of the analysis below, however, we shall apply finer categorisations, especially when this is more strongly entailed by our theoretical results.

The results are shown in columns two to four in Table 2. We find strong eligible employment effects among mothers with a partner who did not work or worked fewer than 16 hours per week (column two in panel A). These women increased the probability of working 16 or more hours per week by 3 percentage points, while increasing the full-time employment rate by 2 percentage points. Interestingly, these results are close to those found for single mothers (Gregg and Harkness, 2003; Francesconi and van der Klaauw, 2007). These results are consistent with our predictions in section 2, where we showed that women married to low-income men (women in class A households) generally had a greater incentive to work or increase their hours worked following the reform. Our theoretical analysis implies further response heterogeneities which will be considered in greater detail below when we differentiate by the number and ages of children.

For women whose partners work 16 or more hours per week we find instead no statistically

significant labour supply response regardless of the man's position in the earnings distri- 
bution (third and fourth columns). The estimates in column 4 can be seen as applying to women who are closer to what we referred to as type 4 in Section 2. According to our model and the comparative statics results for class A and class B households, in absence of a change in bargaining power, such women would either not have responded to the reform (if the partner's earnings were relatively high), or would have experienced a negative labour supply effect (if household earnings were not far above the income eligibility threshold). This negative response could be offset by an increase in bargaining power as long as the wife has a higher valuation on an additional hour of her labour supply than her husband does (Result 3.b). But the small magnitude of the response and the lack of its statistical significance point to a relatively modest role played by intra-household bargaining power.

Another dimension over which we may expect heterogeneous responses is women's education, even though this is not explicitly examined in the theoretical setup of Section 2. The heterogeneity may come about because educational levels could be correlated not only with wage rates but also with female labour market attachment and husband's characteristics through assortative mating (and this, in turn, may place women in different segments of the male earnings and hours distributions). Panels B and C of Table 2 report fixed-effects estimates obtained from the subsample limited to women with educational qualifications below A level ("low education sample") and with A level or higher qualification ("high education sample") respectively. The effects are slightly larger for women in the low-education sample, but the differences in impact with respect to the women in the other sample are never statistically significant. Besides small sample size considerations, this result suggests that differential responses along the educational gradient are likely to be limited. This echoes some of the results for single mothers presented in Francesconi and van der Klaauw (2007).

\section{Labour Market Outcome Estimates by Child's Age}

As mentioned in the Introduction to this Symposium, the increase in the base amount of the tax credit implied by the WFTC reform was greatest for parents of younger children (Brewer et al., 2007). By eliminating the differential treatment that Family Credit had on children of different ages (achieved via a larger credit increase in favour of younger children) and by providing more generous support to childcare costs, the WFTC reform could have generated different labour market responses depending on the number and ages of children. ${ }^{28}$ To analyze this possibility, we estimate separate treatment effects by the number of dependent

${ }^{28}$ This indeed has been the case for single mothers (see Gregg and Harkenss, 2003; Blundell et al., 2004; Francesconi and van der Klaauw, 2007). 
children, and distinguishing by age of the youngest child in the age intervals $0-4,5-10$, and 11-18. ${ }^{29}$ The fixed-effects estimates of this analysis for all women (first column) and for the three groups of women stratified according to their partners' labour supply and earnings (the remaining three columns) are shown in Table 3.

Looking at the whole sample of women, we cannot detect differential labour supply responses across mothers with children in different age groups or with a different number of children. The results in the next three columns of Table 3, however, indicate that the reform led to a statistically significant 4.8 percentage point increase in eligible employment among women with a partner who did not work or worked fewer than 16 hours per week and with one pre-school aged child. Mothers with one child aged 5-10 also increased their probability of working 16 or more hours per week by 4.4 percentage points, while mothers with two preschool children increased the probability of eligible employment by 3.6 percentage points. There is instead little evidence of an increase in eligible employment of mothers with multiple older children. These results tie in well with those found for single mothers by Gregg and Harkness (2003) and Francesconi and Van der Klaauw (2007). There is instead little variation in the labour supply responses by child's age and number of children of mothers with partners who work more than 16 hours per week, regardless of their position in the male earnings distribution. Again, the lack of a significant effect among these women suggests that the reform had at most a relatively modest impact on bargaining power.

Finally, a comparison of the full-time employment effects with the eligible employment effects is quite revealing. The full-time employment estimates are always smaller for women whose partner works fewer than 16 hours per week. They are, however, larger for women whose partner works 16 or more hours (irrespective of his earnings): even though such responses are never statistically significant, they are invariably positive and range between 1 and 3 percentage point increases. The comparative statics results following Results 1 and 2 in Section 2 suggest that type- 4 women (presumably better identified by women whose partner works 16 or more hours per week and has high earnings) should either have not altered or reduced their labour supply in response to the introduction of WFTC. But, as indicated

${ }^{29}$ In particular, the specifications we analyse take the following form:

$$
y_{i t}=a_{0}+a_{1} d_{i t}+\left(a_{21}+a_{22} d_{i t}\right) t+\left[a_{31}+a_{32}(t-s)\right] I(t \geq s)+\sum_{j=1}^{6} b_{j} d_{i t} N_{i j t} I(t \geq s)+\mathbf{X}_{i t}^{\prime} \Gamma+\varphi_{i}+u_{i t},
$$

where $N_{i j t}$ is a dummy variable that equals one if woman $i$ at time $t$ has her youngest child in group $j$, and $j=1, \ldots, 6$ distinguishes mothers of one child from mothers of two or more children with the only child or the youngest child being aged $0-4$, or 5-10, or 11-18. 
in Result 3.b, the reform could have generated changes in marital bargaining power that would have offset the negative labour supply response at the top of the wage distribution. Therefore, the greater full-time employment effects among women with high-earning partners (although not statistically significant) is consistent with a (modest) reform-induced change in bargaining power.

In summary, our estimates imply a strong positive effect on eligible employment and a smaller positive and statistically insignificant effect on full-time employment, for women who are likely to be in class-A households. Both findings are consistent with our comparative statics results in section 2. The results for class B households are similarly consistent with an overall ambiguous labour supply effect of WFTC, predicted by our theoretical model.

\section{Employment Transitions}

Because we use panel data, we can examine whether the introduction of WFTC led to changes in the rate at which married women entered and left the labour force. That is, we can directly assess the impact of WFTC on year-to-year employment transitions. For this purpose, we estimate the WFTC effect both on the probability of staying in any of the two labour market states analysed so far and on the probability of starting a job with 16 or more hours of work per week, or a full-time job. We label the former set of probabilities as persistence probabilities and the latter as entry probabilities. The corresponding treatment effect estimates are shown in Table 4, in which we report estimates for the whole sample of women (first column) and for the three groups of women distinguished by their husbands' labour supply and earnings (second to fourth columns).

For the entire sample, we cannot find any significant impact of the WFTC reform on persistence probabilities in the two labour market states, nor can we detect any impact on entry probabilities. But as expected from our theoretical analysis as well as the previously reported empirical results, there is some sizable heterogeneity across women depending on their husbands' employment status and earnings. In particular, the introduction of the in-work benefit reform increased mothers' persistence rates in eligible employment and full-time employment by 4 and 3 percentage points respectively if their partners did not work or worked fewer than 16 hours per week. Entry rates for the same group of women show slightly lower but similarly important and statistically significant increases along both labour market margins. Such findings line up nicely with the theoretical predictions for class A households. But the labour market transitions for mothers with husbands working 16 or more hours per week do 
not significantly differ from the transition of comparable married women without children. This does not contradict our theoretical predictions (see the comparative statics results for class A households in section 2). In general, therefore, estimates of the reform's impact on employment transitions are coherently tied with those found earlier for employment levels. It is also worth emphasizing that the overall pattern of the results for women with husbands working fewer than 16 hours echoes that found for lone mothers (Francesconi and van der Klaauw, 2007). The fact that the overall labor supply response among lone mothers was somewhat larger, and especially so among those with pre-school children, can be explained by the fact that lone mothers were also potentially eligible for the more generous child care credit, while women married to men working fewer than 16 hours per week are instead ineligible for this credit.

\section{E. Labour Market Outcomes of Married Men}

For simplicity, our model takes husbands' labour supply and earnings as given. Despite this, we analyzed male labour supply responses to WFTC in a similar fashion to what we have done so far for women.

Table 5 displays the fixed-effects estimates of the WFTC effect on men's labour market outcomes. For the whole sample, there is no evidence of an effect of the in-work benefit reform on men's behaviour. This emerges also after distinguishing men on the basis of their female partners' labour supply and earnings. We also repeated some of the analysis performed on women, such as labour market transitions, and found again no measurable significant effect (for brevity, these estimates are not shown). Thus, the WFTC programme seems to have had no impact on married men, suggesting that our assumption on the exogeneity of husband's labour market behaviour to the in-work benefit reform is credible. ${ }^{30}$

In this analysis, however, men were stratified on the basis of their partners' labour supply and earnings observed over the whole sample period (both before and after the reform). But our earlier estimates showed that married women's labour supply changed substantially across the male hours/earnings distribution as a result of the WFTC reform. Consequently, the composition of the male groups (that is, the samples used for the three last columns of Table 5) might have changed quite substantially too around the 1999 reform date. As

\footnotetext{
${ }^{30}$ Blundell et al. (2004) report an overall negative effect on labour force participation for men. This effect seems to be driven by the effect on men whose partners were working. However, that result turns out to be not robust to a number of sensitivity tests.
} 
an additional sensitivity check, therefore, we re-estimated the same regressions reported in Table 5 with the difference that men were now distinguished on the basis of their wives' labour supply and earnings observed only in the years that preceded the reform (1991-1998). With similar point estimates and slighly larger standard errors in all groups and outcomes, the results (not shown) confirm those of Table 5.

\section{F. Other Outcomes}

The introduction of WFTC might have affected married women's (and their families') behaviour in domains other than labour supply. As explained in Section 2, WFTC may have had an impact on people's decisions about whether to dissolve their marriage. A couple would face a marriage penalty if the utility gains from the reform were lower within marriage than after divorce. As compared to the large body of research on the effect of welfare reforms on non-labour-market outcomes in the United States (e.g., Blank (2002), Hotz and Scholz (2003), Bitler et al. (2004), and references therein), this literature is virtually nonexistent for Britain. ${ }^{31}$

The first row of Table 6 shows estimates of the reform's impact on divorce. There is no evidence of a marriage penalty as a consequence of the in-work benefit reform for the whole sample of married mothers, nor is there evidence that it affected the divorce rate of women married to partners in eligible employment. But women married to a partner who does not work or works fewer than 16 hours per week were more than 2 percentage points more likely to dissolve their partnership after the reform than their childless counterparts. This is a substantial impact on the divorce rate, representing an increase of almost 160 percent with respect to the pre-reform period. This result implies that for such women, the introduction of WFTC reduced the gains from marriage. This is consistent with substantial improvements in the employment and financial positions of single mothers as a result of the reform (Gregg and Harkness, 2003; Francesconi and van der Klaauw, 2007), which might have provided an attractive "outside option" to mothers married to low earning partners. It is also consistent with the scenario described in Result 5 and illustrated in Figure 4.B. While the more generous tax credit would have left couples with more resources unaffected, it also led to a greater utility increase for women outside marriage, and this increase seems to have been greater for women in poorer households. In the next subsection we shall consider a more disaggregated analysis of this finding.

\footnotetext{
${ }^{31}$ Francesconi and van der Klaauw (2007) provide an analysis of marital status choices using BHPS data for lone mothers, but not for married women.
} 
The remaining rows of Table 6 include estimates of the impact of WFTC on several additional outcomes. On average, during the post-reform period, the probability that a married woman received a WFTC award did not change significantly when compared to the prereform period (second row, Table 6). However, in line with our theoretical predictions for type A households, this probability increased significantly by about 3 percentage points among women with a partner who did not work or worked fewer than 16 hours per week. Among women married to men working more than 16 hours per week but with relatively low earnings, we also find an increased probability of WFTC receipt, but this increase is not statistically significant; whereas, for women married to the high-earning partners, we find essentially a zero effect on the likelihood of receiving WFTC. These estimates are entirely in line with the theoretical comparative statics results discussed in Section 2. Interestingly, we do not find any effect of the reform on the probability of IS receipt among married women, either as a whole (first column) or for any of the three subgroups (next three columns). However, given the low share of households in our sample who are actually eligible and receiving IS support prior to the reform (less than 3 percent), this result is not very surprising.

In Section 2, we discussed the positive effect of the childcare component of WFTC on the use of paid childcare services among eligible mothers. This positive response, however, might be offset by negative income effects driven by the increases in the credit base amount and the threshold, which work in the opposite direction. The estimates in Table 6 (fourth and fifth rows) indicate virtually no effect on average. The only positive and significant impact emerges for women married to men working at least 16 hours per week and with low earnings. Because the childcare credit component is available only to couples where both partners work more than 16 hours per week, the absence of an effect for the first group is entirely reasonable. The increase in childcare usage for women married to low earning men in eligible employment, on the other hand, appears to reflect primarily an increase in eligibility or takeup among the subset of these women in eligible employment, as the results in Tables 3-4 did not detect a sizeable increase in eligible employment among this group of women.

Finally, the reform could have changed fertility patterns of both married mothers (by altering their subsequent fertility decisions) and married childless women (by changing their likelihood of entering motherhood). As shown in Table 6 (last two rows), both such transitions were slowed down by WFTC, but these effects are small and never statistically significant, irrespective of the subgroups of mothers we consider. On the basis of these results, therefore, even though our model treats fertility as exogenous to labour supply, childcare, and marital status decisions, this assumption does not seem to be problematic. 


\section{G. Heterogeneous Impacts on Divorce}

Finally, given the lack of significant differences between low- and high-education women on the one hand, with large variation in labor supply responses revealed in Table 3 by the number age ages of children on the other hand, it is of interest to examine whether the WFTC's impact on divorce is similarly heterogeneous. The estimates in Table 7 show comparable increases in the divorce rates for low- and high-educated women whose husband worked fewer than 16 hours per week, but reveal significant variation with the number and ages of children. As was the case with the mother's labor supply responses in class A households, the impact of divorce was greatest in households with young children. As discussed earlier, the increase in the child credit under WFTC was particularly large for families with young children. Moreover, the increased generosity of the child care credit implied potentially very large utility gains associated with eligible employment in divorce, while no such gains existed if the mother remained married to a husband working fewer than 16 hours per week. The requirement for both parents to work at least 16 hours per week may therefore inadvertently have contributed to a considerable increase in the divorce rate for a subset of married women.

\section{Conclusion}

In October 1999, the Working Families' Tax Credit replaced Family Credit as the main package of in-work support for low-income families with children in Britain. Although it has been replaced by new tax credits in 2003, many of its key principles remain operative to date. This paper examines the impact of 1999 WFTC reform on married couples using for first time longitudinal data drawn from the British Household Panel and collected between 1991 and 2002.

Our study contributes to the existing literature in two important ways. First, it develops a bargaining model of household decisions which offers a number of implications to examine the incentives for female employment and divorce generated by WFTC in two-parent households. One of the most insightful results of the model is the identification of highly heterogeneous responses to the in-work benefit reform depending on the household's position in the male earnings and hours distributions. Second, it considers effects on a broad set of socioeconomic outcomes, some of which have never been examined before for British couples. Our empirical analysis identifies the effect of WFTC through comparisons of changes in behaviour for married mothers and married women without children, and uses specific aspects of the 
reform design and panel nature of the data to understand how the estimated responses came about.

We stress four empirical policy-relevant results. First, the financial incentives of the reform had virtually no effect on many aspects of behaviour of married mothers, such as eligible and full-time employment, employment transitions, childcare utilisation, and divorce rates. Second, women's responses were however highly heterogeneous and - in line with the theoretical predictions - depended upon their partners' labour supply and earnings. Mothers married to low-income men showed larger responses in employment, especially if they had younger children. They were more likely to remain in the labour force and had higher rates at which they entered it. While more likely to receive the tax credit, they also experienced a greater risk of divorce. Third, we find instead no effect for women with higher-income husbands. Fourth, there are also no statistically significant responses among married men.

On the policy side, the result that WFTC had strong employment and divorce effects on married mothers in poor households is very important. These women are effectively "similar" to single mothers and, as stressed by our findings, they are more vulnerable to become such. Indeed, the better employment position of single mothers as a result of the reform (as documented in Gregg and Harkness (2003) and Francesconi and van der Klaauw (2007), perhaps through its more generous childcare provision) could have generated a valuable "outside option" to mothers partnered to low-earning men. This response could have been an unintended consequence of the reform, which may turn out to be important for the evaluation of the longer-term success of the reform itself.

This result echoes one of the findings delivered by our theoretical analysis. That analysis in fact can help us understand why the childcare component of WFTC might have not been strong enough to induce more couples with children into eligible employment and marriage: essentially because both husband and wife had to work 16 or more hours per week in order to receive the childcare credit of WFTC. If the reform enhanced the economic position of single mothers, the bargaining power of married women - especially those in poorer households - could have been improved; rather than leading to a greater claim on thin household resources, this might have induced a greater risk of family disruption. To pin down the deep parameters that lie behind such results and perform more general policy simulations, a natural extension is to follow Chiappori, Fortin, and Lacroix (2002), Blundell, Chiappori, and Meghir (2005) and Blundell et al. (2007) and embed our theoretical framework into a more structural estimation procedure. 


\section{References}

[1] Anderberg, Dan, Kondylis, Florence and Walker, Ian (2006). 'Partnership Penalties and Bonuses Created by Two Major UK Benefit Programs', mimeo.

[2] Bitler, Marianne P., Gelbach, Jonah B., Hoynes, Hilary W. and Zavodny, Madeline (2002). 'The Impact of Welfare Reform on Marriag and Divorce', Demography, vol. 41(2), pp. 216-36.

[3] Blackwell, A. and Dawe, F. (2003). Non-resident Parental Contact. London: Office for National Statistics, Social and Vital Statistics Division.

[4] Blank, Rebecca M. (2002) 'Evaluating Welfare Reform in the United States', Journal of Economic Literature, vol. 40(4), pp. 1105-66.

[5] Blundell, Richard (2001). 'Welfare Reform for Low Income Workers', Oxford Economic Papers, vol. 53(2), pp. 189-214.

[6] Blundell, Richard, Brewer, Mike, Reed, Howard and Shepard, Andrew (2004). 'Evaluation the Labour Market Impact of the Working Families' Tax Credit Using Difference-in-Differences', mimeo, Institute for Fiscal Studies, August.

[7] Blundell, Richard, Chiappori, Pierre-André, Magnac, Thierry and Meghir, Costas (2007). 'Collective Labor Supply: Heterogeneity and Non-Participation', Review of Economic Studies, vol. $74(?)$, pp. $417-45$.

[8] Blundell, Richard, Chiappori, Pierre-André and Meghir, Costas (2005). 'Collective Labor Supply with Children', Journal of Political Economy, vol. 113(6), pp. 1277-1306.

[9] Blundell, Richard, Duncan, Alan, McCrae, Julian and Meghir, Costas (2000). 'The Labour Market Impact of the Working Families' Tax Credit', Fiscal Studies, vol. 21(1), pp. 75-104.

[10] Blundell, Richard and Hoynes, Hilary (2004). 'Has 'In-Work' Benefit Reform Helped the Labour Market?,' in (R. Blundell, D. Card and R.B. Freemand, eds.) Seeking a Premier League Economy, Chicago: University of Chicago Press, pp. ??

[11] Blundell, Richard and Walker, Ian (2001). 'Working Families' Tax Credit: A Review of the Evidence, Issues and Prospects for Further Research', Inland Revenue Research Report No. 1. London: Inland Revenue. Available at http://www.hmrc.gov.uk/research/wftc6rb.pdf.

[12] Brewer, Mike, Francesconi, Marco, Gregg, Paul and Grogger, Jeff (2007). 'Symposium on InWork Benefit Reform in a Cross-National Perspective: Introduction', mimeo.

[13] Chiappori, Pierre-André, Fortin, Bernard and Lacroix, Guy (2002). 'Marriage Market, Divorce Legislation, and Household Labor Supply', Journal of Political Economy, vol. 110(1), pp. 3772 . 
[14] Clark, Simon (1999). 'Law, Property, and Marital Dissolution', Economic Journal, vol. 109, pp. C41-C54.

[15] Del Boca, Daniela and Flinn, Christopher J. (1995). 'Rationalizing Child-Support Decisions', American Economic Review, vol. 85(5), pp. 1241-1262.

[16] Eissa, Nada and Hoynes, Hilary (2004). 'Taxes and the Labor Market Participation of Married Couples: The Earned Income Tax Credit', Journal of Public Economics, vol. 88(9-10), pp. 1931-58.

[17] Ermisch, John F. and Pronzato, Chiara (2006). 'Intra-household Allocation of Resources: Inferences from Non-resident Fathers' Child Support Payments'. Working Paper of Institute for Social and Economic Research, paper 2006-57. Colchester: University of Essex.

[18] Fella, Guilio, Manzini, Paola and Mariotti, Marco (2004). 'Does Divorce Law Matter', Journal of the European Economic Association, vol. 2, pp. 607-33.

[19] Flinn, Christopher J. (2000). 'Modes of Interaction Between Divorced Parents', International Economic Review, vol. 41(3), pp. 545-578.

[20] Francesconi, Marco and van der Klaauw, Wilbert (2007). 'The Socioeconomic Consequences of "In-Work" Benefit Reform for British Lone Mothers', Journal of Human Resources, vol. 42(1), pp. 1-31.

[21] Gregg, Paul and Harkness, Susan (2003). 'Welfare Reform and Lone Parents Employment in the UK', mimeo, University of Bristol, January.

[22] Grogger, Jeff and Lynn A. Karoly (2007). 'The Effects of Work-Conditioned Transfers on Marriage and Child Well-Being: A Review', mimeo.

[23] Iyigun, Murat F. and Walsh, Randall P. (2007). 'Endogenous Gender Power, Household Labor Supply and the Demographic Transition', Journal of Development Economics, vol. 82(1), pp. $138-55$.

[24] Heckman, James J. (1993). 'What Has Been Learned About Labor Supply in the Past Twenty Years?' American Economic Review Papers and Proceedings, vol. 83(2), pp. 116-21.

[25] Hotz, Joseph v. and Scholz, John K. (2003). 'The Earned Income Tax Credit', in (R.A. Moffitt, ed.) Means-Tested Transfer Programs in the United States, Chicago: University of Chicago Press.

[26] Manser, Marilyn and Brwon, Murray (1980). 'Marriage and Household Decision Theory: A Bargaining Analysis', International Economic Review, vol. 21(1), pp. 21-34.

[27] McElroy, Marjorie B. and Horney, Mary J. (1981). 'Nash-Bargained Decisions: Towards a Generalization of Demand Theory', International Economic Review, vol. 22(2), pp. 333-49. 
[28] Rainer, Helmut (2007). 'Should We Write Prenuptial Contracts', European Economic Review, vol. 51(2), pp. 337-63.

[29] Rasul, Imran (2006). 'The Economics of Child Custody', Economica, vol. 73(289), pp. 1-26.

[30] Weiss, Yoram and Willis, Robert J. (1985). 'Children as Collective Goods and Divorce Settlements', Journal of Labor Economics, vol. 3(3), pp. 268-292. 
Figure 5

Labour Market Outcomes -All married women

\section{A. Working 16 or more hours per week}

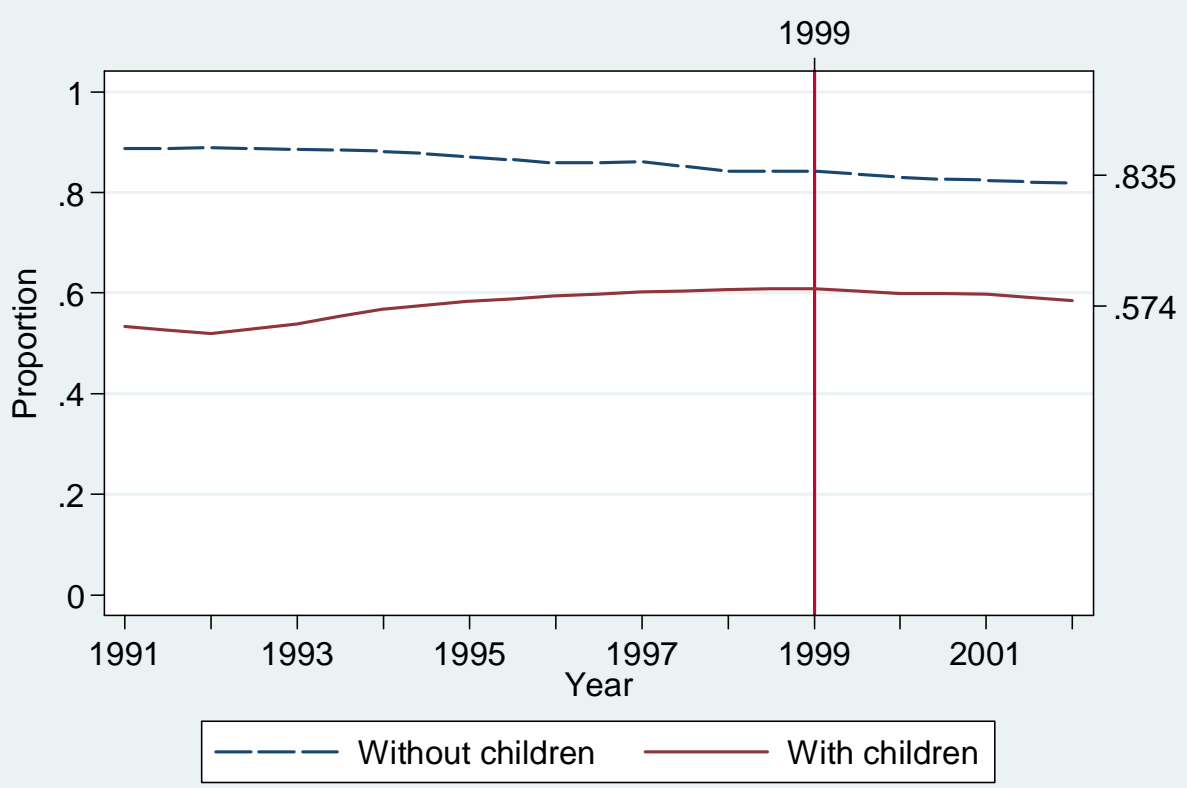

\section{B. Working 30 or more hours per week}

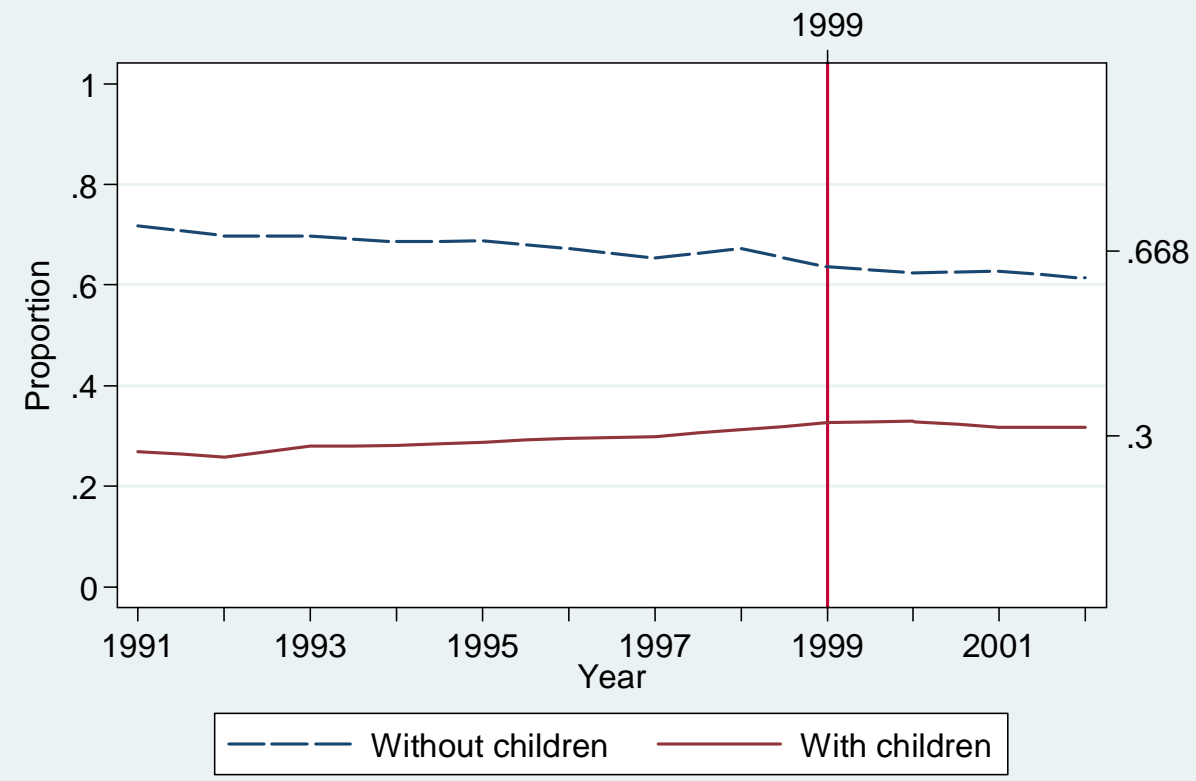

Source: British Household Panel Survey, 1991-2002.

Notes: Figures are computed on our sample of married couples described in section 3, with corresponding summary statistics reported in Table 1. 
Figure 6

Labour Market Outcomes

Married women whose partner does not work or works fewer than 16 hours per week

A. Working 16 or more hours per week

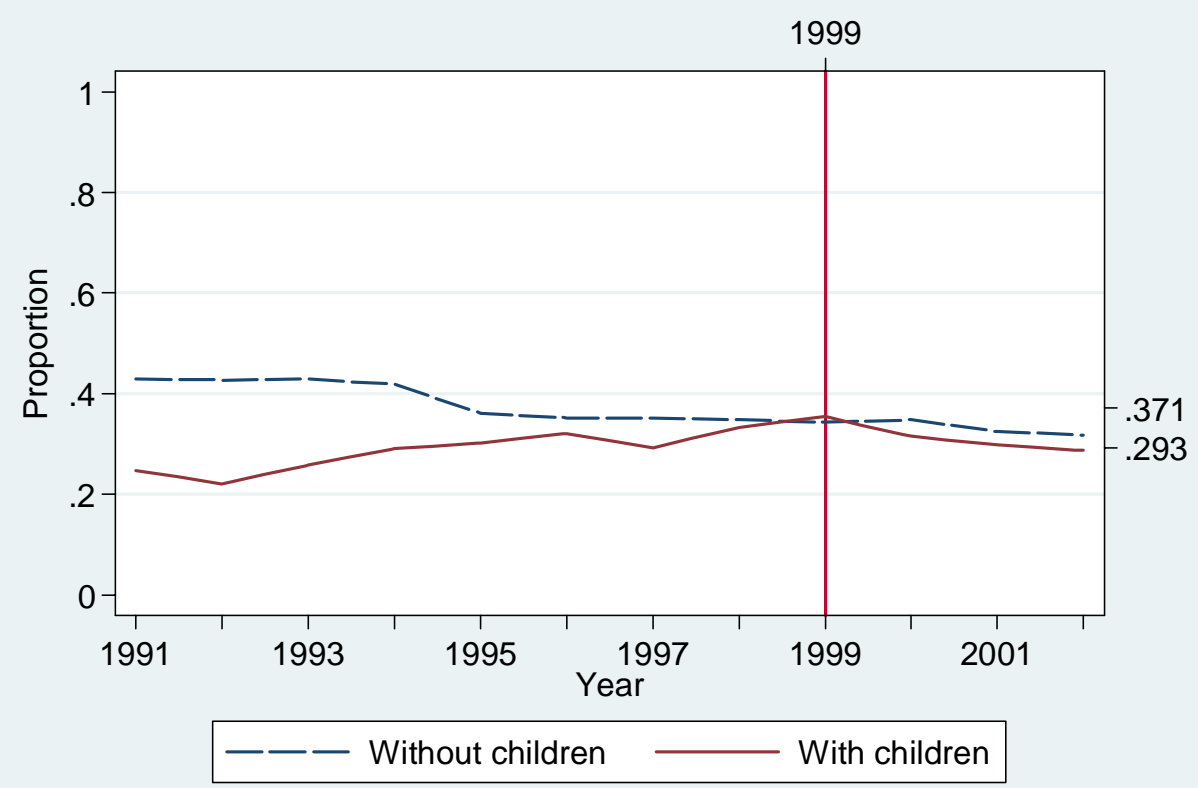

B. Working 30 or more hours per week

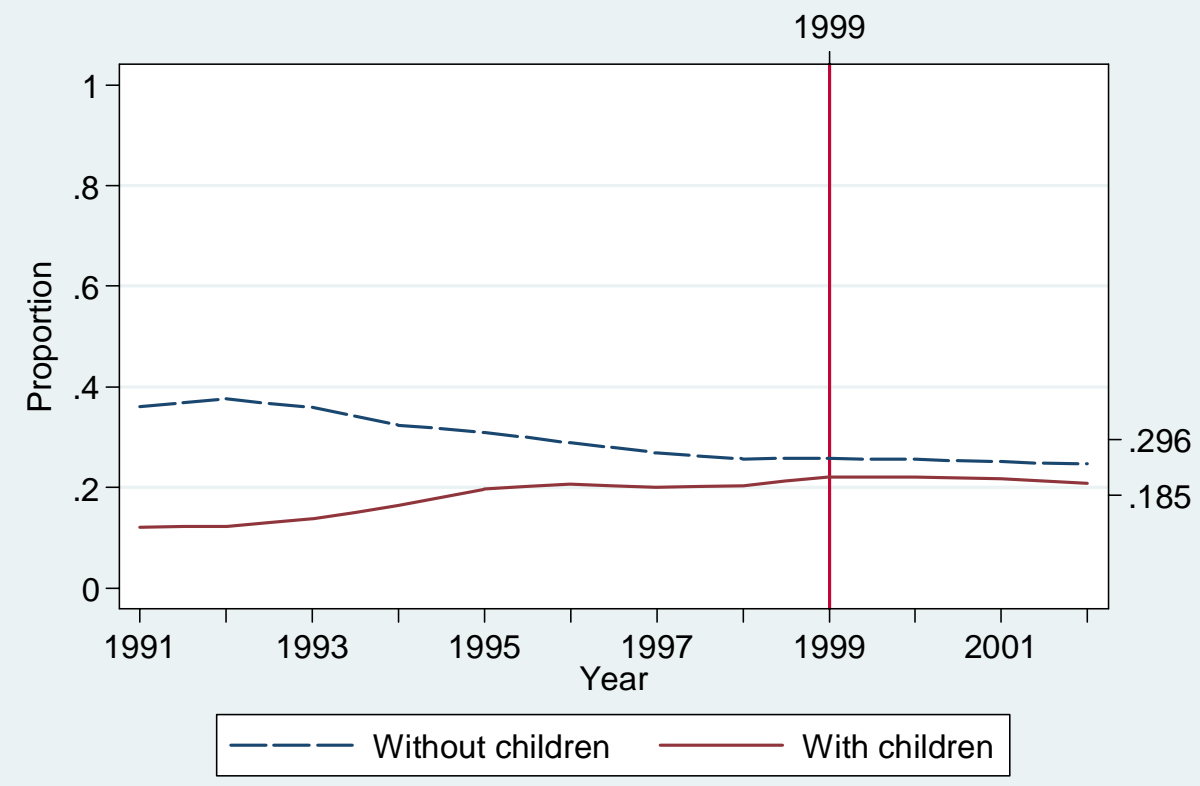


Figure 7

Labour Market Outcomes

Married women whose partner works 16+ hours a week and low earnings

\section{A. Working 16 or more hours per week}

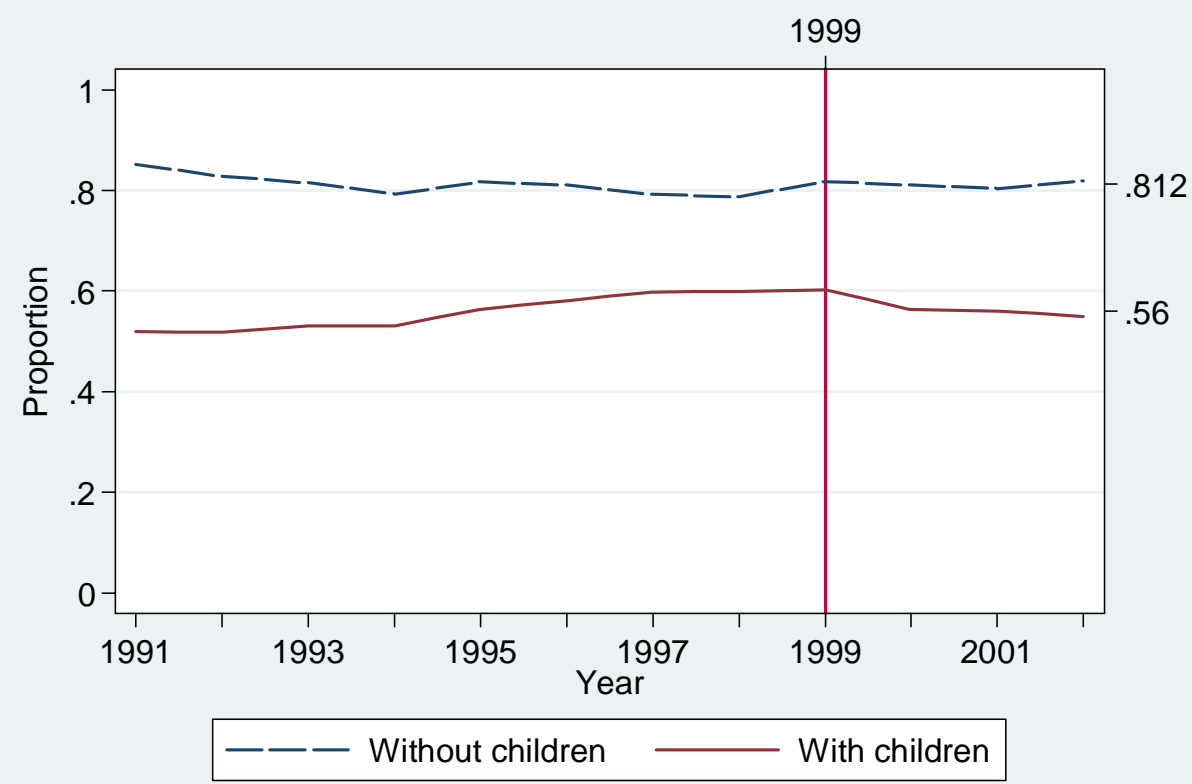

\section{B. Working 30 or more hours per week}

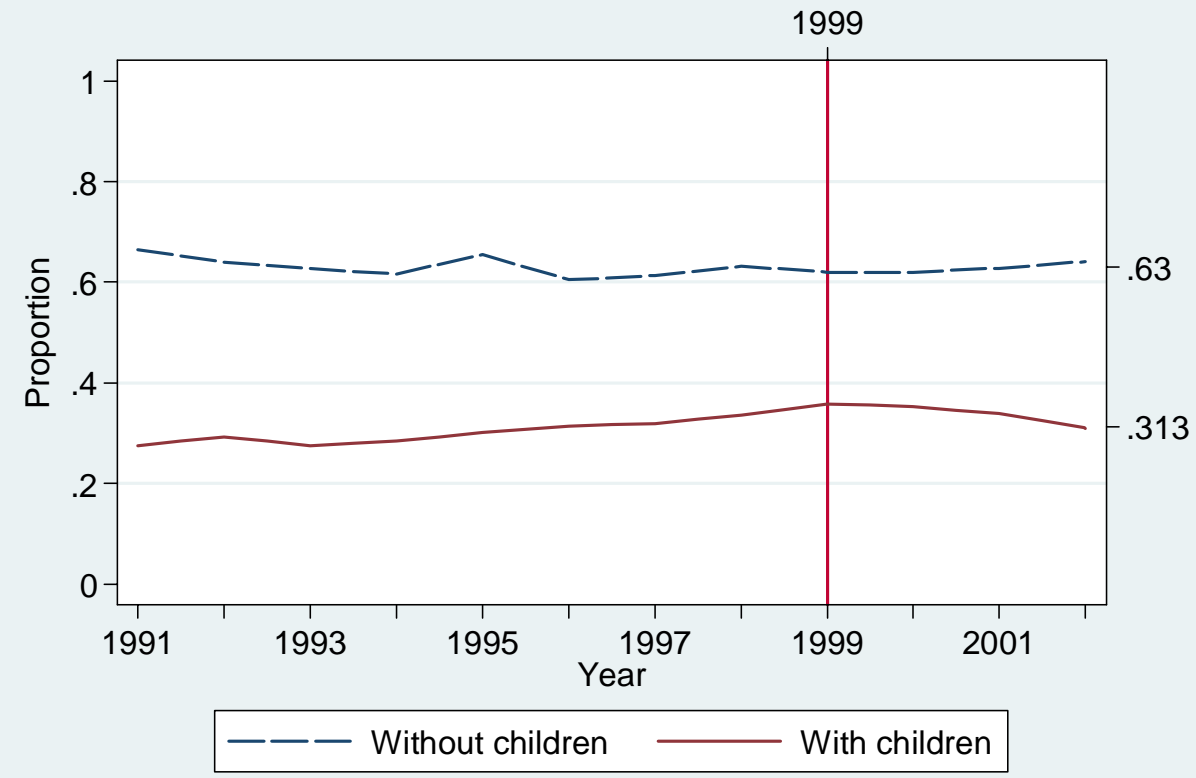

Source: British Household Panel Survey, 1991-2002.

Notes: Figures are computed for all married couples in our sample whose male partner's earnings are in the bottom third in the (wave-specific) monthly male gross earnings distribution for our sample. 
Figure 8

Labour Market Outcomes

Married women whose partner works 16+ hours a week and has high earnings

A. Working 16 or more hours per week

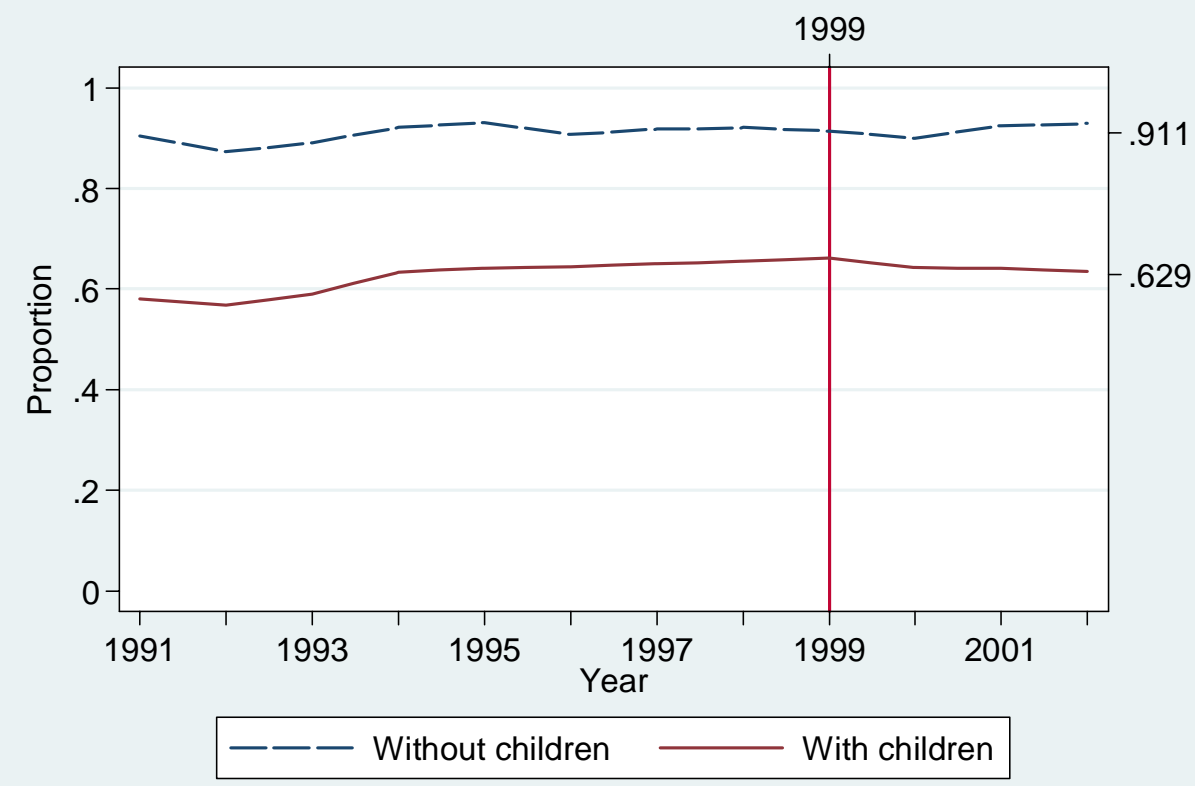

\section{B. Working 30 or more hours per week}

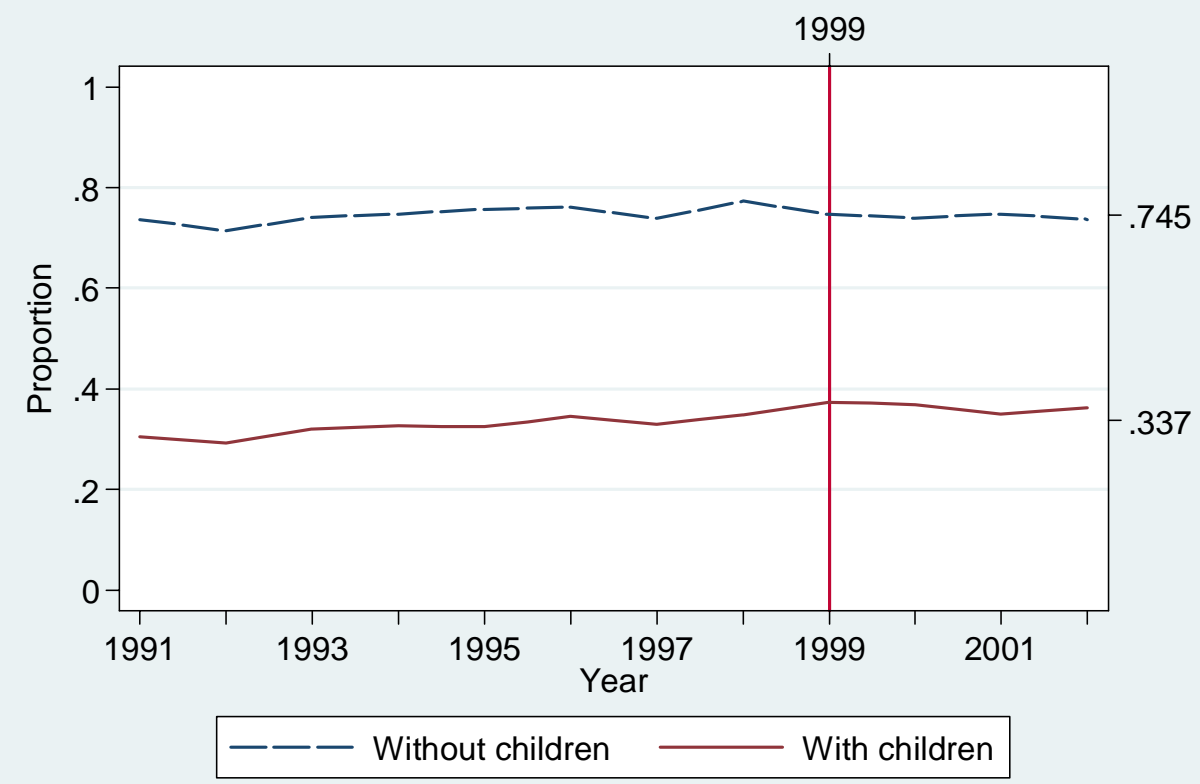

Source: British Household Panel Survey, 1991-2002.

Notes: Figures are computed for all married couples in our sample whose male partner's earnings are in the top two-thirds in the (wave-specific) monthly male gross earnings distribution for our sample. 
Figure 9

Labour Market Outcomes

Married men

\section{A. Working 16 or more hours per week}

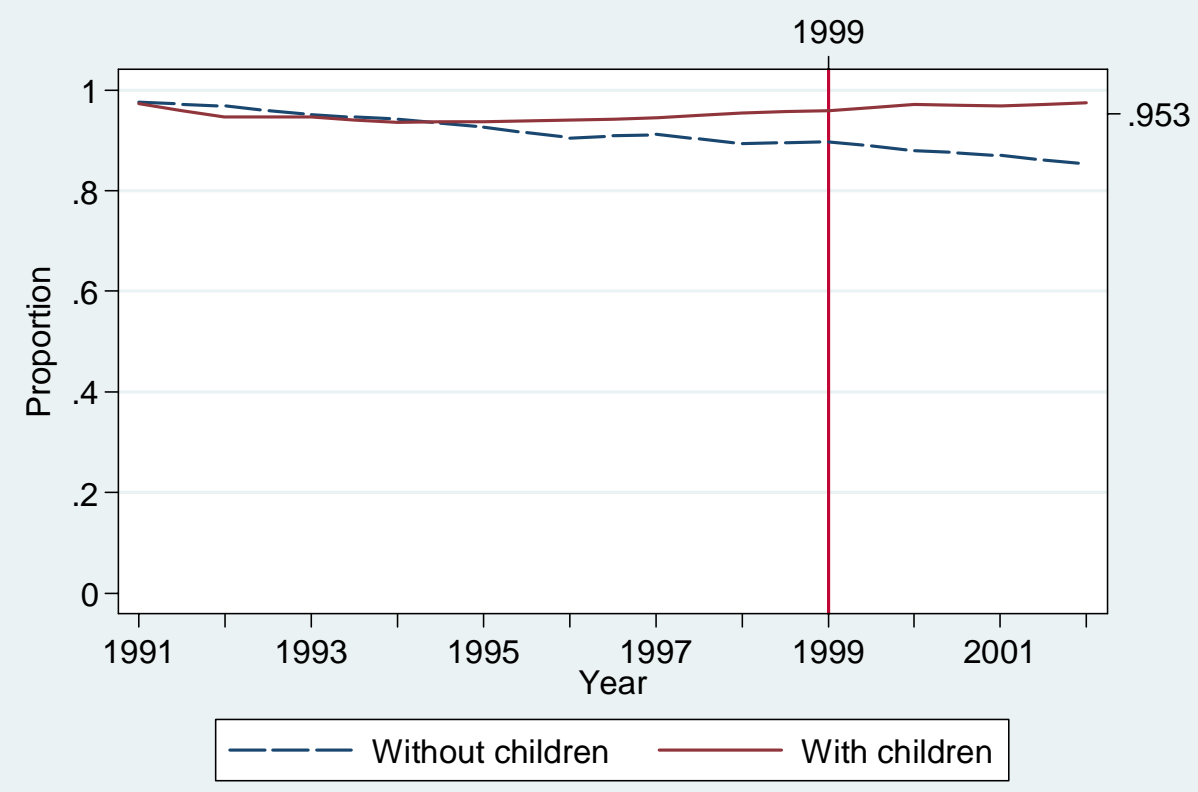

B. Working 30 or more hours per week

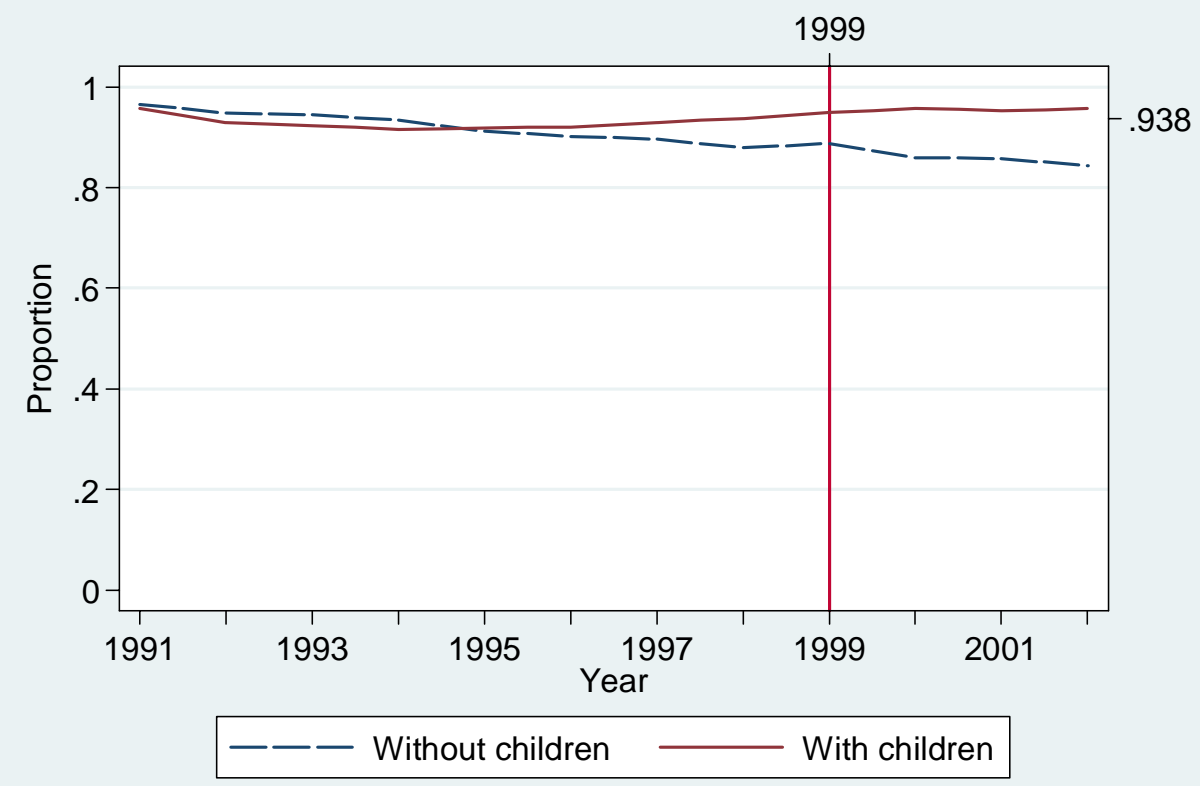


Table 1

Summary Statistics for Married Couples with and without Children

\begin{tabular}{|c|c|c|}
\hline & Without children & With children \\
\hline \multicolumn{3}{|l|}{ Household-level outcomes } \\
\hline FC/WFTC receipt & & 0.082 \\
\hline Income Support receipt & 0.010 & 0.029 \\
\hline Paid childcare utilisation ${ }^{\mathrm{a}}$ & & 0.149 \\
\hline 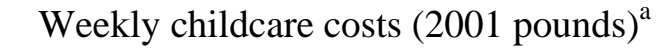 & & $45.10(33.72)$ \\
\hline Divorce rates & 0.021 & 0.030 \\
\hline \multicolumn{3}{|l|}{ Wife } \\
\hline \multicolumn{3}{|l|}{ Outcomes } \\
\hline Working 16 or more hours per week & 0.835 & 0.574 \\
\hline Working 30 or more hours per week & 0.668 & 0.300 \\
\hline \multicolumn{3}{|l|}{ Persistence probability in: } \\
\hline Working 16+ per week & 0.855 & 0.728 \\
\hline Working 30+ per week & 0.820 & 0.709 \\
\hline \multicolumn{3}{|l|}{ Entry probability in: } \\
\hline Working 16+ per week & 0.068 & 0.083 \\
\hline Working 30+ per week & 0.035 & 0.030 \\
\hline Birth rates for married mothers & & 0.037 \\
\hline Entry into motherhood & 0.034 & \\
\hline \multicolumn{3}{|l|}{ Main explanatory variables } \\
\hline Age & $38.8(9.3)$ & 35.7 (7.3) \\
\hline \multicolumn{3}{|l|}{ Education: } \\
\hline No qualification & 0.179 & 0.173 \\
\hline Less than O level/GCSE & 0.101 & 0.139 \\
\hline O level/GCSE (or equivalent) & 0.244 & 0.294 \\
\hline A level (or equivalent) & 0.128 & 0.098 \\
\hline Higher vocational qualification & 0.236 & 0.221 \\
\hline University degree or more & 0.112 & 0.075 \\
\hline \multicolumn{3}{|l|}{ Ethnic origin: } \\
\hline White & 0.974 & 0.954 \\
\hline Black & 0.007 & 0.006 \\
\hline Indian & 0.009 & 0.021 \\
\hline Pakistani/Bangladeshi & 0.002 & 0.010 \\
\hline Chinese or other & 0.008 & 0.009 \\
\hline \multicolumn{3}{|l|}{ Husband } \\
\hline \multicolumn{3}{|l|}{ Outcomes } \\
\hline Working 16 or more hours per week & 0.916 & 0.953 \\
\hline Working 30 or more hours per week & 0.902 & 0.938 \\
\hline \multicolumn{3}{|l|}{ Main explanatory variables } \\
\hline Age & $41.3(9.6)$ & 38.0 (7.9) \\
\hline \multicolumn{3}{|l|}{ Education: } \\
\hline No qualification & 0.178 & 0.170 \\
\hline
\end{tabular}




$\begin{array}{lcc}\text { Less than O level/GCSE } & 0.092 & 0.110 \\ \text { O level/GCSE (or equivalent) } & 0.206 & 0.229 \\ \text { A level (or equivalent) } & 0.146 & 0.137 \\ \text { Higher vocational qualification } & 0.275 & 0.271 \\ \text { University degree or more } & 0.103 & 0.083 \\ \text { Ethnic origin: } & & \\ \text { White } & 0.970 & 0.955 \\ \text { Black } & 0.008 & 0.007 \\ \text { Indian } & 0.009 & 0.020 \\ \text { Pakistani/Bangladeshi } & 0.003 & 0.010 \\ \text { Chinese or other } & 0.010 & 0.008\end{array}$

Other (household-level) explanatory

variables:

Number of children by age group: ${ }^{\mathrm{b}}$

$0-4$

$0.506(0.651)$

5-10

$0.775(0.858)$

$11-18$

$0.456(0.676)$

Housing tenure:

$\begin{array}{lll}\text { Owner } & 0.822 & 0.759\end{array}$

In social housing $\quad 0.077 \quad 0.180$

In privately rented accommodation $\quad 0.101 \quad 0.061$

$\begin{array}{lcc}\text { Number of women } & 1,805 & 1,430\end{array}$

$\begin{array}{lll}\text { Observations } & 11,984 & 10,162\end{array}$

Source: British Household Panel Survey, 1991-2002.

Notes: The statistics in this table are computed on our sample of all married couples. The sample is restricted to couples where the female partner is aged 55 or less, and whose partner's earnings are below the top quartile in the male (wave-specific) gross monthly earnings distribution. For convenience, the table does not report summary statistics on region (16 dummies). Standard deviations are in parentheses.

${ }^{a}$ Computed over the subsample of couples with children where the youngest child is aged 12 or less.

b Averages are computed over the entire subsample of couples with children. If computed over the three specific subsamples of couples with children in each child group, the averages (standard deviations) are: 1.200 (0.415), $1.453(0.628)$ and 1.273 (0.486) respectively. 
Table 2

The WFTC Effect on Married Women's Employment, Overall and by Woman's Education

\begin{tabular}{|c|c|c|c|c|}
\hline $\begin{array}{l}\text { Type of sample, outcome, } \\
\text { and estimation }\end{array}$ & $\begin{array}{c}\text { All } \\
\text { households }\end{array}$ & $\begin{array}{c}\text { Partner does } \\
\text { not work or } \\
\text { works fewer } \\
\text { than } 16 \text { hours } \\
\text { a week } \\
\end{array}$ & $\begin{array}{l}\text { Partner works } \\
16+\text { hours a } \\
\text { week with low } \\
\text { earnings }\end{array}$ & $\begin{array}{c}\text { Partner works } \\
16+\text { hours a } \\
\text { week with high } \\
\text { earnings } \\
\end{array}$ \\
\hline \multicolumn{5}{|c|}{ A. Total sample } \\
\hline Working 16+ hours a week & $\begin{array}{r}0.007 \\
(0.012)\end{array}$ & $\begin{array}{r}\mathbf{0 . 0 3 1} \\
(0.014)\end{array}$ & $\begin{array}{r}0.006 \\
(0.017)\end{array}$ & $\begin{array}{r}0.001 \\
(0.011)\end{array}$ \\
\hline Working $30+$ hours a week & $\begin{array}{c}0.017 \\
(0.010)\end{array}$ & $\begin{array}{c}0.019 \\
(0.018)\end{array}$ & $\begin{array}{c}0.023 \\
(0.020)\end{array}$ & $\begin{array}{c}0.012 \\
(0.014)\end{array}$ \\
\hline Observations & 22,146 & 4,994 & 5,982 & 11,170 \\
\hline \multicolumn{5}{|c|}{ B. Low education sample (fixed effects estimates) } \\
\hline Working $16+$ hours a week & $\begin{array}{r}0.008 \\
(0.009)\end{array}$ & $\begin{array}{r}\mathbf{0 . 0 3 3} \\
(0.014)\end{array}$ & $\begin{array}{r}0.007 \\
(0.018)\end{array}$ & $\begin{array}{c}0.001 \\
(0.016)\end{array}$ \\
\hline Working $30+$ hours a week & $\begin{array}{c}\mathbf{0 . 0 2 0} \\
(0.010)\end{array}$ & $\begin{array}{c}0.021 \\
(0.018)\end{array}$ & $\begin{array}{r}0.025 \\
(0.023)\end{array}$ & $\begin{array}{r}0.015 \\
(0.019)\end{array}$ \\
\hline Observations & 12,438 & 3,016 & 3,140 & 6,282 \\
\hline \multicolumn{5}{|c|}{ C. High education sample (fixed effects estimates) } \\
\hline Working $16+$ hours a week & $\begin{array}{r}0.006 \\
(0.012)\end{array}$ & $\begin{array}{c}\mathbf{0 . 0 2 8} \\
(0.013)\end{array}$ & $\begin{array}{r}0.006 \\
(0.020)\end{array}$ & $\begin{array}{c}0.001 \\
(0.018)\end{array}$ \\
\hline Working $30+$ hours a week & $\begin{array}{c}0.014 \\
(0.022)\end{array}$ & $\begin{array}{c}0.016 \\
(0.021)\end{array}$ & $\begin{array}{c}0.020 \\
(0.034)\end{array}$ & $\begin{array}{r}0.009 \\
(0.015)\end{array}$ \\
\hline Observations & 9,708 & 1,978 & 2,842 & 4,888 \\
\hline \multicolumn{5}{|c|}{$\begin{array}{l}\text { Notes: Standard errors are shown in parentheses. Estimates are obtained from fixed-effects linear probability models on } \\
\text { the sample of married women without children and married women with children, which include group-specific linear } \\
\text { trends. Estimated coefficients in bold face are statistically different from zero at the } 5 \text { percent significance level. The } \\
\text { other variables included in each regression pertain to the wife. They are a quartic polynomial in age, number of children } \\
\text { by age group of the youngest child (6 groups: one child aged } 0-4 \text {, one child aged 5-10, one child aged } 11-18 \text {; two or } \\
\text { more children with the youngest aged } 0-4 \text {, two or more children with the youngest aged 5-10, two or more children with } \\
\text { the youngest aged 11-18), dummy variables for ethnic origin ( } 4 \text { dummies; white is the base category), highest } \\
\text { educational qualification (5; no qualification), housing tenure (2; owner) region of residence (16; Greater London); and } \\
\text { interactions between age and number of children by age group, age and the educational group dummies, and education } \\
\text { and number of children by age group. N is the number of person-wave observations. Low (high) partner's earnings are } \\
\text { defined as those in the bottom one third (top two-thirds) in the (wave-specific) monthly male gross earnings distribution } \\
\text { for our sample. In panels B and C, the education groups of women are defined as being 'low' if the woman has O } \\
\text { level/GCSE or lower qualification, and 'high' if she has A level or higher qualification. }\end{array}$} \\
\hline
\end{tabular}


Table 4

The WFTC Effect on Married Women's Labour Supply Transitions

All Sample

\begin{tabular}{|c|c|c|c|c|}
\hline Outcome & $\begin{array}{c}\text { All } \\
\text { households }\end{array}$ & $\begin{array}{l}\text { Partner does } \\
\text { not work or } \\
\text { works fewer } \\
\text { than } 16 \text { hours } \\
\text { a week }\end{array}$ & $\begin{array}{l}\text { Partner works } \\
16+\text { hours a } \\
\text { week with low } \\
\text { earnings }\end{array}$ & $\begin{array}{l}\text { Partner works } \\
\text { 16+ hours a } \\
\text { week with high } \\
\text { earnings }\end{array}$ \\
\hline \multicolumn{5}{|l|}{ A. Persistence probability ${ }^{\mathrm{a}}$} \\
\hline Working $16+$ hours a week & $\begin{array}{c}0.008 \\
(0.013) \\
10,959\end{array}$ & $\begin{array}{c}\mathbf{0 . 0 3 9} \\
(0.017) \\
1,306\end{array}$ & $\begin{array}{c}0.008 \\
(0.026) \\
2,944\end{array}$ & $\begin{array}{r}0.002 \\
(0.009) \\
6,709\end{array}$ \\
\hline Working 30+ hours a week & $\begin{array}{c}0.014 \\
(0.022) \\
7,144\end{array}$ & $\begin{array}{c}\mathbf{0 . 0 2 8} \\
(0.012) \\
781\end{array}$ & $\begin{array}{c}0.013 \\
(0.039) \\
1,925\end{array}$ & $\begin{array}{r}0.011 \\
(0.026) \\
4,438\end{array}$ \\
\hline \multicolumn{5}{|l|}{ B. Entry probability ${ }^{\mathrm{b}}$} \\
\hline Working $16+$ hours a week & $\begin{array}{c}0.013 \\
(0.018) \\
7,039\end{array}$ & $\begin{array}{c}\mathbf{0 . 0 2 2} \\
(0.010) \\
2,924\end{array}$ & $\begin{array}{c}0.003 \\
(0.037) \\
1,702\end{array}$ & $\begin{array}{r}0.010 \\
(0.033) \\
2,403\end{array}$ \\
\hline Working 30+ hours a week & $\begin{array}{l}0.010 \\
(0.012) \\
10,838\end{array}$ & $\begin{array}{c}\mathbf{0 . 0 1 8} \\
(0.009) \\
3,492\end{array}$ & $\begin{array}{c}0.006 \\
(0.023) \\
2,631\end{array}$ & $\begin{array}{r}0.007 \\
(0.019) \\
4,715\end{array}$ \\
\hline \multicolumn{5}{|c|}{$\begin{array}{l}\text { Notes: Standard errors are shown in parentheses. Estimates are obtained from linear } \\
\text { probability models of transition in labour market states on the sample of married women } \\
\text { without children and married women with children, which include group-specific linear trends. } \\
\text { Estimates are from the specification with a constant post-reform effect. Estimated coefficients } \\
\text { in bold face are statistically different from zero at the } 5 \text { percent significance level. The other } \\
\text { variables included in each regression pertain to the wife. They are listed in the note to Table } 2 \text {. } \\
\text { N denotes the number of wave-on-wave state-specific transitions. } \\
\text { a Conditional on working ( } 16+\text { hours a week, or } 30+\text { hours a week) in the year prior to that } \\
\text { which the outcomes refer to. } \\
\text { b Conditional on not working ( } 16+\text { hours a week, or } 30+\text { hours a week) in the year prior to that } \\
\text { which the outcomes refer to. }\end{array}$} \\
\hline
\end{tabular}


Table 5

The WFTC Effect on Married Men's Labour Supply

All Sample, Fixed Effects Estimates

\begin{tabular}{|c|c|c|c|c|}
\hline Outcome & $\begin{array}{c}\text { All } \\
\text { households }\end{array}$ & $\begin{array}{c}\text { Partner does } \\
\text { not work or } \\
\text { works fewer } \\
\text { than } 16 \text { hours } \\
\text { a week }\end{array}$ & $\begin{array}{l}\text { Partner works } \\
16+\text { hours a } \\
\text { week with low } \\
\text { earnings }\end{array}$ & $\begin{array}{c}\text { Partner works } \\
16+\text { hours a } \\
\text { week with } \\
\text { high earnings }\end{array}$ \\
\hline Working 16+ hours a week & $\begin{array}{c}0.003 \\
(0.009)\end{array}$ & $\begin{array}{c}0.005 \\
(0.016)\end{array}$ & $\begin{array}{c}0.014 \\
(0.021)\end{array}$ & $\begin{array}{c}0.001 \\
(0.010)\end{array}$ \\
\hline Working $30+$ hours a week & $\begin{array}{c}0.004 \\
(0.010)\end{array}$ & $\begin{array}{c}0.006 \\
(0.013)\end{array}$ & $\begin{array}{c}0.005 \\
(0.032)\end{array}$ & $\begin{array}{c}0.002 \\
(0.012)\end{array}$ \\
\hline $\mathrm{N}$ & 22,146 & 8,460 & 1,842 & 11,844 \\
\hline \multicolumn{5}{|c|}{$\begin{array}{l}\text { Notes: Standard errors are shown in parentheses. Estimates are obtained from fixed effects } \\
\text { linear probability models on the sample of married men without children and married men } \\
\text { with children, which include group-specific linear trends. Estimates are from the specification } \\
\text { with a constant post-reform effect. The other variables included in each regression are listed in } \\
\text { the note to Table } 2 \text { but they pertain to the husband. } \mathrm{N} \text { is the number of person-wave } \\
\text { observations. }\end{array}$} \\
\hline
\end{tabular}


Table 6

The WFTC Effects on Married Women's Outcomes Other than Employment

\begin{tabular}{|c|c|c|c|c|}
\hline Outcome & $\begin{array}{c}\text { All } \\
\text { households }\end{array}$ & $\begin{array}{c}\text { Partner does } \\
\text { not work or } \\
\text { works fewer } \\
\text { than } 16 \text { hours } \\
\text { a week } \\
\end{array}$ & $\begin{array}{l}\text { Partner works } \\
\text { 16+ hours a } \\
\text { week with low } \\
\text { earnings } \\
\end{array}$ & $\begin{array}{c}\text { Partner works } \\
16+\text { hours a } \\
\text { week with high } \\
\text { earnings } \\
\end{array}$ \\
\hline $\begin{array}{l}\text { Divorce rates }^{\mathrm{a}} \\
\mathrm{N}\end{array}$ & $\begin{array}{c}0.007 \\
(0.011) \\
18,917\end{array}$ & $\begin{array}{c}\mathbf{0 . 0 2 4} \\
(0.011) \\
4,089\end{array}$ & $\begin{array}{c}0.009 \\
(0.012) \\
4,980\end{array}$ & $\begin{array}{c}0.001 \\
(0.016) \\
9,848\end{array}$ \\
\hline $\begin{array}{l}\text { FC/WFTC receipt } \\
\mathrm{N}\end{array}$ & $\begin{array}{l}0.011 \\
(0.020) \\
10,162\end{array}$ & $\begin{array}{c}\mathbf{0 . 0 3 3} \\
(0.012) \\
1,731\end{array}$ & $\begin{array}{c}0.018 \\
(0.021) \\
2,644\end{array}$ & $\begin{array}{r}0.004 \\
(0.011) \\
5,787\end{array}$ \\
\hline $\begin{array}{l}\text { Income Support } \\
\text { receipt }^{\mathrm{C}} \\
\mathrm{N}\end{array}$ & $\begin{array}{l}-0.003 \\
(0.014) \\
22,146\end{array}$ & $\begin{array}{l}-0.001 \\
(0.014) \\
4,994\end{array}$ & $\begin{array}{c}-0.002 \\
(0.002) \\
5,982\end{array}$ & $\begin{array}{c}-0.004 \\
(0.003) \\
11,170\end{array}$ \\
\hline $\begin{array}{l}\text { Paid childcare } \\
\text { utilisation }^{\mathrm{d}} \\
\text { N }\end{array}$ & $\begin{array}{c}0.007 \\
(0.010) \\
7,436\end{array}$ & $\begin{array}{c}0.008 \\
(0.024) \\
469\end{array}$ & $\begin{array}{c}\mathbf{0 . 0 2 3} \\
(0.011) \\
1,566\end{array}$ & $\begin{array}{r}0.002 \\
(0.013) \\
5,401\end{array}$ \\
\hline $\begin{array}{l}\text { Weekly childcare } \\
\text { costs }^{\mathrm{e}} \\
\mathrm{N}\end{array}$ & $\begin{array}{c}0.78 \\
(2.15) \\
1,517\end{array}$ & $\begin{array}{c}0.04 \\
(0.31) \\
120\end{array}$ & $\begin{array}{r}0.34 \\
(2.19) \\
364\end{array}$ & $\begin{array}{c}1.02 \\
(2.48) \\
1,033\end{array}$ \\
\hline $\begin{array}{l}\text { Birth rates for } \\
\text { married mothers } \\
\quad \mathrm{N}\end{array}$ & $\begin{array}{l}-0.005 \\
(0.006) \\
6,890\end{array}$ & $\begin{array}{c}-0.010 \\
(0.018) \\
1,010\end{array}$ & $\begin{array}{c}-0.006 \\
(0.012) \\
1,793\end{array}$ & $\begin{array}{r}-0.003 \\
(0.007) \\
4,087\end{array}$ \\
\hline $\begin{array}{l}\text { Entry into } \\
\text { motherhood }^{\mathrm{g}} \\
\quad \mathrm{N}\end{array}$ & $\begin{array}{l}-0.0007 \\
(0.001) \\
9,673\end{array}$ & $\begin{array}{c}-0.0003 \\
(0.002) \\
2,422\end{array}$ & $\begin{array}{c}-0.002 \\
(0.002) \\
1,987\end{array}$ & $\begin{array}{c}-0.0004 \\
(0.0011) \\
5,264\end{array}$ \\
\hline
\end{tabular}

Notes: Standard errors are shown in parentheses. Estimated coefficients in bold face are statistically different from zero at the 5 percent significance level. $\mathrm{N}$ denotes the number of person-wave observations.

${ }^{a}$ Estimates are obtained from linear probability models of transition into partnership breakdown on the sample of married childless women and married mothers with groupspecific linear trends. For each woman, the dependent variable takes value zero if the woman is married, and value one in the period when her partnership (marriage or cohabitation) is dissolved (after which her observations are censored). Multiple entries for the same woman are allowed. Explanatory variables are listed in the note to Table 2.

$\mathrm{b}$ Estimates are obtained from linear probability models with individual fixed effects on the subsample of married mothers. Explanatory variables are listed in the note to Table 2, except for the term capturing the trend for married women without children.

${ }^{\mathrm{c}}$ Estimates are obtained from linear probability models with individual fixed effects on the sample of childless women and mothers. Explanatory variables are listed in the note to Table 2.

${ }^{\mathrm{d}}$ Estimates are obtained from linear probability models with individual fixed effects on the subsample of mothers. The dependent variable takes value one if the mother works, 
has at least one child aged 12 or less, and pays for childcare arrangements, and zero otherwise. Explanatory variables are listed in the note to Table 2, except for the term capturing the trend for married women without children.

${ }^{\mathrm{e}}$ Estimates are obtained from linear regression models with individual fixed effects on the subsample of mothers who work, have at least one child aged 12 or less, and report positive expenditures on childcare arrangements. The weekly childcare expenditures are expressed in constant (2002) prices. Explanatory variables are listed in the note to Table 2, except for the term capturing the trend for married women without children.

${ }^{\mathrm{f}}$ Estimates are obtained from linear probability models of transition into birth on the subsample of married mothers from the second time they were observed in the panel onwards. Explanatory variables are listed in the note to Table 2, except for the term capturing the trend for married women without children.

${ }^{\mathrm{g}}$ Estimates are obtained from linear probability models of transition into motherhood for the subsample of married women without children. For each woman, the dependent variable takes value zero if the woman is married childless, and value one in the period when she has a child (after which her observations are censored). Explanatory variables are listed in the note to Table 2, except for the term capturing the trend for married women with children. 
Table 7

The WFTC Effect on the Probability of Divorce among Couples with Children

\begin{tabular}{|c|c|c|c|c|}
\hline & \multicolumn{2}{|c|}{$\begin{array}{l}\text { Male partner does not } \\
\text { work or works fewer } \\
\text { than } 16 \text { hours a week } \\
\text { and wife's education is: }\end{array}$} & \multicolumn{2}{|c|}{$\begin{array}{l}\text { Partner works } 16+ \\
\text { hours a week and has } \\
\text { low pre-reform } \\
\text { earnings and wife’s } \\
\text { education is: }\end{array}$} \\
\hline & Low & High & Low & High \\
\hline Overall & $\begin{array}{c}0.022 \\
(0.014)\end{array}$ & $\begin{array}{c}\mathbf{0 . 0 2 6} \\
(0.013)\end{array}$ & $\begin{array}{c}0.003 \\
(0.013)\end{array}$ & $\begin{array}{l}-0.001 \\
(0.010)\end{array}$ \\
\hline One child aged 0-4 & $\begin{array}{c}\mathbf{0 . 0 3 9} \\
(0.008)\end{array}$ & $\begin{array}{c}\mathbf{0 . 0 3 8} \\
(0.016)\end{array}$ & $\begin{array}{c}0.015 \\
(0.015)\end{array}$ & $\begin{array}{c}0.002 \\
(0.019)\end{array}$ \\
\hline One child aged 5-10 & $\begin{array}{c}0.023 \\
(0.018)\end{array}$ & $\begin{array}{c}\mathbf{0 . 0 3 4} \\
(0.016)\end{array}$ & $\begin{array}{c}0.0001 \\
(0.018)\end{array}$ & $\begin{array}{c}0.001 \\
(0.013)\end{array}$ \\
\hline One child aged 11-18 & $\begin{array}{c}0.016 \\
(0.024)\end{array}$ & $\begin{array}{c}0.019 \\
(0.022)\end{array}$ & $\begin{array}{c}0.004 \\
(0.027)\end{array}$ & $\begin{array}{l}-0.004 \\
(0.010)\end{array}$ \\
\hline $\begin{array}{l}\text { Two children or more, } \\
\text { youngest } 0-4\end{array}$ & $\begin{array}{c}\mathbf{0 . 0 2 7} \\
(0.012)\end{array}$ & $\begin{array}{c}\mathbf{0 . 0 2 6} \\
(0.013)\end{array}$ & $\begin{array}{c}0.006 \\
(0.019)\end{array}$ & $\begin{array}{c}0.002 \\
(0.014)\end{array}$ \\
\hline $\begin{array}{l}\text { Two children or more, } \\
\text { youngest 5-10 }\end{array}$ & $\begin{array}{c}0.012 \\
(0.022)\end{array}$ & $\begin{array}{c}0.015 \\
(0.028)\end{array}$ & $\begin{array}{l}-0.001 \\
(0.031)\end{array}$ & $\begin{array}{l}-0.002 \\
(0.018)\end{array}$ \\
\hline $\begin{array}{l}\text { Two children or more, } \\
\text { youngest } 11-18\end{array}$ & $\begin{array}{c}0.009 \\
(0.024)\end{array}$ & $\begin{array}{c}0.016 \\
(0.020)\end{array}$ & $\begin{array}{l}-0.002 \\
(0.022)\end{array}$ & $\begin{array}{l}-0.003 \\
(0.027)\end{array}$ \\
\hline Observations & 2,142 & 1,947 & 5,160 & 4,688 \\
\hline \multicolumn{5}{|c|}{$\begin{array}{l}\text { Notes: Standard errors are shown in parentheses. Estimated coefficients in bold face } \\
\text { are statistically different from zero at the } 5 \text { percent significance level. Estimates are } \\
\text { obtained from linear probability models of transition into partnership breakdown on } \\
\text { the sample of married childless women and married mothers with group-specific } \\
\text { linear trends. For each woman, the dependent variable takes value zero if the woman } \\
\text { is married, and value one in the period when her partnership (marriage or } \\
\text { cohabitation) is dissolved (after which her observations are censored). Multiple entries } \\
\text { for the same woman are allowed (See first row of Table 6). The couples' position in } \\
\text { the male earnings distribution is based only on the (wave-specific) position in the } \\
\text { monthly gross earnings distribution observed before the introduction of the WFTC } \\
\text { reform. Explanatory variables are listed in the note to Table } 2 \text {. }\end{array}$} \\
\hline
\end{tabular}




\section{Appendix 1: Work Incentives}

Household Class A: Derivation of $\left(w^{*}, w^{* *}, w^{* * *}\right)$ and Comparative Statitcs Note that each household can choose to be in one of two "regimes". First, each household can decide not to meet the eligibility criteria for the WFTC, or when she does, decide not to participate in the programme $(P=0)$. In the absence of WFTC each family maximizes $\Omega \equiv \theta U_{w}+(1-\theta) U_{h}$ subject to $x_{h}+x_{w}+p_{c} l_{w}=w l_{w}+m$ and $0 \leqslant l_{w} \leqslant t$. For notational convenience, let $\Delta \equiv \gamma-\delta$. Furthermore, let $\mathbf{a}(\theta) \equiv \alpha_{w} \theta+\alpha_{h}(1-\theta)$ and $\mathbf{b}(\theta) \equiv \beta_{w} \theta+\beta_{h}(1-\theta)$. It is readily shown that if $w \leqslant \bar{w}=p_{c}+\frac{\mathbf{b}(\theta) m \Delta}{\mathbf{a}(\theta) \gamma t}$, then the optimal resource allocation is

$$
l_{w}^{1, a}=0, \quad x_{w}^{1, a}=\frac{\alpha_{w} \theta m}{\mathbf{a}(\theta)}, \quad x_{h}^{1, a}=\frac{\alpha_{h}(1-\theta) m}{\mathbf{a}(\theta)} .
$$

The corresponding indirect utility is

$$
\Omega_{a}^{P=0}=K+\mathbf{a}(\theta) \ln \left[\frac{m}{\mathbf{a}(\theta)}\right]+\mathbf{b}(\theta) \ln (\gamma t)
$$

where $K=\ln \left[\left(\alpha_{w} \theta\right)^{\alpha_{w} \theta}\left[\alpha_{h}(1-\theta)\right]^{\alpha_{h}(1-\theta)}\right]$. If instead $w>p_{c}+\frac{\mathbf{b}(\theta) m \Delta}{\mathbf{a}(\theta) \gamma t}$, then the optimal resource allocation is

$$
l_{w}^{1, b}=\frac{\mathbf{a}(\theta) \gamma t\left(w-p_{c}\right)-\mathbf{b}(\theta) \Delta m}{[\mathbf{a}(\theta)+\mathbf{b}(\theta)](w-p) \Delta}, x_{w}^{1, b}=\frac{\left[\gamma t\left(w-p_{c}\right)+\Delta m\right]}{\left[\alpha_{w} \theta\right]^{-1}[\mathbf{a}(\theta)+\mathbf{b}(\theta)] \Delta}, x_{h}^{1, b}=\frac{\left[\gamma t\left(w-p_{c}\right)+\Delta m\right]}{\left[\alpha_{h}(1-\theta)\right]^{-1}[\mathbf{a}(\theta)+\mathbf{b}(\theta)] \Delta} .
$$

The corresponding indirect utility is

$$
\Omega_{b}^{P=0}=K+\mathbf{a}(\theta) \ln \left[\frac{\left[\gamma t\left(w-p_{c}\right)+\Delta m\right]}{[\mathbf{a}(\theta)+\mathbf{b}(\theta)] \Delta}\right]+\mathbf{b}(\theta) \ln \left[\frac{\mathbf{b}(\theta)\left[\gamma t\left(w-p_{c}\right)+\Delta m\right]}{\left(w-p_{c}\right)[\mathbf{a}(\theta)+\mathbf{b}(\theta)]}\right] .
$$

Second, each family can choose to meet the eligibility criteria for the WFTC and participate in the programme $(P=1)$. Letting $\mathbf{m} \equiv(1-\pi) m+T_{\max }+\pi M_{\min }$, each family now maximizes $\Omega \equiv \theta U_{w}+(1-\theta) U_{h}$ subject to $x_{h}+x_{w}+p l_{w}=(1-\pi) w l_{w}+\mathbf{m} \underline{\text { and }} \underline{l} \leqslant l_{w} \leqslant t$. It is readily shown that there exists a cutoff wage

$$
w^{* *}=\frac{p_{c}}{1-\pi}+\frac{\mu(\theta) \mathbf{m} \Delta}{(1-\pi)[\gamma t-(1+\mu(\theta)) \underline{l} \Delta]}, \text { where } \mu(\theta)=\frac{\mathbf{b}(\theta)}{\mathbf{a}(\theta)},
$$

which has the following properties. As long as $w \leqslant w^{* *}$, it is optimal for the female partner to work just $\underline{l}$ hours to be eligible for in-work support. In this case, the optimal resource allocation is

$$
l_{w}^{2}=\underline{l}, \quad x_{w}^{2}=\frac{\theta \alpha_{w}}{\mathbf{a}(\theta)}\left[\left(w(1-\pi)-p_{c}\right) \underline{l}+\mathbf{m}\right], \quad x_{h}^{2}=\frac{(1-\theta) \alpha_{h}}{\mathbf{a}(\theta)}\left[\left(w(1-\pi)-p_{c}\right) \underline{l}+\mathbf{m}\right],
$$

and the corresponding utility is

$$
\Omega_{2}^{P=1}=K+\mathbf{a}(\theta) \ln \left[\frac{\left[\left(w(1-\pi)-p_{c}\right) \underline{l}+\mathbf{m}\right]}{\mathbf{a}(\theta)}\right]+\mathbf{b}(\theta) \ln (\gamma t-\Delta \underline{l}) .
$$

If instead $w>w^{* *}$, the optimal resource allocation is:

$$
l_{w}^{3}=\frac{\mathbf{a}(\theta) \gamma t\left(w(1-\pi)-p_{c}\right)-\mathbf{b}(\theta) \mathbf{m} \Delta}{\left(w(1-\pi)-p_{c}\right)(\mathbf{a}(\theta)+\mathbf{b}(\theta)) \Delta}, x_{w}^{3}=\frac{\left[\gamma t\left(w(1-\pi)-p_{c}\right)+\mathbf{m} \Delta\right]}{\left[\alpha_{w} \theta\right]^{-1}[\mathbf{a}(\theta)+\mathbf{b}(\theta)] \Delta}, x_{h}^{3}=\frac{\left[\gamma t\left(w(1-\pi)-p_{c}\right)+\mathbf{m} \Delta\right]}{\left[\alpha_{h}(1-\theta)\right]^{-1}[\mathbf{a}(\theta)+\mathbf{b}(\theta)] \Delta} .
$$

The corresponding indirect utility is

$$
\Omega_{3}^{P=1}=K+\mathbf{a}(\theta) \ln \left[\frac{\left[\gamma t\left(w(1-\pi)-p_{c}\right)+\mathbf{m} \Delta\right]}{[\mathbf{a}(\theta)+\mathbf{b}(\theta)] \Delta}\right]+\mathbf{b}(\theta) \ln \left[\frac{\mathbf{b}(\theta)\left[\gamma t\left(w(1-\pi)-p_{c}\right)+\mathbf{m} \Delta\right]}{\left(w(1-\pi)-p_{c}\right)[\mathbf{a}(\theta)+\mathbf{b}(\theta)]}\right] .
$$

Result 1 in the main text provides a categorization of the population based on the cutoff wages $\left(w^{*}, w^{* *}, w^{* * *}\right)$. We now turn to the derivation and comparative statics analysis of $\left(w^{*}, w^{* *}, w^{* * *}\right)$. 
Equation $A_{1}$, to be derived next, implicitly characterizes $w^{*}$. In the context of the categorization of the population in Result $1, w^{*}$ solves $A_{1} \equiv \Omega_{b}^{P=0}-\Omega_{2}^{P=1}=0$ [see (4) and (6)]. In other words, $w^{*}$ solves

$$
\begin{aligned}
A_{1} & \equiv \mathbf{a}(\theta)\left[\ln \left[\frac{\left[\gamma t\left(w-p_{c}\right)+\Delta m\right]}{[\mathbf{a}(\theta)+\mathbf{b}(\theta)] \Delta}\right]-\ln \left[\frac{\left[\left(w(1-\pi)-p_{c}\right) \underline{l}+\mathbf{m}\right]}{\mathbf{a}(\theta)}\right]\right]+\mathbf{b}(\theta)\left[\ln \left[\frac{\mathbf{b}(\theta)\left[\gamma t\left(w-p_{c}\right)+\Delta m\right]}{\left(w-p_{c}\right)[\mathbf{a}(\theta)+\mathbf{b}(\theta)]}\right]-\ln (\gamma t-\Delta \underline{l})\right]=0 \\
& \equiv \mathbf{a}(\theta) \ln \left[\frac{\mathbf{a}(\theta)}{[\mathbf{a}(\theta)+\mathbf{b}(\theta)] \Delta} \cdot \frac{\gamma t\left(w-p_{c}\right)+m \Delta}{\left(w(1-\pi)-p_{c}\right) \underline{l}+\mathbf{m}}\right]+\mathbf{b}(\theta) \ln \left[\frac{\mathbf{b}(\theta)}{\mathbf{a}(\theta)+\mathbf{b}(\theta)} \cdot \frac{\gamma t\left(w-p_{c}\right)+m \Delta}{(\gamma t-\underline{l} \Delta)\left(w-p_{c}\right)}\right]=0 \\
& \equiv \ln \left[\frac{1}{(1+\mu(\theta)) \Delta} \cdot \frac{\gamma t\left(w-p_{c}\right)+m \Delta}{\left(w(1-\pi)-p_{c}\right) \underline{l}+\mathbf{m}}\right]+\mu(\theta) \ln \left[\frac{\mu(\theta)}{1+\mu(\theta)} \cdot \frac{\gamma t\left(w-p_{c}\right)+m \Delta}{(\gamma t-\underline{l} \Delta)\left(w-p_{c}\right)}\right]=0, \text { where } \mu(\theta)=\frac{\mathbf{b}(\theta)}{\mathbf{a}(\theta)} .
\end{aligned}
$$

An evaluation of the effect of marginal changes in program parameters on labor supply involves an analysis of comparative statics on $w^{*}$. We will show that

- It is increasing in the taper rate $\pi$.

- It is decreasing in the tax credit $T_{\max }$.

- It is decreasing in the threshold $M_{\min }$.

These comparative statics are readily established in two steps. The first step is to note that, for Result 1 to hold, it is necessarily the case that

$$
\left.\left.\frac{\partial A_{1}}{\partial w}\right|_{w=w^{*}} \equiv\left[\frac{\partial \Omega_{b}^{P=0}}{\partial w}-\frac{\partial \Omega_{2}^{P=1}}{\partial w}\right]\right|_{w=w^{*}}<0 .
$$

The second step is to implicitly differentiate $A_{1}$ with respect to $\left(\pi, T_{\max }, M_{\min }, \theta\right)$, taking $\partial A_{1} / \partial w$ to be negative:

$$
\begin{gathered}
\frac{\partial w^{*}}{\partial \pi}=-\left[\frac{w \underline{l}+m-M_{\min }}{\left(w(1-\pi)-p_{c}\right) \underline{l}+\mathbf{m}}\right] \cdot\left[\frac{1}{\partial A_{1} / \partial w}\right]>0 \\
\frac{\partial w^{*}}{\partial T_{\max }}=\left[\frac{1}{\left(w(1-\pi)-p_{c}\right) \underline{l}+\mathbf{m}}\right] \cdot\left[\frac{1}{\partial A_{1} / \partial w}\right]<0 \\
\frac{\partial w^{*}}{\partial M_{\min }}=\left[\frac{\pi}{\left(w(1-\pi)-p_{c}\right) \underline{l}+\mathbf{m}}\right] \cdot\left[\frac{1}{\partial A_{1} / \partial w}\right]<0
\end{gathered}
$$

where we use the fact that $w \underline{l}+m>M_{\text {min }}$ which needs to be true for the couple's income to be subject to the taper rate. The comparative statics results combined imply that, with $\theta$ constant, the reform led to a fall in $w^{*}$.

$\underline{\text { Equation } A_{2}}$ defines $w^{* *}$. We establish the following comparative statics on $w^{* *}$ :

- It is increasing in $\pi$ due to a substitution effect and decreasing in $\pi$ due to an income effect.

- It is increasing in the tax credit $T_{\max }$.

- It is increasing in the threshold $M_{\min }$.

These results follow immediately from partially differentiating $w^{* *}$ with respect to $\left(\pi, T_{\max }, M_{\min }, \theta\right)$

$$
\begin{gathered}
\frac{\partial w^{* *}}{\partial \pi}=\underbrace{-\frac{\mu(\theta) \Delta m}{(1-\pi)[\gamma t-(1+\mu(\theta)) \underline{l} \Delta]}+\underbrace{\frac{p_{c}}{(1-\pi)^{2}}+\frac{\mu(\theta) \Delta\left[(1-\pi) m+T_{\max }+M_{\min }\right]}{(1-\pi)^{2}[\gamma t-(1+\mu(\theta)) \underline{l}(\Delta]}}_{\text {Substitution } E .}}_{\text {Income } E .} \\
\frac{\partial w^{* *}}{\partial T_{\max }}=\frac{\mu(\theta) \Delta}{(1-\pi)[\gamma t-(1+\mu(\theta)) \underline{l} \Delta]}>0 \\
\frac{\partial w^{* *}}{\partial M_{\min }}=\frac{\mu(\theta) \pi \Delta}{(1-\pi)[\gamma t-(1+\mu(\theta)) \underline{l} \Delta]}>0
\end{gathered}
$$

Note that in deriving the signs for these comparative statics we exploit the fact that at $w^{* *}$ we have $l_{w}^{3}\left(w^{* *}\right)=\underline{l}$. The latter equation implies that $\frac{\gamma t}{\Delta(1+\mu)}-\frac{\mu \mathbf{m}}{(1+\mu)\left(w(1-\pi)-p_{c}\right)}=\underline{l}$ which in turn implies $\gamma t=(1+\mu) \underline{l} \Delta+\mu \mathbf{m} \Delta /\left[\left(w(1-\pi)-p_{c}\right)\right]$ from which it follows that $\gamma t-(1+\mu) \underline{l} \Delta>0$. The comparative statics results combined imply that, holding $\theta$ constant, the reform had an ambiguous effect on $w^{* *}$. 
Equation $A_{3}$, which we derive next, implicitly characterizes $w^{* * *}$. In the context of the categorization of the population in Result $1, w^{* * *}$ solves $A_{3} \equiv \Omega_{3}^{P=1}-\Omega_{b}^{P=0}=0$ [see (8) and (4)]. In other words, $w^{* * *}$ solves:

$$
\begin{aligned}
A_{3} \equiv & \mathbf{a}(\theta)\left[\ln \left[\frac{\left[\gamma t\left(w(1-\pi)-p_{c}\right)+\mathbf{m} \Delta\right]}{[\mathbf{a}(\theta)+\mathbf{b}(\theta)] \Delta}\right]-\ln \left[\frac{\left[\gamma t\left(w-p_{c}\right)+\Delta m\right]}{[\mathbf{a}(\theta)+\mathbf{b}(\theta)] \Delta}\right]\right] \\
& +\mathbf{b}(\theta)\left[\ln \left[\frac{\mathbf{b}(\theta)\left[\gamma t\left(w(1-\pi)-p_{c}\right)+\mathbf{m} \Delta\right]}{\left(w(1-\pi)-p_{c}\right)[\mathbf{a}(\theta)+\mathbf{b}(\theta)]}\right]-\ln \left[\frac{\mathbf{b}(\theta)\left[\gamma t\left(w-p_{c}\right)+\Delta m\right]}{\left(w-p_{c}\right)[\mathbf{a}(\theta)+\mathbf{b}(\theta)]}\right]\right]=0 \\
\equiv & {[\mathbf{a}(\theta)+\mathbf{b}(\theta)] \ln \left[\frac{\gamma t\left(w(1-\pi)-p_{c}\right)+\mathbf{m} \Delta}{\gamma t\left(w-p_{c}\right)+m \Delta}\right]+\mathbf{b}(\theta) \ln \left[\frac{w-p_{c}}{w(1-\pi)-p_{c}}\right]=0 } \\
\equiv & \ln \left[\frac{\gamma t\left(w(1-\pi)-p_{c}\right)+\mathbf{m} \Delta}{\gamma t\left(w-p_{c}\right)+m \Delta}\right]+\frac{\mu(\theta)}{1+\mu(\theta)} \ln \left[\frac{w-p_{c}}{w(1-\pi)-p_{c}}\right]=0, \text { where } \mu(\theta)=\frac{\mathbf{b}(\theta)}{\mathbf{a}(\theta)} .
\end{aligned}
$$

We derive the following comparative statics on $w^{* * *}$ :

- It is decreasing in the taper rate $\pi$.

- It is increasing in the tax credit $T_{\max }$.

- It is increasing in the threshold $M_{\min }$.

These comparative statics are readily established in two steps. The first step is to note that, for Result 1 to hold, it is necessarily the case that

$$
\left.\left.\frac{\partial A_{3}}{\partial w}\right|_{w=w^{* * *}} \equiv\left[\frac{\partial \Omega_{3}^{P=1}}{\partial w}-\frac{\partial \Omega_{b}^{P=0}}{\partial w}\right]\right|_{w=w^{* * *}}<0 .
$$

The second step is to implicitly differentiate $A_{3}$ with respect to $\left(\pi, T_{\max }, M_{\min }, \theta\right)$, taking $\partial A_{3} / \partial w$ to be negative:

$$
\begin{gathered}
\frac{\partial w^{* * *}}{\partial \pi}=\left[\frac{w \Delta}{\gamma t\left[w(1-\pi)-p_{c}\right]+\Delta \mathbf{m}}\right] \cdot\left[\frac{\gamma t\left[w(1-\pi)-p_{c}\right]-\mu(\theta) \mathbf{m} \Delta}{\left(w(1-\pi)-p_{c}\right) \Delta[1+\mu(\theta)]}+\frac{m-M_{\text {min }}}{w}\right] \cdot\left[\frac{1}{\partial A_{3} / \partial w}\right]<0 \\
\frac{\partial w^{* * *}}{\partial T_{\max }}=-\left[\frac{\Delta}{\gamma t\left[w(1-\pi)-p_{c}\right]+\Delta \mathbf{m}}\right] \cdot\left[\frac{1}{\partial A_{3} / \partial w}\right]>0 \\
\frac{\partial w^{* * *}}{\partial M_{\min }}=-\left[\frac{\pi \Delta}{\gamma t\left[w(1-\pi)-p_{c}\right]+\Delta \mathbf{m}}\right] \cdot\left[\frac{1}{\partial A_{3} / \partial w}\right]>0
\end{gathered}
$$

Note that in deriving the sign of $\partial w^{* * *} / \partial \pi$ we know the second term in brackets to be positive as it equals $l_{w}^{3}+[(m-$ $\left.\left.M_{\min }\right) / w\right]$ which needs to be positive for the couple's income to be subject to the taper rate. ${ }^{1}$.

We are now ready to establish the comparative statics on hours of work chosen by females in Type-A households. For type-1 women, with the optimal hours of work at any given wage below $w^{*}$ being independent of policy parameters, while the marginal changes in these parameters leading to a fall in $w^{*}$, the total labor supply response among those who were type- 1 women prior to reform is positive, as some of these women would enter the program while working $\underline{l}$ hours.

For type-2 women, who worked $\underline{l}$ hours prior to the reform, a drop in $w^{*}$ and an ambiguous effect on $w^{* *}$ implies that the labor supply of these women would stay constant (if $w^{* *}$ increased due to reform) or increase (if $w^{* *}$ fell due to the reform). Note that for the latter scenario to occur, $w^{* *}$ needs to be an increasing function of the taper rate, that is, the substitution effect needs to dominate the income effect.

For type-3 women, the comparative statics for optimal labor supply at any wage below $w^{* * *}$ are:

$$
\begin{gathered}
\frac{\partial l^{3}}{\partial T_{\max }}=-\frac{\mu /(1+\mu)}{\left[w(1-\pi)-p_{c}\right]}<0, \quad \frac{\partial l^{3}}{\partial M_{\min }}=\pi \frac{\partial l^{3}}{\partial T_{\max }}<0 \\
\frac{\partial l^{3}}{\partial \pi}=-\frac{\mu}{1+\mu}\left[\frac{M_{\min }\left[w(1-\pi)-p_{c}\right]+m p_{c}+w T+w \pi M_{\min }}{\left[w(1-\pi)-p_{c}\right]^{2}}\right]<0
\end{gathered}
$$

\footnotetext{
${ }^{1}$ If the couple's income is such that $l_{w}^{3}+\left[\left(m-M_{m i n}\right) / w\right]<0$, or equivalently $w l_{w}^{3}+m<M_{m i n}$, then their income would be below the income threshold, and not subject to (and thus independent of) the taper rate. These results imply that, $\theta$ constant, the reform led to an increase in $w^{* * *}$
} 
The combined effect on the optimal hours of work for type- 3 women with wages between the post-reform values of $w^{* *}$ and $w^{* * *}$ is therefore ambiguous. An increase in $w^{* *}$ due to the reform would lead to a fall in optimal labor supply for women whose wages fall below the new $w^{* *}$, while a decline in $w^{* *}$ would have no direct effect on type-3 women. The predicted increase in $w^{* * *}$ similarly has no implications for type-3 women. Combined with the ambiguous effect on optimal labor supply as indicated by the comparative statics of $l_{w}^{3}$ (with the increase in $T_{\max }, M_{\min }$ producing a decline in hours and the decline in the taper rate producing an increase in hours), the results imply an ambiguous effect of the reform on hours of work for this subset of women.

For type-4 women, the increase in $w^{* * *}$ implies that for those whose wages fall below the post-reform $w^{* * *}$ value, their labor supply will fall, while for those with wages exceeding the post-reform $w^{* * *}$ value the chosen hours of work will remain the same. Thus the overall effect on type- 4 women is to decrease their hours of work.

\section{Indirect Effects}

In deriving the reform's predicted impact on the labor supply of married women in class A households, we assumed that the reform left the woman's bargaining power, as measured by $\theta$ unchanged. However, as discussed in section $\mathrm{C}$ of the paper, the reform may have led to a change in $\theta$. Here we consider the effect of such changes in $\theta$ on the chosen optimal hours of work. We begin by considering the impact of a change in $\theta$ on the reservation wage and the cutoff values $w^{*}, w^{* *}$ and $w^{* * *}$, and show that:

- $\bar{w}$ is decreasing (respectively, increasing) in the bargaining weight $\theta$ if $\frac{\alpha_{w}}{\beta_{w}}>\frac{\alpha_{h}}{\beta_{h}}$ (respectively, if $\frac{\alpha_{w}}{\beta_{w}}<\frac{\alpha_{h}}{\beta_{h}}$ ).

- $w^{*}$ is decreasing (respectively, increasing) in the bargaining weight $\theta$ if $\frac{\alpha_{w}}{\beta_{w}}>\frac{\alpha_{h}}{\beta_{h}}$ (respectively, if $\frac{\alpha_{w}}{\beta_{w}}<\frac{\alpha_{h}}{\beta_{h}}$ ).

- $w^{* *}$ is decreasing (increasing) in the bargaining weight $\theta$ if $\frac{\alpha_{w}}{\beta_{w}}>\frac{\alpha_{h}}{\beta_{h}}$ (if $\frac{\alpha_{w}}{\beta_{w}}<\frac{\alpha_{h}}{\beta_{h}}$ ).

- $w^{* * *}$ is decreasing (increasing) in the bargaining weight $\theta$ if $\frac{\alpha_{w}}{\beta_{w}}>\frac{\alpha_{h}}{\beta_{h}}$ (if $\frac{\alpha_{w}}{\beta_{w}}<\frac{\alpha_{h}}{\beta_{h}}$ ).

These results follow from the following derivations:

$$
\begin{gathered}
\frac{\partial \bar{w}}{\partial \theta}=\frac{m \Delta}{\gamma t} \frac{\partial \mu}{\partial \theta}=-\frac{m \Delta}{\gamma t}\left[\frac{\alpha_{w} \beta_{h}-\beta_{w} \alpha_{h}}{\mathbf{a}(\theta)^{2}}\right] \lesseqgtr 0 \Leftrightarrow \frac{\alpha_{w}}{\beta_{w}} \gtreqless \frac{\alpha_{h}}{\beta_{h}} \\
\frac{\partial w^{*}}{\partial \theta}=\ln \left[\frac{\mu(\theta)}{1+\mu(\theta)} \cdot \frac{\gamma t\left(w-p_{c}\right)+m \Delta}{(\gamma t-\underline{l} \Delta)\left(w-p_{c}\right)}\right] \cdot\left[\frac{\alpha_{w} \beta_{h}-\alpha_{h} \beta_{w}}{\left[\alpha_{w} \theta+\alpha_{h}(1-\theta)\right]^{2}}\right] \cdot\left[\frac{1}{\partial A_{1} / \partial w}\right] \lesseqgtr 0 \Leftrightarrow \frac{\alpha_{w}}{\beta_{w}} \gtreqless \frac{\alpha_{h}}{\beta_{h}}
\end{gathered}
$$

Note that the first term in the equation for $\partial w^{*} / \partial \theta$ is proportional to the difference in utility from child quality measured as $\mathbf{b}(\theta)\left[\ln \left(\gamma t-\Delta l_{w}^{1, b}\right)-\ln (\gamma t-\Delta \underline{l})\right.$ which is positive as $l_{w}^{1, b}<\underline{l}$.

$$
\begin{gathered}
\frac{\partial w^{* *}}{\partial \theta}=-\frac{\Delta \mathbf{m}(\gamma t-\Delta \underline{l})\left[\alpha_{w} \beta_{h}-\alpha_{h} \beta_{w}\right]}{(1-\pi)[\mathbf{a}(\theta) \gamma t-\underline{l}[\mathbf{b}(\theta)+\mathbf{a}(\theta)] \Delta]^{2}} \lesseqgtr 0 \Leftrightarrow \frac{\alpha_{w}}{\beta_{w}} \gtreqless \frac{\alpha_{h}}{\beta_{h}} \\
\frac{\partial w^{* * *}}{\partial \theta}=\ln \left[\frac{w-p_{c}}{w(1-\pi)-p_{c}}\right] \cdot\left[\frac{\alpha_{w} \beta_{h}-\alpha_{h} \beta_{w}}{[\mathbf{a}(\theta)+\mathbf{b}(\theta)]^{2}}\right] \cdot\left[\frac{1}{\partial A_{3} / \partial w}\right] \lesseqgtr 0 \Leftrightarrow \frac{\alpha_{w}}{\beta_{w}} \gtreqless \frac{\alpha_{h}}{\beta_{h}}
\end{gathered}
$$

We can now evaluate the effect on the bargaining weight $\theta$ on labor supply. First, for women with wages between $\bar{w}$ and $w^{*}$,

$$
\frac{\partial l^{1, b}}{\partial \theta}=\frac{1}{(1+\mu)^{2}}\left[\frac{(w-p) \gamma t+\Delta m}{(w-p) \Delta}\right]\left[\frac{\alpha_{w} \beta_{h}-\beta_{w} \alpha_{h}}{\mathbf{a}(\theta)^{2}}\right] \lesseqgtr 0 \Leftrightarrow \frac{\alpha_{w}}{\beta_{w}} \lesseqgtr \frac{\alpha_{h}}{\beta_{h}}
$$

Combined with the predicted increases (decreases) in the reservation wage $\bar{w}$ and in $w^{*}$, this implies a negative (positive) effect on the labour supply of type-1 women when $\frac{\alpha_{w}}{\beta_{w}}<(>) \frac{\alpha_{h}}{\beta_{h}}$.

For type- 2 women, who worked $\underline{l}$ hours prior to the reform, the predicted increases (decreases) in $w^{*}$ and $w^{* *}$ imply that the labor supply of these women would decline (increase) when $\frac{\alpha_{w}}{\beta_{w}}<(>) \frac{\alpha_{h}}{\beta_{h}}$.

For type-3 women, the bargaining weight effect on the optimal hours of work when her wage falls between the post-reform values of $w^{* *}$ and $w^{* * *}$ equals:

$$
\frac{\partial l^{3}}{\partial \theta}=\frac{1}{(1+\mu)^{2}}\left[\frac{\left(w(1-\pi)-p_{c}\right) \gamma t+\Delta \mathbf{m}}{\left(w(1-\pi)-p_{c}\right) \Delta}\right]\left[\frac{\alpha_{w} \beta_{h}-\beta_{w} \alpha_{h}}{\mathbf{a}(\theta)^{2}}\right] \lesseqgtr 0 \Leftrightarrow \frac{\alpha_{w}}{\beta_{w}} \lesseqgtr \frac{\alpha_{h}}{\beta_{h}}
$$


Combined with increases (decreases) in $w^{* *}$ and $w^{* * *}$, these comparative statics imply a decline (increase) in female labor supply when $\frac{\alpha_{w}}{\beta_{w}}<(>) \frac{\alpha_{h}}{\beta_{h}}$.

Finally for type- 4 women, the comparative statics are similar to those of type 1 women with wages between $\bar{w}$ and $w^{*}$. Together with a predicted increase (decrease) in $w^{* * *}$, we find that an increase in $\theta$ leads to a decline (increase) in female hours of work when $\frac{\alpha_{w}}{\beta_{w}}<(>) \frac{\alpha_{h}}{\beta_{h}}$.

Household Class B: Derivation of $\left(w^{\prime}, w^{\prime \prime}, w^{\prime \prime \prime}\right)$ and Comparative Statics Consider now the work incentives for the group of married women whose partners work more than 16 hours per week and therefore satisfy the hours requirement for eligibility to in-work support. In this case, the childcare credit element of WFTC subsidizes a proportion $\phi \in(0,1)$ of the incurred childcare costs, provided both partners work more than 16 hours per week. If the husband's earnings $m$ exceed $M_{\max }$ defined in equation (4), the household would be ineligible for WFTC, irrespective of the wife's hours of work choice. We therefore focus in this analysis on households where the husband's earnings are sufficiently low to render the household eligible for WFTC receipt at 0 hours of work by the wife.

Each household can be in of three regimes. First, each household can decide not to meet the eligibility criteria for the childcare subsidy $(\phi=0)$, but receive WFTC benefits $(P=1)$ based on the tax credit $T_{\max }$, which is subject to the threshold $M_{\text {min }}$ and the taper rate $\pi$. Letting $\mathbf{m} \equiv(1-\pi) m+T_{\max }+\pi M_{\min }$, each family maximizes $\Omega \equiv \theta U_{w}+(1-\theta) U_{h}$ subject to $x_{h}+x_{w}+p l_{w}=(1-\pi) w l_{w}+\mathbf{m}$ and $0 \leqslant l_{w} \leqslant t$. Furthermore, let $\mathbf{a}(\theta) \equiv \alpha_{w} \theta+\alpha_{h}(1-\theta)$ and $\mathbf{b}(\theta) \equiv \beta_{w} \theta+\beta_{h}(1-\theta)$. It is readily shown that if $w \leqslant \tilde{w}=\frac{p_{c}}{1-\pi}+\frac{\mathbf{b}(\theta) \mathbf{m} \Delta}{(1-\pi) \mathbf{a}(\theta) \gamma t}$, then the optimal resource allocation is

$$
l_{w}^{1, a}=0, \quad x_{w}^{1, a}=\frac{\alpha_{w} \theta \mathbf{m}}{\mathbf{a}(\theta)}, \quad x_{h}^{1, a}=\frac{\alpha_{h}(1-\theta) \mathbf{m}}{\mathbf{a}(\theta)} .
$$

The corresponding indirect utility is

$$
\Omega_{a}^{P=1}=K+\mathbf{a}(\theta) \ln \left[\frac{\mathbf{m}}{\mathbf{a}(\theta)}\right]+\mathbf{b}(\theta) \ln (\gamma t) .
$$

If instead $w>\frac{p_{c}}{1-\pi}+\frac{\mathbf{b}(\theta) \mathbf{m} \Delta}{(1-\pi) \mathbf{a}(\theta) \gamma t}$, then the optimal household resource allocation is

$$
l_{w}^{1, b}=\frac{\mathbf{a}(\theta) \gamma t\left(w(1-\pi)-p_{c}\right)-\mathbf{b}(\theta) \mathbf{m} \Delta}{\left(w(1-\pi)-p_{c}\right)(\mathbf{a}(\theta)+\mathbf{b}(\theta)) \Delta}, x_{w}^{1, b}=\frac{\left[\gamma t\left(w(1-\pi)-p_{c}\right)+\mathbf{m} \Delta\right]}{\left[\alpha_{w} \theta\right]^{-1}[\mathbf{a}(\theta)+\mathbf{b}(\theta)] \Delta}, x_{h}^{1, b}=\frac{\left[\gamma t\left(w(1-\pi)-p_{c}\right)+\mathbf{m} \Delta\right]}{\left[\alpha_{h}(1-\theta)\right]^{-1}[\mathbf{a}(\theta)+\mathbf{b}(\theta)] \Delta} .
$$

The corresponding indirect utility is

$$
\Omega_{b}^{P=1}=K+\mathbf{a}(\theta) \ln \left[\frac{\left[\gamma t\left(w(1-\pi)-p_{c}\right)+\mathbf{m} \Delta\right]}{[\mathbf{a}(\theta)+\mathbf{b}(\theta)] \Delta}\right]+\mathbf{b}(\theta) \ln \left[\frac{\mathbf{b}(\theta)\left[\gamma t\left(w(1-\pi)-p_{c}\right)+\mathbf{m} \Delta\right]}{\left(w(1-\pi)-p_{c}\right)[\mathbf{a}(\theta)+\mathbf{b}(\theta)]}\right] .
$$

$\underline{\text { Second }}$, each family can choose to qualify for the childcare subsidy $(\phi>0)$ and be eligible and receive WFTC benefits $(P=1)$. Each family then maximizes $\Omega \equiv \theta U_{w}+(1-\theta) U_{h}$ subject to $x_{h}+x_{w}+p(1-\phi) l_{w}=(1-\pi) w l_{w}+\mathbf{m}$ $\underline{\text { and }} \underline{l} \leqslant l_{w} \leqslant t$. It is readily shown that there exists a cutoff wage

$$
w^{\prime \prime}=\frac{p_{c}(1-\phi)}{1-\pi}+\frac{\mu(\theta) \mathbf{m} \Delta}{(1-\pi)[\gamma t-(1+\mu(\theta)) \underline{l} \Delta]} \text { where } \mu(\theta)=\frac{\mathbf{b}(\theta)}{\mathbf{a}(\theta)},
$$

which has the following properties. As long as $w \leqslant w^{\prime \prime}$, it is optimal for the female partner to work just $\underline{l}$ hours to qualify for the childcare subsidy. In this case, the optimal resource allocation is

$$
l_{w}^{2}=\underline{l}, \quad x_{w}^{2}=\frac{\theta \alpha_{w}}{\mathbf{a}(\theta)}[\mathbf{w} \underline{l}+\mathbf{m}], \quad x_{h}^{2}=\frac{(1-\theta) \alpha_{h}}{\mathbf{a}(\theta)}[\mathbf{w} \underline{l}+\mathbf{m}],
$$

where $\mathbf{w}=\left(w(1-\pi)-p_{c}(1-\phi)\right.$. The corresponding utility is

$$
\Omega_{\phi_{2}}^{P=1}=K+\mathbf{a}(\theta) \ln \left[\frac{[\mathbf{w} \underline{l}+\mathbf{m}]}{\mathbf{a}(\theta)}\right]+\mathbf{b}(\theta) \ln (\gamma t-\Delta \underline{l}) .
$$

If instead $w>w^{\prime \prime}$, the optimal resource allocation is:

$$
l_{w}^{3}=\frac{\mathbf{a}(\theta) \gamma \mathbf{w} t-\mathbf{b}(\theta) \mathbf{m} \Delta}{\mathbf{w}[\mathbf{a}(\theta)+\mathbf{b}(\theta)] \Delta}, x_{w}^{3}=\frac{[\gamma \mathbf{w} t+\mathbf{m} \Delta]}{\left[\alpha_{w} \theta\right]^{-1}[\mathbf{a}(\theta)+\mathbf{b}(\theta)] \Delta}, x_{h}^{3}=\frac{[\gamma \mathbf{w} t+\mathbf{m} \Delta]}{\left[\alpha_{h}(1-\theta)\right]^{-1}[\mathbf{a}(\theta)+\mathbf{b}(\theta)] \Delta},
$$


where $\mathbf{w}=\left(w(1-\pi)-p_{c}(1-\phi)\right.$. The corresponding indirect utility is

$$
\Omega_{\phi_{3}}^{P=1}=K+\mathbf{a}(\theta) \ln \left[\frac{[\gamma \mathbf{w} t+\mathbf{m} \Delta]}{[\mathbf{a}(\theta)+\mathbf{b}(\theta)] \Delta}\right]+\mathbf{b}(\theta) \ln \left[\frac{\mathbf{b}(\theta)[\gamma \mathbf{w} t+\mathbf{m} \Delta]}{\mathbf{w}[\mathbf{a}(\theta)+\mathbf{b}(\theta)]}\right] .
$$

Third, each household can decide not to meet the eligibility criteria for the WFTC and the childcare subsidy, or when she does, decide not to receive the WFTC $(P=0)$ and the childcare subsidy $(\phi=0)$. In the absence of WFTC and the childcare subsidy, each family maximizes $\Omega \equiv \theta U_{w}+(1-\theta) U_{h}$ subject to $x_{h}+x_{w}+p_{c} l_{w}=w l_{w}+m$ and $0 \leqslant l_{w} \leqslant t$. It is readily shown that if $w \leqslant \bar{w}=p_{c}+\frac{\mathbf{b}(\theta) m \Delta}{\mathbf{a}(\theta) \gamma t}$, then the optimal resource allocation is

$$
l_{w}^{4, a}=0, \quad x_{w}^{4, a}=\frac{\alpha_{w} \theta m}{\mathbf{a}(\theta)}, \quad x_{h}^{4, a}=\frac{\alpha_{h}(1-\theta) m}{\mathbf{a}(\theta)} .
$$

The corresponding indirect utility is

$$
\Omega_{a}^{P=0}=K+\mathbf{a}(\theta) \ln \left[\frac{m}{\mathbf{a}(\theta)}\right]+\mathbf{b}(\theta) \ln (\gamma t)
$$

If instead $w>p_{c}+\frac{\mathbf{b}(\theta) m \Delta}{\mathbf{a}(\theta) \gamma t}$, then the optimal household resource allocation is

$$
l_{w}^{4, b}=\frac{\mathbf{a}(\theta) \gamma t\left(w-p_{c}\right)-\mathbf{b}(\theta) \Delta m}{[\mathbf{a}(\theta)+\mathbf{b}(\theta)](w-p) \Delta}, x_{w}^{4, b}=\frac{\left[\gamma t\left(w-p_{c}\right)+\Delta m\right]}{\left[\alpha_{w} \theta\right]^{-1}[\mathbf{a}(\theta)+\mathbf{b}(\theta)] \Delta}, x_{h}^{4, b}=\frac{\left[\gamma t\left(w-p_{c}\right)+\Delta m\right]}{\left[\alpha_{h}(1-\theta)\right]^{-1}[\mathbf{a}(\theta)+\mathbf{b}(\theta)] \Delta} .
$$

The corresponding indirect utility is

$$
\Omega_{b}^{P=0}=K+\mathbf{a}(\theta) \ln \left[\frac{\left[\gamma t\left(w-p_{c}\right)+\Delta m\right]}{[\mathbf{a}(\theta)+\mathbf{b}(\theta)] \Delta}\right]+\mathbf{b}(\theta) \ln \left[\frac{\mathbf{b}(\theta)\left[\gamma t\left(w-p_{c}\right)+\Delta m\right]}{\left(w-p_{c}\right)[\mathbf{a}(\theta)+\mathbf{b}(\theta)]}\right]
$$

Result 2 in the main text provides a categorization of the population based on the cutoff wages $\left(w^{\prime}, w^{\prime \prime}, w^{\prime \prime \prime}\right)$ for the case where $0<\tilde{w}<w^{\prime}<w^{\prime \prime}<w^{\prime \prime \prime}$. We now turn to the derivation and comparative statics analysis of $\left(w^{\prime}, w^{\prime \prime}, w^{\prime \prime \prime}\right)$.

Equation $B_{1}$, which is derived below, implicitly characterizes $w^{\prime}$. In the context of the categorization of the population in Result $2, w^{\prime}$ solves $B_{1} \equiv \Omega_{b}^{P=1}-\Omega_{\phi_{2}}^{P=1}=0$ [see (14) and (16)]. In other words, $w^{\prime}$ solves

$$
\begin{aligned}
B_{1} & \equiv \mathbf{a}(\theta)\left[\ln \left[\frac{\left[\gamma t\left(w(1-\pi)-p_{c}\right)+\Delta \mathbf{m}\right]}{[\mathbf{a}(\theta)+\mathbf{b}(\theta)] \Delta}\right]-\ln \left[\frac{[\mathbf{w} \underline{l}+\mathbf{m}]}{\mathbf{a}(\theta)}\right]\right]+\mathbf{b}(\theta)\left[\ln \left[\frac{\mathbf{b}(\theta)\left[\gamma t\left(w(1-\pi)-p_{c}\right)+\Delta \mathbf{m}\right]}{\left(w(1-\pi)-p_{c}\right)[\mathbf{a}(\theta)+\mathbf{b}(\theta)]}\right]-\ln (\gamma t-\Delta \underline{l})\right]=0 \\
& \equiv \mathbf{a}(\theta) \ln \left[\frac{\mathbf{a}(\theta)}{[\mathbf{a}(\theta)+\mathbf{b}(\theta)] \Delta} \cdot \frac{\gamma t\left(w(1-\pi)-p_{c}\right)+\mathbf{m} \Delta}{\mathbf{w} \underline{l}+\mathbf{m}}\right]+\mathbf{b}(\theta) \ln \left[\frac{\mathbf{b}(\theta)}{\mathbf{a}(\theta)+\mathbf{b}(\theta)} \cdot \frac{\gamma t\left(w(1-\pi)-p_{c}\right)+\mathbf{m} \Delta}{(\gamma t-\underline{l} \Delta)\left(w(1-\pi)-p_{c}\right)}\right]=0 \\
& \equiv \ln \left[\frac{1}{(1+\mu(\theta)) \Delta} \cdot \frac{\gamma t\left(w(1-\pi)-p_{c}\right)+\mathbf{m} \Delta}{\mathbf{w} \underline{l}+\mathbf{m}}\right]+\mu(\theta) \ln \left[\frac{\mu(\theta)}{1+\mu(\theta)} \cdot \frac{\gamma t\left(w(1-\pi)-p_{c}\right)+\mathbf{m} \Delta}{(\gamma t-\underline{l} \Delta)\left(w(1-\pi)-p_{c}\right)}\right]=0,
\end{aligned}
$$

where $\mu(\theta)=\frac{\mathbf{b}(\theta)}{\mathbf{a}(\theta)}$ and $\mathbf{w}=w(1-\pi)-p_{c}(1-\phi)$. In evaluating the effects of marginal changes in program parameters on labor supply, we use the following comparative statics on $w^{\prime}$ :

- It is decreasing in the childcare subsidy $\phi$.

- It is increasing in the taper rate $\pi$ due to a substitution effect and decreasing in $\pi$ due to an income effect.

- It is increasing in tax credit $T_{\max }$.

- It is increasing in the threshold $M_{\min }$.

These comparative statics are readily established in two steps. The first step is to note that, for Result 2 to hold, it is necessarily the case that

$$
\left.\left.\frac{\partial B_{1}}{\partial w}\right|_{w=w^{\prime}} \equiv\left[\frac{\partial \Omega_{b}^{P=1}}{\partial w}-\frac{\partial \Omega_{\phi_{2}}^{P=1}}{\partial w}\right]\right|_{w=w^{\prime}}<0 .
$$

The second step is to implicitly differentiate $B_{1}$ with respect to $\left(\phi, \pi, T_{\max }, M_{\min }, \theta\right)$, taking $\partial B_{1} / \partial w$ to be negative:

$$
\frac{\partial w^{\prime}}{\partial \phi}=\left[\frac{p_{c} \underline{\underline{l}}}{\mathbf{w} \underline{\underline{l}}+\mathbf{m}}\right] \cdot\left[\frac{1}{\partial B_{1} / \partial w}\right]<0
$$




$$
\begin{gathered}
\frac{\partial w^{\prime}}{\partial \pi}=\left[\left(\frac{(1+\mu) \Delta}{\gamma t\left(w(1-\pi)-p_{c}\right)+\Delta \mathbf{m}}\right) \cdot\left(w l_{w}^{1, b}+m-M_{\text {min }}\right)-\left(\frac{1}{\mathbf{w} \underline{\underline{l}}+\mathbf{m}}\right) \cdot\left(w \underline{l}+m-M_{\text {min }}\right)\right] \cdot\left[\frac{1}{\partial B_{1} / \partial w}\right] \text { ambiguous sign }, \\
\frac{\partial w^{\prime}}{\partial T_{\max }}=-\underbrace{\left[\frac{(1+\mu(\theta)) \Delta}{\gamma t(w(1-\pi)-p)+\Delta \mathbf{m}}-\frac{1}{\mathbf{w}+\mathbf{m}}\right]}_{\text {positive for all } w \in\left[\underline{w}, w^{\prime \prime}\right]} \cdot\left[\frac{1}{\partial B_{1} / \partial w}\right]>0 \\
\frac{\partial w^{\prime}}{\partial M_{\min }}=-\underbrace{\left[\frac{\pi(1+\mu(\theta)) \Delta}{\gamma t(w(1-\pi)-p)+\Delta \mathbf{m}}-\frac{\pi}{\mathbf{w}+\mathbf{m}}\right]}_{\text {positive for all } w \in\left[\underline{w}, w^{\prime \prime}\right]} \cdot\left[\frac{1}{\partial B_{1} / \partial w}\right]>0
\end{gathered}
$$

where in $\partial w^{\prime} / \partial \pi$ the value $l_{w}^{1, b}=\frac{\gamma t\left(w(1-\pi)-p_{c}\right)-\mu \Delta \mathbf{m}}{(1+\mu) \Delta\left(w(1-\pi)-p_{c}\right)}$.

Note that in deriving the signs on these partial derivatives, we use the fact that the first term in brackets in the expression for $\partial w^{\prime} / \partial T_{\max }$ is positive. To see this, note that $\left(B_{1}\right)$ is equivalent to

$$
\ln \left[\frac{x_{w}^{1, b}+x_{h}^{1, b}}{x_{w}^{2}+x_{h}^{2}}\right]+\mu\left[\frac{\gamma t-\Delta l_{w}^{1, b}}{\gamma t-\Delta l_{w}^{2}}\right]=0 .
$$

We now that, at $w^{\prime}, l_{w}^{2}=\underline{l}>l_{w}^{1, b}$ (see Fig.2). Thus a necessary condition for $\left(B_{1}\right)$ to hold is $x_{w}^{2}+x_{h}^{2}>x_{w}^{1, b}+x_{h}^{1, b}$ which is equivalent to $\mathbf{w} \underline{l}+\mathbf{m}>\frac{\gamma t\left(w(1-\pi)-p_{c}\right)+\Delta \mathbf{m}}{(1+\mu) \Delta}$. It follows immediately that the first term in brackets in $\frac{\partial w^{\prime}}{\partial T_{m a x}}$ and $\frac{\partial w^{\prime}}{\partial M_{\min }}$, respectively, is necessarily positive. The comparative statics results combined imply that the reform is predicted to have an ambiguous effect on $w^{\prime}$.

$\underline{\text { Equation } B_{2}}$ defines $w^{\prime \prime}$. Comparative statics on $w^{\prime \prime}$ show:

- It is decreasing in the childcare subsidy $\phi$.

- It is increasing in $\pi$ due to a substitution effect and decreasing in $\pi$ due to an income effect.

- It is increasing in the tax credit $T_{\max }$.

- It is increasing in the threshold $M_{\min }$.

These results follow immediately from partially differentiating $w^{\prime \prime}$ with respect to $\left(\phi, \pi, T_{\max }, M_{\min }, \theta\right)$

$$
\begin{aligned}
& \frac{\partial w^{\prime \prime}}{\partial \phi}=-\frac{p_{c}}{1-\pi}<0 \\
& \frac{\partial w^{\prime \prime}}{\partial \pi}=\underbrace{-\frac{\mu(\theta) \Delta\left(M_{\min }-m\right)}{(1-\pi)[\gamma t-(1+\mu(\theta)) \underline{l} \Delta]}}_{\text {Income } E .}+\underbrace{\frac{p_{c}(1-\phi)}{(1-\pi)^{2}}+\frac{\mu(\theta) \Delta\left[(1-\pi) m+T_{\max }+M_{\min }\right]}{(1-\pi)^{2}[\gamma t-(1+\mu(\theta)) \underline{l} \Delta]}}_{\text {Substitution } E .} \\
& \frac{\partial w^{\prime \prime}}{\partial T_{\max }}=\frac{\mu(\theta) \Delta}{(1-\pi)[\gamma t-(1+\mu(\theta)) \underline{l} \Delta]}>0 \\
& \frac{\partial w^{\prime \prime}}{\partial M_{\min }}=\frac{\mu(\theta) \pi \Delta}{(1-\pi)[\gamma t-(1+\mu(\theta)) \underline{l} \Delta]}>0
\end{aligned}
$$

where again we use the result $\gamma t-(1+\mu) \underline{l} \Delta>0$ shown in deriving the comparative statics results on $w^{* *}$ for class-A households. These comparative statics findings indicate that the reform is predicted to have an ambiguous effect on $w^{\prime \prime}$.

Equation $B_{3}$ to be derived next implicitly characterizes $w^{\prime \prime \prime}$. In the context of the categorization of the population in Result $2, w^{\prime \prime \prime}$ solves $B_{3} \equiv \Omega_{\phi_{3}}^{P=1}-\Omega_{b}^{P=0}=0$ [see (22) and (18)]. In other words, $w^{\prime \prime \prime}$ solves:

$$
\begin{aligned}
B_{3} \equiv & \mathbf{a}(\theta)\left[\ln \left[\frac{[\gamma t \mathbf{w}+\mathbf{m} \Delta]}{[\mathbf{a}(\theta)+\mathbf{b}(\theta)] \Delta}\right]-\ln \left[\frac{\left[\gamma t\left(w-p_{c}\right)+\Delta m\right]}{[\mathbf{a}(\theta)+\mathbf{b}(\theta)] \Delta}\right]\right] \\
& +\mathbf{b}(\theta)\left[\ln \left[\frac{\mathbf{b}(\theta)[\gamma t \mathbf{w}+\mathbf{m} \Delta]}{\mathbf{w}[\mathbf{a}(\theta)+\mathbf{b}(\theta)]}\right]-\ln \left[\frac{\mathbf{b}(\theta)\left[\gamma t\left(w-p_{c}\right)+\Delta m\right]}{\left(w-p_{c}\right)[\mathbf{a}(\theta)+\mathbf{b}(\theta)]}\right]\right]=0 \\
\equiv & \ln \left[\frac{\gamma t \mathbf{w}+\mathbf{m} \Delta}{\gamma t\left(w-p_{c}\right)+m \Delta}\right]+\frac{\mu(\theta)}{1+\mu(\theta)} \ln \left[\frac{w-p_{c}}{\mathbf{w}}\right]=0
\end{aligned}
$$

where $\mu(\theta)=\frac{\mathbf{b}(\theta)}{\mathbf{a}(\theta)}$ and $\mathbf{w}=w(1-\pi)-p_{c}(1-\phi)$. We can derive the following comparative statics on $w^{\prime \prime \prime}$ : 
- It is increasing in the childcare subsidy $\phi$.

- It is decreasing in the taper rate $\pi$.

- It is increasing in the tax credit $T_{\max }$.

- It is increasing in the threshold $M_{\min }$.

These comparative statics are readily established in two steps. The first step is to note that, for Result 2 to hold, it is necessarily the case that

$$
\left.\left.\frac{\partial B_{3}}{\partial w}\right|_{w=w^{\prime \prime \prime}} \equiv\left[\frac{\partial \Omega_{\phi_{3}}^{P=1}}{\partial w}-\frac{\partial \Omega_{b}^{P=0}}{\partial w}\right]\right|_{w=w^{\prime \prime \prime}}<0 .
$$

The second step is to implicitly differentiate $B_{3}$ with respect to $\left(\pi, T_{\max }, M_{\min }, \theta\right)$, taking $\partial B_{3} / \partial w$ to be negative:

$$
\frac{\partial w^{\prime \prime \prime}}{\partial \phi}=-\left[\frac{p_{c} \Delta}{\gamma t \mathbf{w}+\Delta \mathbf{m}}\right] \cdot\left[\frac{\gamma t \mathbf{w}-\mu(\theta) \mathbf{m} \Delta}{\mathbf{w} \Delta[1+\mu(\theta)]}\right] \cdot\left[\frac{1}{\partial B_{3} / \partial w}\right]>0
$$

where we use the fact that the second term in brackets equals $l_{w}^{3}$ which is positive.

$$
\frac{\partial w^{\prime \prime \prime}}{\partial \pi}=\left[\frac{w \Delta}{\gamma t \mathbf{w}+\Delta \mathbf{m}}\right] \cdot\left[\frac{\gamma t \mathbf{w}-\mu(\theta) \mathbf{m} \Delta}{\mathbf{w} \Delta[1+\mu(\theta)]}+\frac{m-M_{\text {min }}}{w}\right] \cdot\left[\frac{1}{\partial B_{3} / \partial w}\right]<0
$$

where we use the fact that the second term in brackets equals $w l_{w}^{3}+m-M_{m i n}$ which has to be positive for the couple's income to be subject to the taper rate $\pi$.

$$
\begin{gathered}
\frac{\partial w^{\prime \prime \prime}}{\partial T_{\max }}=-\left[\frac{\Delta}{\gamma t \mathbf{w}+\Delta \mathbf{m}}\right] \cdot\left[\frac{1}{\partial B_{3} / \partial w}\right]>0 \\
\frac{\partial w^{\prime \prime \prime}}{\partial M_{\min }}=-\left[\frac{\pi \Delta}{\gamma t \mathbf{w}+\Delta \mathbf{m}}\right] \cdot\left[\frac{1}{\partial B_{3} / \partial w}\right]>0
\end{gathered}
$$

where $\mathbf{w}=w(1-\pi)-p_{c}(1-\phi)$. Combined these results produce a positive effect of the reform on $w^{\prime \prime \prime}$.

We are now ready to establish the comparative statics on hours of work chosen by females in Class B households. For type-1 women, the comparative statics for optimal labor supply at any wages between the post-reform values of $\tilde{w}$ and $w^{\prime}$ are identical to those described for type-3 women in Class A households (ie. an ambiguous effect). In addition, the comparative statics for the reservation wage $\tilde{w}$ for labor force participation are:

$$
\begin{gathered}
\frac{\partial \tilde{w}}{\partial T_{\max }}=\frac{\mu \Delta}{(1-\pi) \gamma t}>0 \\
\frac{\partial \tilde{w}}{\partial M_{\min }}=\pi \frac{\partial \tilde{w}}{\partial T_{\max }}>0 \\
\frac{\partial \tilde{w}}{\partial \pi}=\frac{p \gamma t+M \mu \Delta(1-\pi)+\mu \Delta T_{\max }+\mu \Delta \pi M_{\min }}{(1-\pi)^{2} \gamma t}>0
\end{gathered}
$$

These results, combined with an ambiguous effect of the policy parameter changes on $w^{\prime}$, imply that the effect of the reform on hours of work for this subset of women is theoretically ambiguous.

For type-2 women, who worked $\underline{l}$ hours prior to the reform, ambiguous effects on $w^{\prime}$ and $w^{\prime \prime}$ imply that impact on the labor supply of these women is ambiguous.

For type-3 women, the comparative statics for optimal labor supply at any wage between the post-reform values of $w^{\prime \prime}$ and $w^{\prime \prime \prime}$ are:

$$
\begin{gathered}
\frac{\partial l^{3}}{\partial T_{\max }}=-\frac{\mu /(1+\mu)}{\left[w(1-\pi)-p_{c}(1-\phi)\right]}<0, \frac{\partial l^{3}}{\partial M_{\min }}=\pi \frac{\partial l^{3}}{\partial T_{\max }}<0 \\
\frac{\partial l^{3}}{\partial \pi}=-\frac{\mu}{1+\mu}\left[\frac{M_{\min } \mathbf{w}+m p_{c}(1-\phi)+w T+\pi w M_{\min }}{\mathbf{w}^{2}}\right]<0 \\
\frac{\partial l^{3}}{\partial \phi}=\frac{\mu}{1+\mu}\left[\frac{p \mathbf{m} \Delta}{\mathbf{w}^{2}}\right]>0
\end{gathered}
$$

An increase in $w^{\prime \prime}$ due to the reform would lead to a fall in optimal labor supply for women whose wages will fall below the new $w^{\prime \prime}$, while a decline in $w^{\prime \prime}$ would have no direct effect on type-3 women. The predicted increase in 
$w^{\prime \prime \prime}$ similarly has no implications for type-3 women. Combined with the ambiguous effect on optimal labor supply as indicated by the comparative statics for $l_{w}^{3}$, the results imply an ambiguous effect of the reform on hours of work for this subset of women.

For type- 4 women, the predicted increase in $w^{\prime \prime \prime}$ implies that those whose wages fall below the new $w^{\prime \prime \prime}$ value their labor supply will fall, while for those with wages exceeding the post-reform $w^{\prime \prime \prime}$ value the chosen hours of work will remain the same.

\section{Indirect Effects}

We next consider the impact of a change in $\theta$ on the reservation and cutoff wages, and show:

- $\tilde{w}$ is decreasing (increasing) in the bargaining weight $\theta$ if $\frac{\alpha_{w}}{\beta_{w}}>\frac{\alpha_{h}}{\beta_{h}}$ (if $\frac{\alpha_{w}}{\beta_{w}}<\frac{\alpha_{h}}{\beta_{h}}$ ).

- $w^{\prime}$ is decreasing (increasing) in the bargaining weight $\theta$ if $\frac{\alpha_{w}}{\beta_{w}}>\frac{\alpha_{h}}{\beta_{h}}$ (if $\frac{\alpha_{w}}{\beta_{w}}<\frac{\alpha_{h}}{\beta_{h}}$ ).

- $w^{\prime \prime}$ is decreasing (increasing) in the bargaining weight $\theta$ if $\frac{\alpha_{w}}{\beta_{w}}>\frac{\alpha_{h}}{\beta_{h}}$ (if $\frac{\alpha_{w}}{\beta_{w}}<\frac{\alpha_{h}}{\beta_{h}}$ ).

- $w^{\prime \prime \prime}$ is decreasing (increasing) in the bargaining weight $\theta$ if $\frac{\alpha_{w}}{\beta_{w}}>\frac{\alpha_{h}}{\beta_{h}}$ (if $\frac{\alpha_{w}}{\beta_{w}}<\frac{\alpha_{h}}{\beta_{h}}$ ).

First we consider the effects of $\theta$ on the reservation wage and the cutoff values $w^{\prime}, w^{\prime \prime}$ and $w^{\prime \prime \prime}$ :

$$
\begin{gathered}
\frac{\partial \tilde{w}}{\partial \theta}=\left[\frac{\mathbf{m} \Delta}{(1-\pi) \gamma t}\right] \frac{\partial \mu}{\partial \theta} \\
=-\left[\frac{\mathbf{m} \Delta}{(1-\pi) \gamma t}\right] \frac{\alpha_{w} \beta_{h}-\beta_{w} \alpha_{h}}{\mathbf{a}(\theta)^{2}} \lesseqgtr 0 \Leftrightarrow \frac{\alpha_{w}}{\beta_{w}} \gtreqless \frac{\alpha_{h}}{\beta_{h}} \\
\frac{\partial w^{\prime}}{\partial \theta}=\ln \left[\frac{\mu(\theta)}{1+\mu(\theta)} \cdot \frac{\gamma t\left(w(1-\pi)-p_{c}\right)+\mathbf{m} \Delta}{(\gamma t-\underline{l} \Delta)\left(w(1-\pi)-p_{c}\right)}\right] \cdot\left[\frac{\alpha_{w} \beta_{h}-\alpha_{h} \beta_{w}}{\left[\alpha_{w} \theta+\alpha_{h}(1-\theta)\right]^{2}}\right] \cdot\left[\frac{1}{\partial A_{1} / \partial w}\right] \lesseqgtr 0 \Leftrightarrow \frac{\alpha_{w}}{\beta_{w}} \gtreqless \frac{\alpha_{h}}{\beta_{h}}
\end{gathered}
$$

where we use the fact that the first expression in brackets under the logarithm is greater than 1 as is equals $(\gamma t-$ $\left.\Delta l_{w}^{1, b}\right) /\left(\gamma t-\Delta l_{w}^{2}\right)$. Because at $w^{\prime}, l_{w}^{2}=\underline{l}>l_{w}^{1, b}$, it follows that the term is greater than 1.

$$
\begin{gathered}
\frac{\partial w^{\prime \prime}}{\partial \theta}=-\frac{\Delta \mathbf{m}(\gamma t-\Delta \underline{l})\left[\alpha_{w} \beta_{h}-\alpha_{h} \beta_{w}\right]}{(1-\pi)[\mathbf{a}(\theta) \gamma t-\underline{l}[\mathbf{b}(\theta)+\mathbf{a}(\theta)] \Delta]^{2}} \lesseqgtr 0 \Leftrightarrow \frac{\alpha_{w}}{\beta_{w}} \gtreqless \frac{\alpha_{h}}{\beta_{h}} \\
\frac{\partial w^{\prime \prime \prime}}{\partial \theta}=\ln \left[\frac{w-p_{c}}{\mathbf{w}}\right] \cdot\left[\frac{\alpha_{w} \beta_{h}-\alpha_{h} \beta_{w}}{[\mathbf{a}(\theta)+\mathbf{b}(\theta)]^{2}}\right] \cdot\left[\frac{1}{\partial B_{3} / \partial w}\right] \lesseqgtr 0 \Leftrightarrow \frac{\alpha_{w}}{\beta_{w}} \gtreqless \frac{\alpha_{h}}{\beta_{h}}
\end{gathered}
$$

where we use the fact that in the U.K., the taper rate $\pi$ has exceeded the childcare subsidy $\phi$ both before and after the introduction of WFTC, implying that $w-p_{c}>(1-\pi) w-(1-\pi) p_{c}>\mathbf{w}$.

We can now evaluate the effect on the bargaining weight $\theta$ on labor supply. First for women with wages between $\tilde{w}$ and $w^{\prime}$,

$$
\frac{\partial l^{1, b}}{\partial \theta}=\frac{1}{(1+\mu)^{2}}\left[\frac{\left(w(1-\pi)-p_{c}\right) \gamma t+\Delta \mathbf{m}}{\left(w(1-\pi)-p_{c}\right) \Delta}\right] \frac{\alpha_{w} \beta_{h}-\beta_{w} \alpha_{h}}{\mathbf{a}(\theta)^{2}} \lesseqgtr 0 \Leftrightarrow \frac{\alpha_{w}}{\beta_{w}} \lesseqgtr \frac{\alpha_{h}}{\beta_{h}}
$$

Combined with the predicted increases (decreases) in the reservation wage $\tilde{w}$ and in $w^{\prime}$, this implies a negative (positive) effect on the labour supply of type-1 women when $\frac{\alpha_{w}}{\beta_{w}}<(>) \frac{\alpha_{h}}{\beta_{h}}$.

For type- 2 women, who worked $\underline{l}$ hours prior to the reform, the predicted increases (decreases) in $w^{\prime}$ and $w^{\prime \prime}$ imply that the labor supply of these women would decline (increase) when $\frac{\alpha_{w}}{\beta_{w}}<(>) \frac{\alpha_{h}}{\beta_{h}}$.

For type-3 women, the bargaining weight effect on the optimal hours of work when her wage falls between the post-reform values of $w^{\prime \prime}$ and $w^{\prime \prime \prime}$ equals:

$$
\frac{\partial l^{3}}{\partial \theta}=\frac{1}{(1+\mu)^{2}}\left[\frac{\mathbf{w} \gamma t+\Delta \mathbf{m}}{\mathbf{w} \Delta}\right] \frac{\alpha_{w} \beta_{h}-\beta_{w} \alpha_{h}}{\mathbf{a}(\theta)^{2}} \lesseqgtr 0 \Leftrightarrow \frac{\alpha_{w}}{\beta_{w}} \lesseqgtr \frac{\alpha_{h}}{\beta_{h}}
$$

Combined with increases (decreases) in $w^{\prime \prime}$ and $w^{\prime \prime \prime}$, these comparative statics imply a decline (increase) in female labor supply when $\frac{\alpha_{w}}{\beta_{w}}<(>) \frac{\alpha_{h}}{\beta_{h}}$.

Finally for type- 4 women, the effect on optimal hours of work for woman with wages greater than $w^{\prime \prime \prime}$ equals

$$
\frac{\partial l^{4}}{\partial \theta}=\frac{1}{(1+\mu)^{2}}\left[\frac{(w-p) \gamma t+\Delta m}{(w-p) \Delta}\right] \frac{\alpha_{w} \beta_{h}-\beta_{w} \alpha_{h}}{\mathbf{a}(\theta)^{2}} \lesseqgtr 0 \Leftrightarrow \frac{\alpha_{w}}{\beta_{w}} \lesseqgtr \frac{\alpha_{h}}{\beta_{h}}
$$

Together with a predicted increase (decrease) in $w^{\prime \prime \prime}$, this implies that an increase in $\theta$ leads to a decline (increase) in female hours of work when $\frac{\alpha_{w}}{\beta_{w}}<(>) \frac{\alpha_{h}}{\beta_{h}}$. 


\section{Appendix 2: Subgame Perfect Equilibrium after Divorce}

The Extended Model with Divorce. Divorce is endogenous and occurs whenever one of the spouses can be made better off by breaking the relationship and the other spouse is not willing or unable to compensate her for this potential gain (Weiss and Willis, 1985; Clark, 1999). We assume that either partner can costlessly initiate a divorce, even without the consent of the other. Remarriage is assumed not to be an option. Suppose that, after divorce, child custody is assigned to the mother and the mother is the only parent spending time and resources on childcare, even though both parents continue to receive utility from childcare quality. Let $a$ be a child support transfer from the father to the mother, such that $0 \leqslant a \leqslant m$. We take the child support transfer made by the noncustodial father, $a \in[0, m]$, to be chosen voluntarily. Finally, let $\sigma$ be a shock common to the spouses's divorce payoffs, which can be thought of as a measure of the mismatch of the marriage that disappears on divorce. Each partner's utility in the divorce state is given by $D_{i}=\alpha_{i} \ln \left(x_{i}\right)+\beta_{i} \ln \left(\gamma t-\Delta l_{w}\right)+\eta_{i} \ln (\sigma)$, where $\Delta=\gamma-\delta>0$. For purposes of simplicity we shall assume that $\alpha_{i}=\beta_{i}=\eta_{i}(i \in\{h, w\})$. It thus follows that

$$
D_{h}=\alpha_{h} \ln \left[\sigma x_{h}\left(\gamma t-\Delta l_{w}\right)\right] \quad \text { and } \quad D_{w}=\alpha_{w} \ln \left[\sigma x_{w}\left(\gamma t-\Delta l_{w}\right)\right]
$$

Through her labor supply decision, the mother controls the level of childcare quality, a public good. The only way in which the father can affect childcare quality is through voluntary child support transfer to the mother. Thus the choice variable of the mother is $l_{w}$ and the father's is $a$, the child support transfer to the mother. The decision making in the divorce state proceeds sequentiallly. The timing is as follows: (1) the father chooses a child support transfer $a \in[0, m] ;(2)$ the mother observes $a$ and then, through her labor supply decision $l_{w} \in[0, t]$, determines the amount of childcare quality. In this sequential game, the father anticipates the mother's decision rule when choosing the child support transfer. To solve for the subgame-perfect equilibrium (SPE, for short), we first compute the mother's labor supply decision for an arbitrary child support transfer by the father.

Subgame-Perfect Equilibrium (SPE). Conditional on the father's transfer, the mother can choose to be in one of two regimes. First, she can decide not to meet the eligibility criteria of the WFTC, or, when she does, decide not to participate in the program. Let $\omega=w-p_{c}$ denote the mother's net wage in the absence of in-work benefits. The mother solves

and her decision rule is

$$
\max _{l_{w} \in[0, t]} \alpha_{w} \ln \left[\sigma x_{w}\left(\gamma t-\Delta l_{w}\right)\right] \quad \text { subject to } \quad x_{w}=\omega l_{w}+a
$$

$$
\begin{cases}l_{w}^{00}=0 & \text { if } a \geq \omega \gamma t / \Delta \\ l_{w}^{10}=[\omega \gamma t-\Delta a] /(2 \omega \Delta) & \text { if } a<\omega \gamma t / \Delta\end{cases}
$$

The value of the mother's utility maximization problem is

$$
\begin{cases}D_{w}^{00}=\alpha_{w} \ln [\sigma a \gamma t] & \text { if } a \geq \omega \gamma t / \Delta \\ D_{w}^{10}=\alpha_{w} \ln \left[\sigma(\omega \gamma t+\Delta a)^{2} /(4 \omega \Delta)\right] & \text { if } a<\omega \gamma t / \Delta\end{cases}
$$

Second, the mother can choose to meet the eligibility criteria for WFTC and participate in the program. Let $\mathbf{w}=w(1-$ $\pi)-p_{c}(1-\phi)$ denote the mother's net wage in the presence of in-work benefits. ${ }^{2}$ Furthermore, let $\mathbf{d}=T_{\max }+\pi M_{\min }$ be a measure of amount of tax credit received by the mother. The mother now maximizes

$$
\max _{l_{w} \in[\underline{l}, t]} \alpha_{w} \ln \left[\sigma x_{w}\left(\gamma t-\Delta l_{w}\right)\right] \quad \text { subject to } \quad x_{w}=\mathbf{w} l_{w}+a+\mathbf{d}
$$

and her decision rule is

$$
\begin{cases}l_{w}^{01}=\underline{l} & \text { if } a \geq[\mathbf{w}(\gamma t-2 \underline{l} \Delta)-\Delta \mathbf{d}] / \Delta \\ l_{w}^{11}=[\mathbf{w} \gamma t-\Delta(a+\mathbf{d})] /(2 \mathbf{w} \Delta) & \text { if } a<[\mathbf{w}(\gamma t-2 \underline{l} \Delta)-\Delta \mathbf{d}] / \Delta\end{cases}
$$

\footnotetext{
${ }^{2}$ Recall that $\omega=w-p_{c}$ denotes the mother's net wage in the absence of in-work benefits. Since the taper rate $\pi$ exceeded the childcare subsidy $\phi$ both before and after the introduction of WFTC, it follows that $\omega>\mathbf{w}$ as $\omega>(1-\pi) \omega=w(1-\pi)-p_{c}(1-\pi)>$ $w(1-\pi)-p_{c}(1-\phi)=\mathbf{w}$.
} 
The value of the mother's utility maximization problem is

$$
\begin{cases}D_{w}^{01}=\alpha_{w} \ln [\sigma(\mathbf{w} \underline{l}+a+\mathbf{d})(\gamma t-\Delta \underline{l})] & \text { if } a \geq[\mathbf{w}(\gamma t-2 \underline{l} \Delta)-\Delta \mathbf{d}] / \Delta \\ D_{w}^{11}=\alpha_{w} \ln \left[\sigma(\mathbf{w} \gamma t+\Delta(a+\mathbf{d}))^{2} /(4 \mathbf{w} \Delta)\right] & \text { if } a<[\mathbf{w}(\gamma t-2 \underline{l} \Delta)-\Delta \mathbf{d}] / \Delta\end{cases}
$$

Conditional on an arbitrary $a \in[0, m]$, we now determine the conditions under which it is optimal for a divorced single mother to work and receive WFTC. We will focus on parameter values for which the population of divorced women can be the divided in the following four groups: (1) non-working and not receiving WFTC, the utility value of which is $D_{w}^{00} ;(2)$ working exactly $\underline{l}$ hours and receiving WFTC, the utility value of which is $D_{w}^{01} ;(3)$ working more than $\underline{l}$ hours and receiving WFTC, the utility value of which is $D_{w}^{11}$; (4) working more than $\underline{l}$ hours and not receiving WFTC, the utility value of which is $D_{w}^{10}$. It is useful to provide this categorization in terms of the transfer $a$. To do so, observe that

$$
\begin{array}{ccc}
D_{w}^{00} \gtreqless D_{w}^{01} & \text { if and only if } & a \gtreqless \frac{(\gamma t-\Delta \underline{l})(\mathbf{w} \underline{l}+\mathbf{d})}{\Delta \underline{l}} \equiv a^{*} \\
D_{w}^{01} \gtreqless D_{w}^{11} & \text { if and only if } & a \gtreqless \frac{\mathbf{w}(\gamma t-2 \underline{l} \Delta)-\Delta \mathbf{d}}{\Delta} \equiv a^{* *} \\
D_{w}^{11} \gtreqless D_{w}^{10} & \text { if and only if } & a \gtreqless \frac{\gamma t \sqrt{\mathbf{w} \omega} \xi-\sqrt{\mathbf{w}} \Delta \mathbf{d}}{\Delta \xi} \equiv a^{* * *}
\end{array}
$$

where $\xi=\sqrt{\omega}-\sqrt{\mathbf{w}}>0$. Focusing on parameter values satisfying $a^{*}>a^{* *}>a^{* * *}>0$, we have :

1. Divorced women who receive a transfer larger than or equal to $a^{*}$ don't work and hence are ineligible for WFTC.

2. Divorced women who receive a transfer in the interval $\left(a^{*}, a^{* *}\right]$ work exactly $\underline{l}$ hours and receive WFTC.

3. Divorced women who receive a transfer in the interval $\left(a^{* *}, a^{* * *}\right]$ work strictly more than $\underline{l}$ hours and receive WFTC.

4. Divorced women who receive a transfer smaller than $a^{* * *}$ work strictly more than $\underline{l}$ hours and either have earnings too high to be eligible for WFTC or choose not to participate.

The implied labor supply schedule is

$$
\begin{cases}l_{w}^{00}=0 & \text { if } a \geqslant a^{*} \\ l_{w}^{01}=\underline{l} & \text { if } a^{* *} \leqslant a<a^{*} \\ l_{w}^{11}=[\mathbf{w} \gamma t-\Delta(a+\mathbf{d})] /(2 \mathbf{w} \Delta) & \text { if } a^{* * *} \leqslant a<a^{* *} \\ l_{w}^{10}=[\omega \gamma t-\Delta a] /(2 \omega \Delta) & \text { if } a<a^{* * *}\end{cases}
$$

In Figure 1 we plot an example of the mother's labor supply schedule as a function of $a$ for a fixed female wage $w$, male income $m$, and policy parameters $\left(\pi, \phi, T_{\max }, M_{\min }\right)$. Notice that there is a discontinuous downward-jump in the labor supply schedule at both $a^{*}$ and $a^{* * *}$, while the labour supply function is continuous at $a^{* *}{ }^{4}$ Given the mother's labor supply schedule, the father's problem is to choose the level of the transfer to make to her. The father spends his net income, $m-a$, on private consumption, while benefiting from the mother's contributions to childcare quality. His problem is to choose $a \in[0, m]$ so as to maximize

$$
D_{h}(a)= \begin{cases}\alpha_{h} \ln [\sigma(m-a) \gamma t] \equiv D_{h}^{00}(a) & \text { if } a \geqslant a^{*} \\ \alpha_{h} \ln [\sigma(m-a)(\gamma t-\Delta \underline{l})] \equiv D_{h}^{01}(a) & \text { if } a^{* *} \leqslant a<a^{*} \\ \alpha_{h} \ln [\sigma(m-a)[\gamma \mathbf{w} t+\Delta(\mathbf{d}+a)] /(2 \mathbf{w})] \equiv D_{h}^{11}(a) & \text { if } a^{* * *} \leqslant a<a^{* *} \\ \alpha_{h} \ln [\sigma(m-a)(\gamma \omega t+\Delta a) /(2 \omega)] \equiv D_{h}^{10}(a) & \text { if } a<a^{* * *}\end{cases}
$$

The utility function in (31) is only piecewise differentiable and has two points of upward discontinuity, at $a^{* * *}$ and at $a^{*}$. Before deriving the SPE in divorce, it is useful to consider the following additional properties of the utility function in (31).

\footnotetext{
${ }^{3}$ Note that these parametric restrictions rule out optimally choosing to work positive hours under $\underline{l}$ hours

${ }^{4}$ The discontinuity at $a^{* * *}$ follows from the fact that the difference between $l_{w}^{10}$ and $l_{w}^{11}$ at any $a$ is strictly positive for all $\omega-\mathbf{w}>0$.
} 


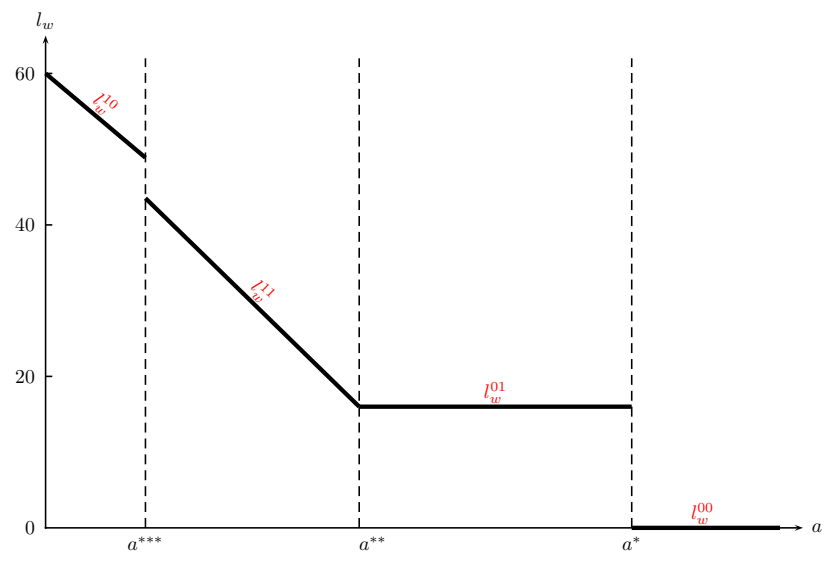

Figure 1

Property 1: The utility of the father is a strictly decreasing function of $a$ over the intervals $\left[a^{* *}, a^{*}\right)$ and $\left[a^{*}, m\right)$ :

$$
\frac{\partial D_{h}^{00}(a)}{\partial a}=-\frac{\alpha}{m-a}<0 \quad \text { and } \quad \frac{\partial D_{h}^{01}(a)}{\partial a}=-\frac{\alpha}{m-a}<0
$$

Property 2: The utility of the father is a strictly concave function of $a$ over the intervals $\left[0, a^{* * *}\right)$ and $\left[a^{* * *}, a^{* *}\right)$ :

$$
\frac{\partial D_{h}^{10}(a)}{\partial a} \gtreqless 0 \Leftrightarrow a \lesseqgtr \frac{\Delta m-\gamma \omega t}{2 \Delta} \equiv \tilde{a} \quad \text { and } \quad \frac{\partial D_{h}^{11}(a)}{\partial a} \gtreqless 0 \Leftrightarrow a \lesseqgtr \frac{\Delta(m-\mathbf{d})-\gamma \mathbf{w} t}{2 \Delta} \equiv \hat{a}
$$

where $\tilde{a}<\hat{a}$ is implied by the condition $a^{* * *}>0$ (see footnote 4 ).

Property 3: For any $a^{* * *}>0$, the derivative of $D_{h}^{10}(a)$ exceeds that of $D_{h}^{11}(a)$. Note that this implies that if $D_{h}^{11}(a)$ evaluated at $a^{* * *}$ is negative, then the derivative of $D_{h}^{10}(a)$ evaluated at $a^{* * *}$ will be negative as well. ${ }^{5}$

We are now ready to characterize the SPE in divorce.

I. Given Properties 1-3, let us first consider two cases that do not conform to the grouping of divorced women discussed above. First, when $a^{* *}<0$, Property 1 implies that it would be optimal for the mother to either work $\underline{l}$ hours (when $a<a^{*}$ ) or to work 0 hours (when $a \geq a^{*}$ ). The third and fourth group of divorced women categorized earlier do not exist in this case. The optimal transfer made by the father when $a^{* *}<0$ would equal 0 when

$$
D_{h}^{01}(0) \geq D_{h}^{00}\left(a^{*}\right) \quad \text { or, equivalently } \quad m<\frac{\gamma t a^{*}}{\Delta \underline{l}}=\frac{\gamma t(\gamma t-\Delta \underline{l})(\mathbf{w} \underline{l}+\mathbf{d})}{m(\Delta \underline{l})^{2}}
$$

and would equal $a^{*}$ otherwise. ${ }^{6}$ In the second case, when $a^{* *}>0$ and $a^{* * *}<0$, we can distinguish between two situations, depending on whether $\hat{a}<a^{* *}$ or $\hat{a} \geq a^{* *}$. Note that in this scenario the fourth group of women (working more than $\underline{l}$ hours while not participating in the program) does not exist. In this case, when $\hat{a}<a^{* *}$, the optimal

${ }^{5}$ To confirm Property 3 , note that $a^{* * *}>0$ requires that

$$
\omega>\frac{[\mathbf{w} \gamma t+\Delta \mathbf{d}]^{2}}{\mathbf{w}(\gamma t)^{2}} .
$$

The derivative of $D_{h}^{11}(a)$ and $D_{h}^{10}(a)$ are respectively given by

$$
\frac{\partial D_{h}^{11}}{\partial a}=-\frac{\alpha[\mathbf{w} \gamma t+\Delta(2 a+\mathbf{d}-m)]}{(m-a)[\mathbf{w} \gamma t+\Delta(a+\mathbf{d})]} \quad \text { and } \quad \frac{\partial D_{h}^{10}}{\partial a}=-\frac{\alpha[\omega \gamma t+\Delta(2 a-m)]}{(m-a)[\omega \gamma t+\Delta a]} .
$$

Therefore

$$
\frac{\partial D_{h}^{10}}{\partial a}<\frac{\partial D_{h}^{11}}{\partial a} \Leftrightarrow \omega>\frac{\mathbf{w} \gamma t+\Delta \mathbf{d}}{\gamma t} .
$$

Observe that (P3.3) is always satisfied given requirement (P3.1). Property 3 now follows immediately.

${ }^{6}$ Note that in absence of positive non-labor income, it will always be the case that $a^{*}>0$ because when $a=0, l_{w}>0$. 

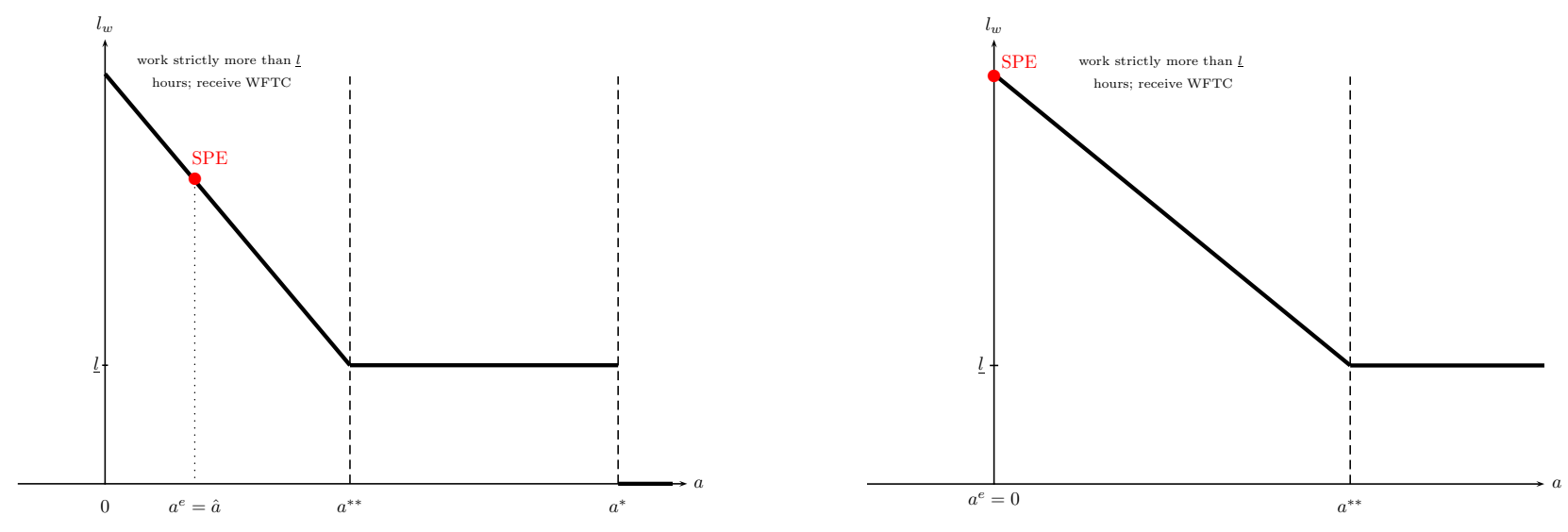

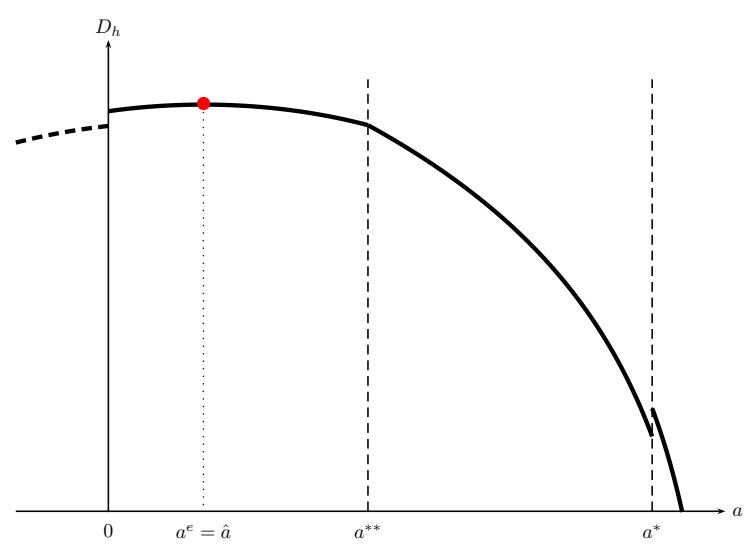

Figure 2: SPE when $a^{* * *}<0<\hat{a}<a^{* *}$ and $D_{h}^{11}(\hat{a})>D_{h}^{00}\left(a^{*}\right)$.

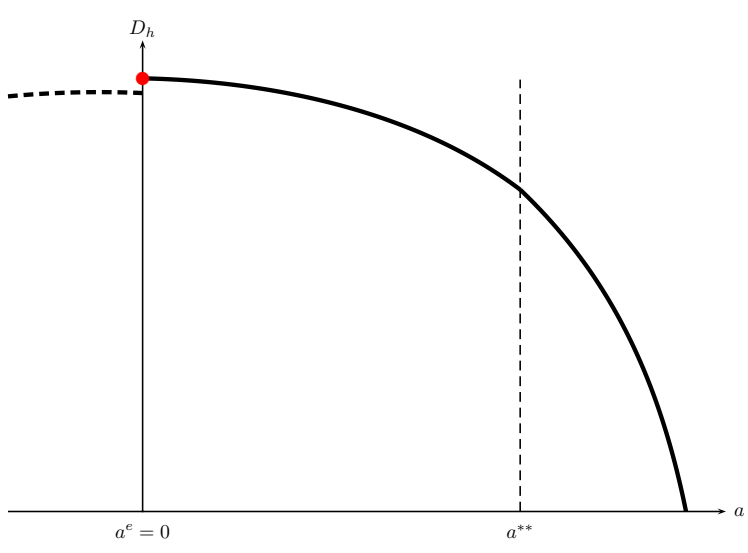

Figure 3: SPE when $\max \left\{a^{* * *}, \hat{a}\right\} \leqslant 0<a^{* *}$ and $D_{h}^{11}(0)>D_{h}^{00}\left(a^{*}\right)$.

transfer amount can take on two possible values. When $\hat{a}<0$ these are 0 (when $\left.D_{h}^{11}(0)>D_{h}^{00}\left(a^{*}\right)\right)$ and $a^{*}($ when $\left.D_{h}^{11}(0)<D_{h}^{00}\left(a^{*}\right)\right)$. When instead $\hat{a}>0$, the optimal transfer amount equals $\hat{a}\left(\right.$ when $\left.D_{h}^{11}(\hat{a})>D_{h}^{00}\left(a^{*}\right)\right)$ or $a^{*}($ when $\left.D_{h}^{11}(\hat{a})<D_{h}^{00}\left(a^{*}\right)\right)$. Finally, when $\hat{a} \geq a^{* *}$, the optimal transfer amount equals $a^{* *}$ (when $\left.D_{h}^{01}\left(a^{* *}\right)>D_{h}^{00}\left(a^{*}\right)\right)$ and $a^{*}$ when the opposite is true.

Figure 2 illustrates the scenario where $a^{* * *}<0<\hat{a}<a^{* *}$ and $D_{h}^{11}(\hat{a})>D_{h}^{00}\left(a^{*}\right)$. In this case, the equilibrium transfer equals $a^{e}=[\Delta m-(\gamma t \mathbf{w}+\Delta \mathbf{d})] /(2 \Delta) \equiv \hat{a}$, which induces the mother work strictly more than $\underline{l}$ hours and to receive WFTC. Figure 3 instead illustrates the scenario where $a^{* * *} \gtreqless \hat{a}<0<a^{* *}$ and $D_{h}^{11}(0)>D_{h}^{00}\left(a^{*}\right)$. In this case, the equilibrium transfer is $a^{e}=0$, which again induces the mother work strictly more than $\underline{l}$ hours and to receive WFTC. When investigating WFTC's impact on divorce rates (see Appendix 3), we will focus on the two cases illustrated in Figure 1 and Figure 2, respectively.

In the discussion that follows we characterize the remaining possible SPE configurations. In so doing, we confine ourselves to parameter values satisfying $a^{* *}>a^{* * *}>0$. The characterization of the remaining SPE configurations proceeds in steps (II)-(VI):

II. Suppose that

$$
\tilde{a} \geq a^{* * *} \quad \text { and } \quad \hat{a} \geq a^{* *} \quad \text { where the latter condition equals } \quad m \geq \frac{\mathbf{w}(4 \gamma t-3 \underline{l} \Delta)-\Delta \mathbf{d}}{\Delta} \equiv m_{2} .
$$

Then, by Property 2, the utility function of the father is increasing for all $a<a^{* *}$, and so no $a<a^{* *}$ is a possible equilibrium transfer. By Property 1 , the only two equilibrium candidates are $a=a^{* *}$ or $a=a^{*}$. The latter $\left(a=a^{*}\right)$ will be an equilibrium if and only if

$$
D_{h}^{00}\left(a^{*}\right) \geq D_{h}^{01}\left(a^{* *}\right) \quad \text { or, equivalently } \quad m \geq \frac{(\gamma t-\Delta \underline{l})[\Delta \underline{l}(2 \underline{\mathbf{w}} \underline{l}+\mathbf{d})+\mathbf{d} \gamma t]}{(\Delta \underline{l})^{2}} \equiv m_{1}
$$


So if $m>m_{1}$, there is a unique subgame-perfect equilibrium, namely $a^{e}=a^{*}$ and $l^{e}=0$ where the father first makes a transfer equal to $a^{*}$, which induces the mother not to work and to be ineligible for in-work support. When instead $m_{2}<m<m_{1}$, the equilibrium is $a^{e}=a^{* *}$ and $l^{e}=\underline{l}$.

III. Suppose that

$$
\tilde{a} \geq a^{* * *} \text { and } \quad a^{* * *} \leq \hat{a}<a^{* *} \quad \text { where the latter condition equals } \quad m_{4} \leq m<m_{2}
$$

where $m_{4} \equiv 2 a^{* * *}+(\gamma t \mathbf{w}+\Delta \mathbf{d}) / \Delta$. As before, by Property 2 , the utility function of the father is increasing for all $a<\hat{a}$, so no $a<\hat{a}$ is a possible equilibrium transfer. By Property 1 , the only two equilibrium candidates are $a=\hat{a}$ or $a=a^{*}$. The former $(a=\hat{a})$ will be an equilibrium if and only if $D_{h}^{11}(\hat{a})>D_{h}^{00}\left(a^{*}\right)$. Therefore, when $D_{h}^{11}(\hat{a})>D_{h}^{00}\left(a^{*}\right)$ there is a unique subgame-perfect equilibrium with $a^{e}=\hat{a}$ (with $\left.l^{e}=l_{w}^{11}\right)$, while if the opposite is true then the equilibrium transfer equals $a^{e}=a^{*}$ (with $l^{e}=0$ ).

IV. Suppose now that

$$
\tilde{a}<a^{* * *} \text { and } \hat{a} \geq a^{* *} \quad \text { where the latter is equivalent to } \quad m<m_{2}
$$

By Properties 1 and 2, the utility function of the father has local maxima at transfer levels $a^{* *}$ and $a^{*}$. Moreover, when $\tilde{a}<0$ it has a local maximum at 0 , and when $\tilde{a}>0$, it instead has a local maximum at $\tilde{a}$. Therefore, if $D_{h}^{00}\left(a^{*}\right)>\max \left\{D_{h}^{01}\left(a^{* *}\right), D_{h}^{10}(0)\right\}$ (when $\tilde{a}<0$ ) or $D_{h}^{00}\left(a^{*}\right)>\max \left\{D_{h}^{01}\left(a^{* *}\right), D_{h}^{10}(\tilde{a})\right\}($ when $\tilde{a}>0)$, then the equilibrium transfer equals $a^{e}=a^{*}$ (with $l^{e}=0$ ); if, on the other hand, $D_{h}^{01}\left(a^{* *}\right)>\max \left\{D_{h}^{00}\left(a^{*}\right), D_{h}^{10}(0)\right\}$ (when $\tilde{a}<0)$ or $D_{h}^{01}\left(a^{* *}\right)>\max \left\{D_{h}^{00}\left(a^{*}\right), D_{h}^{10}(\tilde{a})\right\}$ (when $\left.\tilde{a}>0\right)$, then the equilibrium transfer equals $a^{e}=a^{* *}\left(\right.$ with $\left.l^{e}=\underline{l}\right)$; finally, if $D_{h}^{10}(0)>\max \left\{D_{h}^{00}\left(a^{*}\right), D_{h}^{01}\left(a^{* *}\right)\right\}$ (when $\left.\tilde{a}<0\right)$ then the equilibrium transfer equals $a^{e}=0$ (with $l^{e}=l_{w}^{01}$ ), and if $D_{h}^{10}(\tilde{a})>\max \left\{D_{h}^{00}\left(a^{*}\right), D_{h}^{01}\left(a^{* *}\right)\right\}$ (when $\left.\tilde{a}>0\right)$ then the equilibrium transfer equals $a^{e}=\tilde{a}\left(\right.$ with $\left.l^{e}=l_{w}^{01}\right)$.

V. Suppose again that

$$
\tilde{a}<a^{* * *} \text { and now } a^{* * *} \leq \hat{a}<a^{* *} \quad \text { where the latter is equivalent to } \quad m_{4} \leq m<m_{2} .
$$

As in case II, the utility function of the father will have local maxima at $\hat{a}$ and $a^{*}$. Moreover, when $\tilde{a}<0$ it has a local maximum at 0 , while when $\tilde{a}>0$ it instead has a local maximum at $\tilde{a}$. The equilibrium transfer equals $a^{e}=\hat{a}$ $\left(\right.$ with $\left.l^{e}=l_{w}^{11}\right)$ if $D_{h}^{11}(\hat{a})>\max \left\{D_{h}^{00}\left(a^{*}\right), D_{h}^{10}(0)\right\}($ when $\tilde{a}<0)$ or $D_{h}^{11}(\hat{a})>\max \left\{D_{h}^{00}\left(a^{*}\right), D_{h}^{10}(\tilde{a})\right\}($ when $\tilde{a}>0)$. If $D_{h}^{00}\left(a^{*}\right)>\max \left\{D_{h}^{11}(\hat{a}), D_{h}^{10}(0)\right\}$ (when $\tilde{a}<0$ ) or $D_{h}^{00}\left(a^{*}\right)>\max \left\{D_{h}^{11}(\hat{a}), D_{h}^{10}(\tilde{a})\right\}$ (when $\tilde{a}>0$ ), the equilibrium transfer equals $a^{e}=a^{*}$ (with $l^{e}=0$ ). Finally, if $D_{h}^{10}(0)>\max \left\{D_{h}^{00}\left(a^{*}\right), D_{h}^{11}(\hat{a})\right\}$ (when $\left.\tilde{a}<0\right)$ then the equilibrium transfer equals $a^{e}=0$ (with $l^{e}=l_{w}^{01}$ ), and if $D_{h}^{10}(\tilde{a})>\max \left\{D_{h}^{00}\left(a^{*}\right), D_{h}^{11}(\hat{a})\right\}$ (when $\tilde{a}>0$ ) then the equilibrium transfer equals $a^{e}=\tilde{a}$ (with $\left.l^{e}=l_{w}^{01}\right)$.

VI. Suppose that

$$
\tilde{a}<a^{* * *} \quad \text { and } \quad \hat{a} \leq a^{* * *} \quad \text { where the latter condition is equivalent to } \quad m<m_{4} .
$$

As Properties 1 and 2 imply that the fathers utility function is now declining between $a^{* * *}$ and $a^{*}$, there are local maxima at $a^{* * *}$ and $a^{*}$. In addition, when $\tilde{a}<0$ it has a local maximum at 0 , while when $\tilde{a}>0$ it instead has a local maximum at $\tilde{a}$. Therefore, if $D_{h}^{00}\left(a^{*}\right)>\max \left\{D_{h}^{11}\left(a^{* * *}\right), D_{h}^{10}(0)\right\}($ when $\tilde{a}<0)$ or $D_{h}^{00}\left(a^{*}\right)>$ $\max \left\{D_{h}^{11}\left(a^{* * *}\right), D_{h}^{10}(\tilde{a})\right\}$ (when $\tilde{a}>0$ ), then the equilibrium transfer equals $a^{e}=a^{*}$ (with $l^{e}=0$ ); if, on the other hand, $D_{h}^{11}\left(a^{* * *}\right)>\max \left\{D_{h}^{00}\left(a^{*}\right), D_{h}^{10}(0)\right\}$ (when $\left.\tilde{a}<0\right)$ or $D_{h}^{11}\left(a^{* * *}\right)>\max \left\{D_{h}^{00}\left(a^{*}\right), D_{h}^{10}(\tilde{a})\right\}($ when $\tilde{a}>0)$, then the equilibrium transfer equals $a^{e}=a^{* * *}$ (with $\left.l^{e}=l_{w}^{11}\right)$; finally, if $D_{h}^{10}(0)>\max \left\{D_{h}^{00}\left(a^{*}\right), D_{h}^{11}\left(a^{* * *}\right)\right\}$ (when $\left.\tilde{a}<0\right)$

then the equilibrium transfer equals $a^{e}=0$ (with $l^{e}=l_{w}^{01}$ ), and if $D_{h}^{10}(\tilde{a})>\max \left\{D_{h}^{00}\left(a^{*}\right), D_{h}^{11}\left(a^{* * *}\right)\right\}$ (when $\left.\tilde{a}>0\right)$ then the equilibrium transfer equals $a^{e}=\tilde{a}$ (with $l^{e}=l_{w}^{01}$ ).

\section{Appendix 3: Likelihood of Divorce}

To illustrate the potential effects of WFTC on divorce, we focus on the two specific cases. In the first case (illustrated in Figure 2), the equilibrium transfer of the father in divorce is positive and equals $a^{e}=[\Delta m-(\gamma t \mathbf{w}+\Delta \mathbf{d})] /(2 \Delta) \equiv \hat{a}$, 
which induces the mother work strictly more than $\underline{l}$ hours (i.e., $l^{e}=[\gamma t \mathbf{w}-\Delta(\hat{a}+\mathbf{d}] /(2 \boldsymbol{\Delta}))$ and to receive WFTC. Note that $a^{e}=\hat{a}>0$ requires that $m>(\gamma t \mathbf{w}+\Delta \mathbf{d}) \equiv \hat{m}$. In the second case (illustrated in Figure 3$)$, the equilibrium transfer of the father in divorce is zero $\left(a^{e}=0\right)$, which induces the mother work strictly more than $\underline{l}$ hours (i.e., $\left.l^{e}=[\gamma t \mathbf{w}-\Delta \mathbf{d}] /(2 \boldsymbol{\Delta})\right)$ and to receive WFTC. Note that $a^{e}=0$ requires that $m \leqslant(\gamma t \mathbf{w}+\Delta \mathbf{d}) \equiv \hat{m}$.

Case 1. High Income Father $(m>\hat{m})$ - Couple Ineligible as Family - Mother Eligible as Single Parent - Positive Child Support Payment from Father to Mother $\left(a^{e}=\hat{a}>0\right)$.

- Equilibrium after divorce: With the father's equilibrium transfer given by $\hat{a} \equiv[\Delta m-(\gamma t \mathbf{w}+\Delta \mathbf{d})] /(2 \Delta)$, and the mother's corresponding labor supply given by $[\gamma t \mathbf{w}-\Delta(\hat{a}+\mathbf{d})] /(2 \boldsymbol{\Delta})$, the values of the mother's and father's utility maximization problem after divorce are

$$
D_{w}^{e}(\hat{a})=\alpha_{w} \ln \left[\frac{\sigma[\gamma \mathbf{w} t+\Delta(\hat{a}+\mathbf{d})]^{2}}{4 \Delta \mathbf{w}}\right] \quad \text { and } \quad D_{h}^{e}(\hat{a})=\alpha_{h} \ln \left[\frac{\sigma(m-\hat{a})(\gamma \mathbf{w} t+\Delta(\hat{a}+\mathbf{d}))}{2 \mathbf{w}}\right]
$$

The utility frontier relating the father's utility, $D_{h}$, and the mother's utility, $D_{w}$, after divorce is:

$$
\exp \left(\frac{D_{h}}{\alpha_{h}}\right)=\Phi \cdot \sqrt{\sigma \exp \left(\frac{D_{w}}{\alpha_{w}}\right)}-2 \exp \left(\frac{D_{w}}{\alpha_{w}}\right),
$$

where $\Phi=\gamma t \mathbf{w}+\Delta(m+\mathbf{d}) / \sqrt{\Delta \mathbf{w}}{ }^{7}$ The pair $\left(D_{w}^{e}(\hat{a}), D_{h}^{e}(\hat{a})\right)$ in (38) represents one particular point on $\left(P_{d}\right)$.

- Equilibrium within marriage: Suppose the male partner is in eligible employment and his income $m$ exceeds the post-reform value of $M_{\max }$, that is, the male partner's income is so high that the household will remain ineligible for in-work support even after the reform. Assuming that $w>p_{c}+\frac{\Delta m}{\gamma t}$, the optimal labour supply of the wife equals $\left[\gamma t\left(w-p_{c}\right)-m \Delta\right] /\left[2\left(w-p_{c}\right) \Delta\right]$ (see Appendix A). The female and male utilities are respectively

$$
U_{w}(\theta)=\alpha_{w} \ln [\kappa \Upsilon /(1+\kappa)] \quad \text { and } \quad U_{h}(\theta)=\alpha_{h} \ln [\Upsilon /(1+\kappa)],
$$

where $\Upsilon \equiv\left[\gamma t\left(w-p_{c}\right)+m \Delta\right]^{2} /\left[4 \Delta\left(w-p_{c}\right)\right]$ and $\kappa \equiv \alpha_{w} \theta /\left[\alpha_{h}(1-\theta)\right]$. The implied utility frontier relating $U_{h}$ and $U_{w}$ during marriage is given by: ${ }^{8}$

$$
\exp \left(\frac{U_{h}}{\alpha_{h}}\right)=\Upsilon-\exp \left(\frac{U_{w}}{\alpha_{w}}\right)
$$

- $\underline{\text { Result 4.a: }}$ Let $\hat{\sigma}=4 \mathbf{w} \Delta \Upsilon[\gamma \mathbf{w} t+\Delta(2 m+\mathbf{d}-\hat{a})]^{-1}[\gamma t \mathbf{w}+\Delta(\mathbf{d}+\hat{a})]^{-1}$, where $\hat{a}=[\Delta m-(\gamma t \mathbf{w}+\Delta \mathbf{d})] /(2 \Delta)$ is the optimal child support transfer paid by high-income fathers. Divorce occurs if $\sigma>\hat{\sigma}$, and marriage survives if $\sigma<\hat{\sigma}$.

${ }^{7}$ To derive $\left(P_{d}\right)$, write the values of the mother's and father's utility maximization problem for an arbitrary transfer $a$ as:

$$
\exp \left(\frac{D_{w}}{\alpha_{w}}\right)=\left[\frac{\sigma[\gamma \mathbf{w} t+\Delta(a+\mathbf{d})]^{2}}{4 \Delta \mathbf{w}}\right] \quad \text { and } \quad \exp \left(\frac{D_{h}}{\alpha_{h}}\right)=\left[\frac{\sigma(m-a)(\gamma \mathbf{w} t+\Delta(a+\mathbf{d}))}{2 \mathbf{w}}\right] .
$$

Solving (I.a) for $a$, we obtain:

$$
a=\frac{1}{\sigma \Delta}\left[\sqrt{\sigma \Delta \mathbf{w} \exp \left(\frac{D_{w}}{\alpha_{w}}\right)}-\sigma(\gamma \mathbf{w} t+\Delta \mathbf{d})\right] .
$$

After substituting (II) into (I.b), rearranging and simplifying, one obtains $P_{d}$.

${ }^{8}$ To derive $\left(P_{m}\right)$, rewrite the values of the mother's and father's utility maximization problem within marriage as:

$$
\exp \left(\frac{U_{w}}{\alpha_{w}}\right)=\left[\frac{\alpha_{w} \theta\left[\gamma\left(w-p_{c}\right) t+\Delta m\right]^{2}}{4\left[\alpha_{w} \theta+\alpha_{h}(1-\theta)\right] \Delta\left(w-p_{c}\right)}\right] \quad \text { and } \quad \exp \left(\frac{U_{h}}{\alpha_{h}}\right)=\left[\frac{\alpha_{h}(1-\theta)\left[\gamma\left(w-p_{c}\right) t+\Delta m\right]^{2}}{4\left[\alpha_{w} \theta+\alpha_{h}(1-\theta)\right] \Delta\left(w-p_{c}\right)}\right] .
$$

Solving (III.a) for $\theta$, we obtain:

$$
\theta=\frac{4 \alpha_{h} \exp \left(\frac{D_{w}}{\alpha_{w}}\right) \Delta \omega}{4\left(\alpha_{h}+\alpha_{w}\right) \exp \left(\frac{D_{w}}{\alpha_{w}}\right) \Delta \omega+\alpha_{w}[\gamma t \omega+\Delta m]^{2}} .
$$

After substituting (IV) into (III.b), rearranging and simplifying, one obtains $P_{m}$. 
- Proof: Denote by $U_{w}^{c r i t}$ the utility level of the mother at which $\left(P_{d}\right)$ and $\left(P_{m}\right)$ intersect:

$$
\Upsilon-\exp \left(\frac{U_{w}^{c r i t}}{\alpha_{w}}\right)=\Phi \cdot \sqrt{\sigma \exp \left(\frac{U_{w}^{c r i t}}{\alpha_{w}}\right)}-2 \exp \left(\frac{U_{w}^{c r i t}}{\alpha_{w}}\right) .
$$

Solving (40) for $U^{\text {crit }}$ yields

$$
U_{w}^{c r i t}=\alpha_{w} \ln \left[-\Upsilon+\frac{\Phi}{2}\left(\sigma \Phi+\sqrt{(\sigma \Phi)^{2}-4 \sigma \Upsilon}\right)\right]
$$

The utility pair $\left(D_{h}^{e}(\hat{a}), D_{w}^{e}(\hat{a})\right)$ in (38) lies outside the set of feasible levels of utility that can be achieved through marriage, in which case divorce occurs, if and only if

$$
D_{w}^{e}(\hat{a})>U_{w}^{c r i t}
$$

That is, if and only if,

$$
\alpha_{w} \ln \left[\frac{\sigma[\gamma \mathbf{w} t+\Delta(\hat{a}+\mathbf{d})]^{2}}{4 \Delta \mathbf{w}}\right]>\alpha_{w} \ln \left[-\Upsilon+\frac{\Phi}{2}\left(\sigma \Phi+\sqrt{(\sigma \Phi)^{2}-4 \sigma \Upsilon}\right)\right] .
$$

After substituting $\Phi=\gamma t \mathbf{w}+\Delta(m+\mathbf{d}) / \sqrt{\Delta \mathbf{w}}$ into (43) and solving for $\sigma$, the condition for divorce to occur is:

$$
D_{w}^{e}(\hat{a})>U_{w}^{c r i t} \Leftrightarrow \sigma>\frac{4 \Delta \mathbf{w} \Upsilon}{[\gamma t \mathbf{w}+\Delta(\hat{a}+\mathbf{d})][\gamma t \mathbf{w}+\Delta(2 m+\mathbf{d}-\hat{a})]} \equiv \hat{\sigma},
$$

where $\hat{a}=[\Delta m-(\gamma t \mathbf{w}+\Delta \mathbf{d})] /(2 \Delta)$ and $\Upsilon \equiv[\gamma t \omega+m \Delta]^{2} /[4 \Delta \omega]$. Result 4.a now follows immediately.

Case 2. Low Income Father $(m \leqslant \hat{m})$ - Couple Eligible as Family - Mother Eligible as Single Parent - No Child Support Payment from Father to Mother ( $\left.a^{e}=0\right)$.

- Equilibrium after divorce: With the father's equilibrium transfer being zero $\left(a^{e}=0\right)$, and the mother's corresponding labor supply given by $[\gamma t \mathbf{w}-\Delta \mathbf{d}] /(2 \boldsymbol{\Delta})$, the values of the mother's and father's utility maximization problem after divorce are

$$
D_{w}^{e}(0)=\alpha_{w} \ln \left[\frac{\sigma[\gamma \mathbf{w} t+\Delta \mathbf{d}]^{2}}{4 \Delta \mathbf{w}}\right] \quad \text { and } \quad D_{h}^{e}(0)=\alpha_{h} \ln \left[\frac{\sigma m(\gamma \mathbf{w} t+\Delta \mathbf{d})}{2 \mathbf{w}}\right]
$$

As in Case 1, the utility frontier relating the father's utility, $D_{h}$, and the mother's utility, $D_{w}$, when the couple separates is:

$$
\exp \left(\frac{D_{h}}{\alpha_{h}}\right)=\Phi \cdot \sqrt{\sigma \exp \left(\frac{D_{w}}{\alpha_{w}}\right)}-2 \exp \left(\frac{D_{w}}{\alpha_{w}}\right),
$$

where $\Phi=\gamma t \mathbf{w}+\Delta(m+\mathbf{d}) / \sqrt{\Delta \mathbf{w}}$. The pair $\left(D_{w}^{e}(0), D_{h}^{e}(0)\right)$ in (45) represents one particular point on $\left(P_{d}\right)$.

- Equilibrium within marriage: Suppose that, when married, the father works fewer than 16 hours and has a low income. As we have shown in Result 1, such a family is eligible and chooses to receive WFTC (but not its childcare subsidy) if the mother's wage lies in the interval $\left[w^{*}, w^{* * *}\right)$. As an example, suppose $w \in$ $\left[w^{* *}, w^{* * *}\right)$. Then the optimal female labour supply is $[\gamma t \mathbf{v}-\mathbf{m} \Delta] /[2 \mathbf{v} \Delta]$, where $\mathbf{v}=w(1-\pi)-p_{c}$ and $\mathbf{m}=(1-\pi) m+T_{\max }+\pi M_{\min }$. The corresponding utilities are respectively

$$
U_{w}(\theta)=\alpha_{w} \ln [\kappa \Psi(\mathbf{m}, \mathbf{v}) /(1+\kappa)] \quad \text { and } \quad U_{h}(\theta)=\alpha_{h} \ln [\Psi(\mathbf{m}, \mathbf{v}) /(1+\kappa)] .
$$

where $\Psi(\mathbf{m}, \mathbf{v}) \equiv[\gamma t \mathbf{v}+\mathbf{m} \Delta]^{2} /(4 \Delta \mathbf{v})$ is a measure of the feasible utility levels if the couple remains married. The utility frontier relating $U_{h}$ and $U_{w}$ during marriage is given by:

$$
\exp \left(\frac{U_{h}}{\alpha_{h}}\right)=\Psi(\mathbf{m}, \mathbf{v})-\exp \left(\frac{U_{w}}{\alpha_{w}}\right) .
$$

where $\Psi(\mathbf{m}, \mathbf{v}) \equiv[\gamma t \mathbf{v}+\Delta \mathbf{m}]^{2} /[4 \Delta \mathbf{v}]$.

- Result 5.a: Let $\tilde{\sigma}=4 \mathbf{w} \Delta \Psi(\mathbf{m}, \mathbf{v})[\gamma \mathbf{w} t+\Delta(2 m+\mathbf{d})]^{-1}[\gamma t \mathbf{w}+\Delta \mathbf{d}]^{-1}$. Divorce occurs if $\sigma>\tilde{\sigma}$, and marriage survives if $\sigma<\tilde{\sigma}$. 
- Proof: Denote by $V_{w}^{\text {crit }}$ utility level of the mother at which $\left(P_{d}\right)$ and $\left(P_{m}^{\prime}\right)$ intersect:

$$
\Psi(\mathbf{m}, \mathbf{v})-\exp \left(\frac{V_{w}^{c r i t}}{\alpha_{w}}\right)=\Phi \cdot \sqrt{\sigma \exp \left(\frac{V_{w}^{c r i t}}{\alpha_{w}}\right)}-2 \exp \left(\frac{V_{w}^{c r i t}}{\alpha_{w}}\right) .
$$

Solving (47) for $V_{w}^{\text {crit }}$ yields

$$
V_{w}^{c r i t}=\alpha_{w} \ln \left[-\Psi(\mathbf{m}, \mathbf{v})+\frac{\Phi}{2}\left(\sigma \Phi+\sqrt{(\sigma \Phi)^{2}-4 \sigma \Psi(\mathbf{m}, \mathbf{v})}\right)\right]
$$

The utility pair $\left(D_{h}^{e}(0), D_{w}^{e}(0)\right)$ in (45) lies outside the set of feasible levels of utility that can be achieved through marriage, in which case divorce occurs, if and only if

$$
D_{w}^{e}(0)>V_{w}^{c r i t}
$$

That is, if and only if,

$$
\alpha_{w} \ln \left[\frac{\sigma[\gamma \mathbf{w} t+\Delta \mathbf{d}]^{2}}{4 \Delta \mathbf{w}}\right]>\alpha_{w} \ln \left[-\Psi(\mathbf{m}, \mathbf{v})+\frac{\Phi}{2}\left(\sigma \Phi+\sqrt{(\sigma \Phi)^{2}-4 \sigma \Psi(\mathbf{m}, \mathbf{v})}\right)\right] .
$$

After substituting $\Phi=\gamma t \mathbf{w}+\Delta(m+\mathbf{d}) / \sqrt{\Delta \mathbf{w}}$ into (50) and solving for $\sigma$, the condition for divorce to occur is:

$$
D_{w}^{e}(0)>V_{w}^{c r i t} \Leftrightarrow \sigma>\frac{4 \Delta \mathbf{w} \Psi(\mathbf{m}, \mathbf{v})}{[\gamma t \mathbf{w}+\Delta \mathbf{d}][\gamma t \mathbf{w}+\Delta(2 m+\mathbf{d})]} \equiv \hat{\sigma},
$$

where $\Psi(\mathbf{m}, \mathbf{v}) \equiv[\gamma t \mathbf{v}+\Delta \mathbf{m}]^{2} /[4 \Delta \mathbf{v}]$. Result 5.a now follows immediately. 